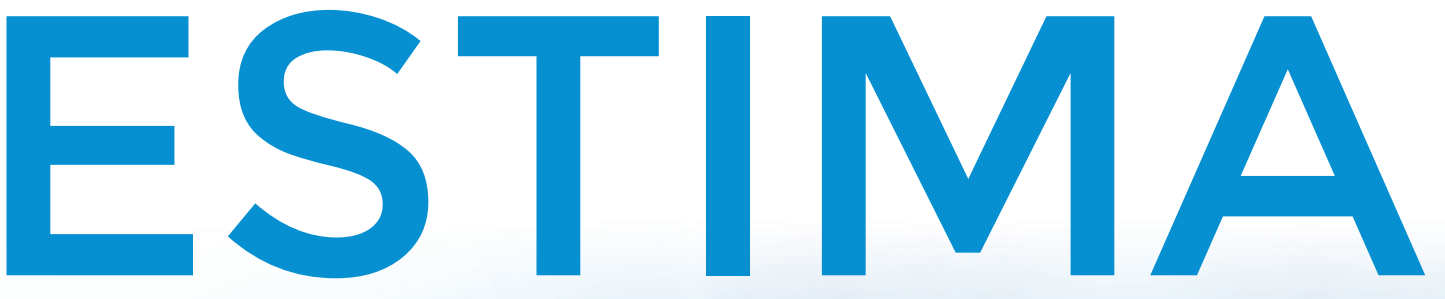

Revista da Associação Brasileira de Estomaterapia: estomias, feridas e incontinências Brazilian Journal of Enterostomal Therapy 

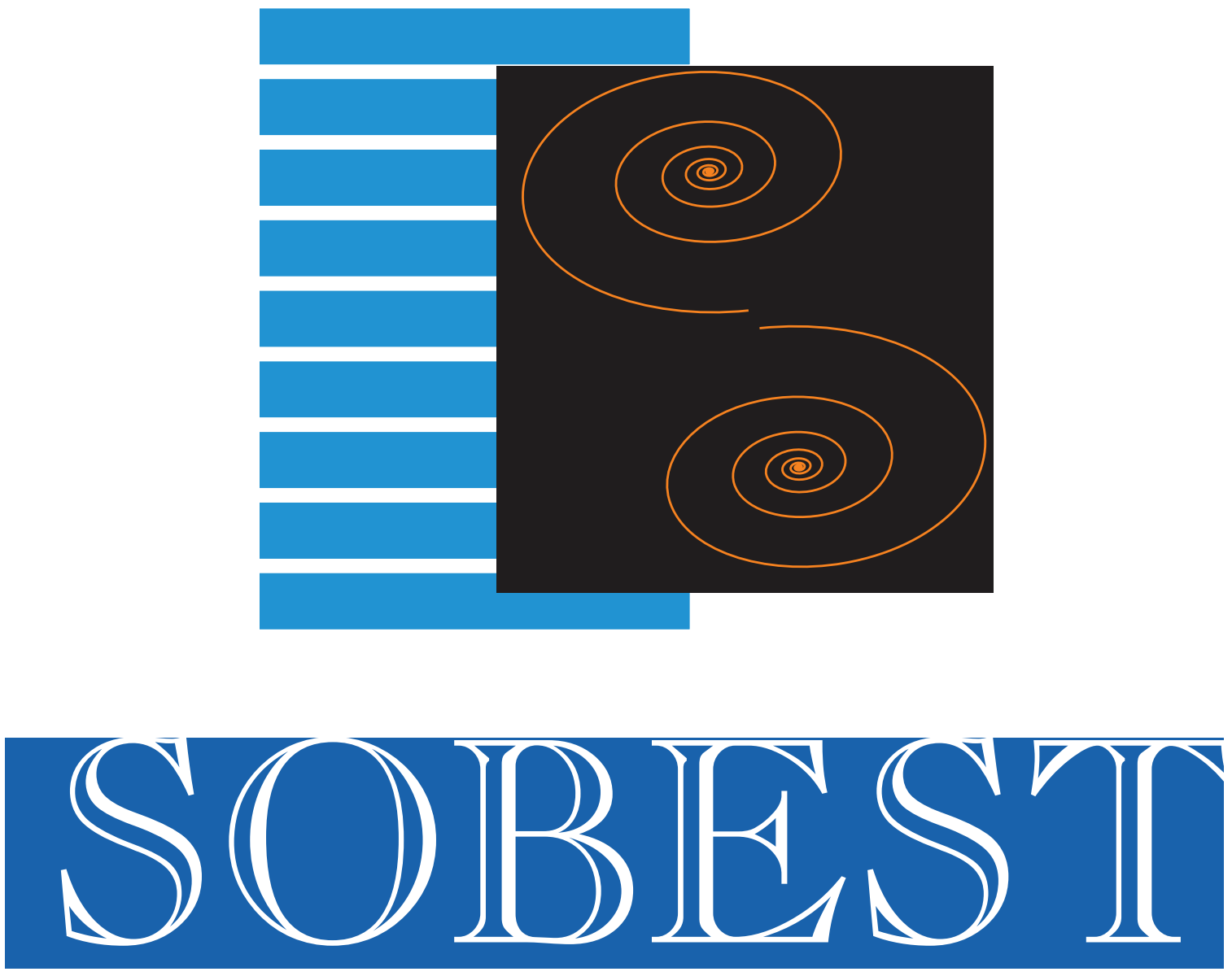

associação brasileira de estomaterapia

- ESTOMIAS • FERIDAS • INCONTINÊNCIAS 

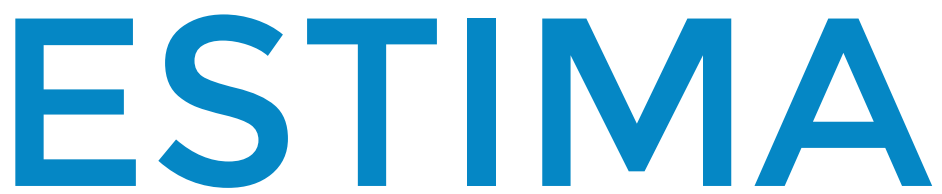

Revista da Associação Brasileira de Estomaterapia: estomias, feridas e incontinências

Brazilian Journal of Enterostomal Therapy

EDITORES: Maria Angela Boccara de Paula e Gisele Regina Azevedo

\section{CONSELHO EDITORIAL}

Adriana Pelegrini dos Santos Pereira

ET TISOBEST, PhD - FAMERP (SP)

Afonso Henrique da Silva e Souza Jr

Médico, PhD - Hospital das Clínicas - FMUSP (SP)

Christine Norton

Continence nurse, PhD - King's College (London)

Diana Lima Vilela

Enfermeira, PhD - Hospital do Câncer (SP)

Diba Maria Sebba Tosta de Souza

Enfermeira, ET, PhD - UNIVÁS (MG)

Eline Lima Borges

ET TISOBEST, PhD - UFMG (MG)

Federico Palomar Llatas

Enfermeiro em Dermatologia, PhD - Unviversid Católica de Valencia (Espanha)

Gisele Martins

Enfermeira, PhD - UnB (DF)

Gisele Regina Azevedo

Enfermeira, ET TiSOBEST,PhD - FCMS-PUC (SP)

Isabel Cristina Vieira Santos

Enfermeira, TiSOBEST, PhD - UPE (PE)

Ivone Kamada

Enfermeira, ET, PhD - UnB (DF)

José Márcio Neves Jorge

Médico, PhD - Hospital das Clínicas - FMUSP (SP)

José Contreras Ruiz

Médico, PhD - Hospial General DR. Manuel Gea

Gonzalez (México)

Kazuko Uchikawa Graziano

Enfermeira, PhD - EEUSP (SP)

Kevin Woo

Enfermeiro, PhD - The New Women's College Hospital

(Canadá)

Leila Blanes

Enfermeira, ET, PhD - Hospital São Paulo (SP)
Letícia Faria Serpa

Enfermeira, PhD - Hospital Alemão Oswaldo Cruz (SP)

Lydia Massako Ferreira

Médica, PhD - UNIFESP (SP)

Manlio Basilio Speranzini

Médico Cirurgião, PhD - FMUSP (SP)

Maria Angela Boccara de Paula

Enfermeira, ET TISOBEST, PhD - UNITAU (SP)

Maria Euridéia de Castro

Enfermeira, ET TiSOBEST, PhD - UECE (CE)

Maria Helena Baena de Moraes Lopes

ET TISOBEST, PhD - UNICAMP (SP)

Maria Helena Barros de Araújo Luz

Enfermeira, ET, PhD - UFPI (PI)

Maria Helena Caliri

Enfermeira, ET, PhD - EEUSP (SP)

Mônica Antar Gamba

Enfermeira, PhD - UNIFESP (SP)

Noemi Marisa Brunet Rogenski

Enfermeira, ET, PhD - Hospital Universitário - USP (SP)

Norma Valéria Dantas de Oliveira Souza

ET TISOBEST - UERJ (RJ)

Pedro Roberto de Paula

Médico, PhD - UNITAU (SP)

Regina Ribeiro Cunha

ET TISOBEST, PhD - UFPA (PA)

Sandra Nidia Guerrero Gamboa

Enfermeira, ET, PhD - Universidad Nacional de Colombia (Colômbia)

Sônia Regina Pérez Evangelista Dantas

ET TISOBEST,PhD - UNICAMP (SP)

Vera Lúcia Conceição Gouveia Santos

ET TiSOBEST,PhD - EEUSP (SP)

Vilma Madalosso Petuco

Enfermeira, ET, PhD - UPF (RS) 


\section{EXPEDIENTE \\ GESTÃO DA SOBEST 2015 - 2017}

\section{DIRETORIA}

Presidente: Maria Angela Boccara de Paula (SP)

Vice-Presidente: Gisele Regina de Azevedo (SP)

presidente@sobest.com.br

Primeiro Tesoureiro: Ana Beatriz Pinto da Silva Morita (SP)

Segundo Tesoureiro: Cintia Hanate (SP)

tesouraria@sobest.com.br

Primeiro Secretário: Ednalda Maria Franck (SP)

Secretária Adjunta: Pollyanna Santos Carneiro da Silva (SP)

secretaria@sobest.com.br

\section{Conselho Científico}

Fernanda Mateus Queiroz Schmidt (SP)

Camila Cantarino Nascentes (RJ)

Silvia Angélica Jorge (SP)

Ciliana Antero Guimarães da Silva Oliveira (SP)

Elisabete Capalbo Ferolla (SP)

\section{Departamento de Educação}

Sônia Regina Pérez Evangelista Dantas (SP)

educacao@sobest.com.br

\section{Departamento de Desenvolvimento Profissional \\ Rita de Cássia Domansky (PR) \\ desenvolvimento.profissional@sobest.com.br}

\section{Departamento de Comunicação e Marketing \\ Suely Rodrigues Thuler (SP) \\ comunicacao@sobest.com.br}

\section{Departamento de Relações Internacionais}

Vera Lúcia Conceição de Gouveia Santos (SP)

international.relations@sobest.com.br

\section{Departamento de Relações Seccionais}

Luciana Mendes (BA)

seccionais@sobest.com.br

\section{Conselho Fiscal}

Vanessa Soares de Araújo (SP)

Rosa Takako Eguchi (SP)

Danivea Bongiovanni Poltronieri Munhoz (SP)

\section{Delegado Internacional}

Suzana Aron (SP)

\section{Seção Bahia}

Presidente Seccional: Roberta Mendonça Viana

\section{Secão Ceará}

Presidente Seccional: Luciana Catunda Gomes de Menezes

\section{Seção Paraná}

Presidente Seccional: Gisela Maria de Assis
Seção Rio de Janeiro

Presidente Seccional: Tânia das Graças de Souza Lima

Seção Rio Grande do Sul

Presidente Seccional: Daniela de Oliveira Cardozo

Seção Distrito Federal

Presidente Seccional: Janete Carvalho de Freitas

Seção Minas Gerais

Presidente Seccional: Claudia Regina de Souza Santos

Seção Pernambuco

Presidente Seccional: Marília Perrelli Valença

Secão Pará

Presidente Seccional: Regina Ribeiro Cunha

Revista Estima

ISSN: 1806-3144

Indexação:

EBSCO

CINAHL - Cumulative Index to Nursing and Allied Health Literature CUIDEN - Base de dados bibliografia de La Fundacion Index

REHIC - Catalogo eletrônico de periódicos

LATINDEX - Sistema Regional de Información en Línea para Revistas Científicas de América Latina, el Caribe, España y Portugal

Primeira edição: 15/06/2003

Editores Fundadores: Beatriz Farias Alves Yamada, Noemi Marisa Brunet Rogenski e Leila Blanes

Revista Oficial da Associação Brasileira de Estomaterapia: estomias, feridas e incontinências - SOBEST

Tiragem: 700 exemplares

Produção Editorial: Associação Brasileira de Estomaterapia / Zeppelini Editorial / Instituto Filantropia

Capa: Zeppelini Editorial

Distribuição: gratuita para membros ativos da Sobest Associação Brasileira de Estomaterapia

Rua Antonio de Godoi, 35, cj. 102 - Centro - São Paulo (SP) CEP: 010334-001

Fone: (11) 30820659

www.sobest.org.br

sobest@sobest.org.br

Edições

anteriores:

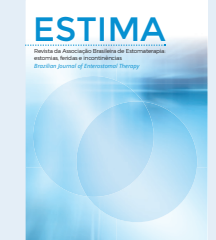

Vol 13 Edição 3

Vol 13 Edição 4

(jul/ago/set 2015)

Propriedades e Direitos: Todos os artigos, desenhos e fotografias estão sob a proteção do Código de Direitos do Autor e não poderão ser reproduzidos sem a permissão por escrito da SOBEST, porém qualquer ilustração editada como cortesia é de propriedade do cedente. A Revista Estima fará o máximo esforço para manter a fidelidade do material original, porém não se responsabiliza pelos erros gráficos surgidos. As opiniões assinadas não representam necessariamente a opinião dos editores da revista. 
ESTIMA $・$ Vol $14 \cdot \operatorname{Num~} 1 \cdot 2016$

2 EDITORIAL

Maria Angela Boccara de Paula

\section{ARTIGO ORIGINAL}

3 Serviço de Estomaterapia na Perspectiva dos Gerentes de Enfermagem em Hospital Público de Referência

The View of Nursing Managers about a Stomatherapy Service in a Public Reference Hospital Perspectiva de las Gerentes de Enfermería acerca del Servicio de Estomaterapia en un Hospital Público de Referencia

Anne Kayline Soares Teixeira, Luciana Catunda Gomes de Menezes, Roberta Meneses Oliveira

13 Implantação de uma Comissão de Cuidados com a Pele em um Hospital de Ensino Implementation of a Skin Care Commission in a University Hospital Implementación de una Comisión de Cuidado de la Piel en un Hospital Universitario Tereza Cristina Caron Krause, Gisela Maria Assis, Mitzy Tannia Reichembach Danski

\section{Caracterização de Pacientes com Feridas Neoplásicas}

Characterization of Patients with Neoplastic Wounds Caracterización de los Pacientes con Heridas Neoplásicas Isabel Neves Duarte Lisboa, Marilia Perrelli Valença

29 Caracterização Sociodemográfica e Clínica de Pessoas com Estomia em Teresina Sociodemographic and Clinic Characterization of People with Ostomy in Teresina Caracterización Sociodemográfica y Clínica de Personas con Ostomía en Teresina Sara Machado Miranda, Maria Helena Barros Araújo Luz, Helena Megumi Sonobe, Elaine Maria Leite Rangel Andrade, Elaine Cristina de Carvalho Moura

36 Ações Preventivas para Úlcera por Pressão em Idosos com Declínio Funcional de Mobilidade Física no Âmbito Domiciliar

Preventive Actions against Pressure Ulcers in Elderly with Functional Decline of Physical Mobility at Home Environment

Acciones Preventivas a las Úlceras por Presión en Ancianos con Declino Funcional de la Movilidad Física en el Entorno Familiar

Josefa Danielma Lopes Ferreira, Elizabeth Souza Silva de Aguiar, Carla Lidiane Jácome de Lima, Karen Krystine Gonçalves de Brito, Marta Miriam Lopes Costa, Maria Júlia Guimarães Oliveira Soares

\section{ARTIGO DE REVISÃO}

43 Cuidados de Enfermagem na Incontinência Urinária: um Estudo de Revisão Integrativa Nursing Care in Urinary Incontinence: a Study of Integrative Review Cuidados de Enfermería en Ia Incontinencia Urinaria: Estudio de Revisión Integral Marilia Perrelli Valença, Andressa Ferreira Leite Ladislau Albuquerque, Gabriela Maria da Silva Rocha, Ana Priscila Duarte de Aguiar

\section{RESUMO DE DISSERTAÇÃO}

50 Qualidade de Vida: Percepção de Crianças e Adolescentes Estomizados e seus Pais e/ou Responsáveis

Quality of Life: Perception of Ostomized Children and Adolescents and their Parents and/or Guardians Calidad de Vida: la Percepción de los Niños y Adolescentes con Estomía y sus Padres y/o Tutores Sandra de Nazaré Costa Monteiro, Ivone Kamada, Ana Lúcia da Silva

51 Prevalência de Úlcera por Pressão em Pacientes em Risco e o Cuidado no Domicílio após Alta Hospitalar Prevalence of Pressure Ulcer in Patients at Risk and Home Care after Hospital Discharge Prevalencia de Úlcera por Presión en Pacientes en Riesgo y Cuidado en Domicilio luego del Alta Hospitalaria Jaísa Valéria Moro, Maria Helena Larcher Caliri 


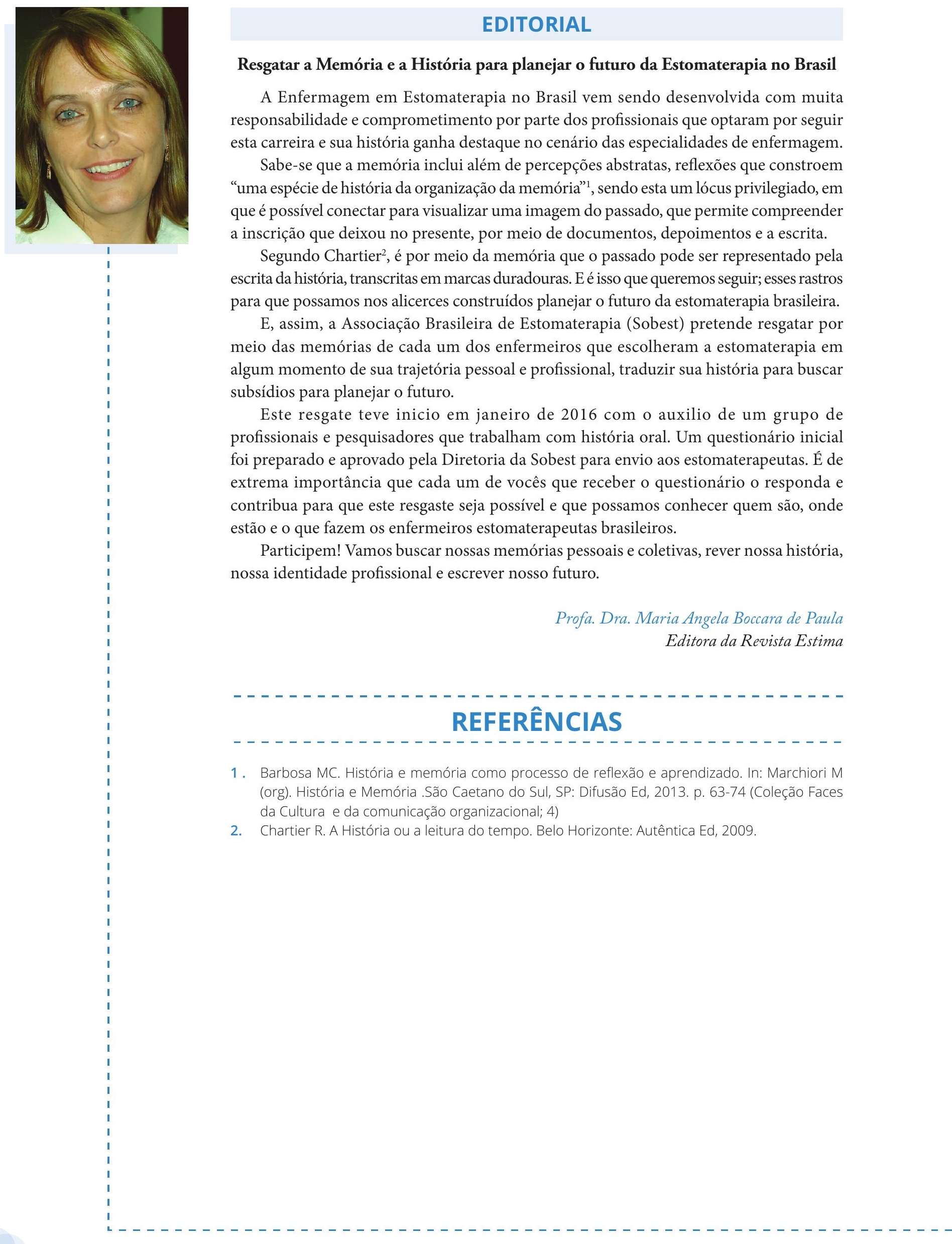




\title{
Serviço de Estomaterapia na Perspectiva dos Gerentes de Enfermagem em Hospital Público de Referência
}

\author{
The View of Nursing Managers about a Stomatherapy \\ Service in a Public Reference Hospital \\ Perspectiva de las Gerentes de Enfermería acerca del Servicio \\ de Estomaterapia en un Hospital Público de Referencia
}

Anne Kayline Soares Teixeiraํ', Luciana Catunda Gomes de Menezes², Roberta Meneses Oliveira ${ }^{3}$

\begin{abstract}
RESUMO
Objetivou-se descrever a percepção dos gerentes de enfermagem das unidades de internação, no tocante ao atendimento do serviço de estomaterapia em um hospital público. Estudo descritivo, com abordagem qualitativa, realizado com 11 enfermeiras em cargo de gerência de unidade. Para coletar os dados, utilizou-se um questionário de entrevista semiestruturada. Para análise dos depoimentos, adotou-se a técnica da análise de conteúdo. Emergiram desta análise duas categorias temáticas. Na primeira, abordaram-se as competências das enfermeiras do serviço de estomaterapia, com relatos sobre visitação e elaboração de pareceres, prevenção, tratamento de feridas e educação permanente no serviço. Na segunda categoria, os depoimentos das entrevistadas permitiram uma apreciação crítica do serviço de estomaterapia, em que foram discutidos aspectos críticos relacionados à capacitação e aos treinamentos necessários/insuficientes, às estruturas física e humana, ao material inapropriado e à frequência restrita de visitas às unidades. Apesar das dificuldades relatadas, as gerentes demonstraram satisfação com a atuação do serviço de Estomaterapia, principalmente no que diz respeito à comunicação e ao relacionamento interpessoal entre unidades.
\end{abstract}

DESCRITORES: Estomaterapia. Enfermagem. Gerência. Estomia. Serviços de enfermagem.

\begin{abstract}
The aim of this study was to describe the perception of nursing managers from inpatient units, regarding the care of the stomatherapy service in a public hospital. A descriptive study with a qualitative approach was carried out with 11 nurses working in hospital unit management. For data collection, we used semi-structured interviews. For analysis of statements, it was adopted the content analysis technique. This analysis provided two thematic categories. In the first, skills of the nurses from the stomatherapy service were addressed, with reports about visitation and development of opinions, prevention, treatment of wounds, and permanent education in the service. In the second category, the interviewees' statements allowed a critical assessment of the stomatherapy service, in which they discussed critical issues related to practice and necessary/insufficient trainings, physical and human structures, inappropriate material, and restricted frequency of visitations to the units. Despite the reported difficulties, the managers were satisfied with the performance of the stomatherapy service, especially with regard to communication and interpersonal relationship between units.
\end{abstract}

DESCRIPTORS: Stomatherapy. Nursing. Management. Ostomy. Nursing services.

${ }^{1}$ Enfermeira Estomaterapeuta do Hospital Geral Doutor Waldemar Alcântara. Membro da Comissão de Segurança do Paciente (COSEP) Fortaleza (CE), Brasil. Endereço para correspondência: Avenida Ministro José Américo, 150, Cambeba - CEP: 60824-245 - Fortaleza (CE), Brasil E-mail: kaylinesoares@hotmail.com

Enfermeira Estomaterapeuta Titulada pela Associação Brasileira de Estomaterapia (SOBEST) - Fortaleza (CE)

${ }^{3}$ Doutora em Cuidados Clínicos em Enfermagem e Saúde pelo Programa de Pós-Graduação Cuidados Clínicos em Enfermagem e Saúde da Universidade Estadual do Ceará (UECE) - Fortaleza (CE), Brasil.

Artigo recebido em: 07/02/2015 - Aceito para publicação em: 08/04/2015 


\section{RESUMEN}

El objetivo fue describir la percepción de los gerentes de las unidades hospitalarias de enfermería, con respecto al cuidado del servicio de estomaterapia en un hospital público. Estudio descriptivo con enfoque cualitativo, realizado con 11 enfermeros encargados de la gestión de la unidad. Para recoger los datos, se utilizó un cuestionario de la entrevista semiestructurada. Para el análisis de las declaraciones, fue adoptada la técnica de análisis del contenido. Surgió a partir de este análisis dos categorías temáticas. En un primer momento, se discutieron las habilidades de enfermeras del servicio de estomaterapia, con informes sobre las visitas y la elaboración de opiniones técnicas, la prevención, el tratamiento de las heridas y la educación permanente en el servicio. En la segunda categoría, las declaraciones de los entrevistados permitieron una evaluación crítica del servicio de estomaterapia, en la que discutieron temas críticos relacionados con la formación y la capacitación necesaria/insuficiente, estructura humana y física; material inadecuado y frecuencia de las visitas a las unidades restringidas. A pesar de las dificultades señaladas, los administradores se mostraron satisfechos con el rendimiento del servicio de estomaterapia, especialmente con respecto a la comunicación y la relación interpersonal entre las unidades.

DESCRIPTORES: Estomaterapia. Enfermería. Gerencia. Estomía. Servicios de enfermería.

\section{INTRODUÇÃO}

A estomaterapia é uma especialidade exclusiva da área de enfermagem (pós-graduação/especialização), instituída no Brasil em 1990, cujo enfoque clínico-assistencial destina-se a pessoas com estomias, fístulas, tubos, cateteres e drenos, feridas agudas e crônicas e incontinências anal e urinária, nos seus aspectos preventivos, terapêuticos e de reabilitação em busca de melhoria da qualidade de vida ${ }^{1}$.

Tal atividade é versátil, pois oferece diversas possibilidades de trabalho e exige conhecimentos específicos para atuar no âmbito profissional. Esta atuação se dá de forma autônoma e ambulatorial, no ensino e na pesquisa, em consultoria e assessoria nas empresas de produtos hospitalares e em serviços constituídos em nível hospitalar².

A atuação em âmbito hospitalar ocorre a partir da formação de comissões ou serviços, podendo fazer parte deste grupo profissionais enfermeiros especialistas em estomaterapia ou com conhecimento na área, além de equipes multidisciplinares, incluindo médicos e nutricionistas. É importante destacar o papel central dos profissionais de enfermagem na composição destas equipes, visto que desempenham um cuidado mais direto na prevenção e no tratamento de feridas ${ }^{3}$.

A criação de um serviço de estomaterapia em âmbito hospitalar tem a intenção de melhorar a estrutura e ampliar o atendimento a pacientes que estejam internados ou que receberam alta hospitalar; além de buscar inovações no cuidado com o uso de terapêuticas eficientes, almejando excelência da assistência, além da redução de custos e do tempo de permanência hospitalar.
Desenvolver esta atividade especializada requer do enfermeiro estomaterapeuta habilidades para manter um bom relacionamento com os demais profissionais, em especial com enfermeiros generalistas/assistenciais e seus gerentes de enfermagem, com os quais detém maior contato no dia a dia. Cabe salientar a atuação dos gerentes de enfermagem das unidades de internação, visto que são mediadores de planejamento e avaliação dos cuidados de enfermagem das unidades, representando um papel importante na manutenção das condutas adotadas ou indicadas pelos especialistas.

Desse modo, os profissionais envolvidos no atendimento de estomaterapia devem estar implicados na qualidade do cuidado, incluindo enfermeiros gerentes, generalistas e estomaterapeutas. Assim, a articulação desses pode promover mudanças significativas para a qualidade de vida dos pacientes.

Tendo em vista a complexidade dos hospitais públicos, bem como o trabalho do estomaterapeuta, são necessárias a descrição e as avaliações do serviço de estomaterapia.

Tais avaliações podem sinalizar o ponto de partida para o planejamento de ações que promovam mudanças na redução da ocorrência de eventos adversos, tais como o aumento da incidência de lesões cutâneas, proporcionalmente com o crescimento da população idosa, gravidade das patologias, manejo de feridas complexas, restrição ao leito e pele vulnerável.

Cientificamente, esta pesquisa contribui como referência para a criação de novos serviços de estomaterapia em outras instituições ou otimização dos já existentes. Notam-se poucos trabalhos produzidos nessa área, com isto, almeja-se que 
os resultados auxiliem na tomada de decisão e na produção de um conhecimento específico relacionado a este tipo de serviço em âmbito hospitalar.

\section{OBJETIVO}

Descrever a percepção dos gerentes de enfermagem das unidades de internação a respeito do atendimento do serviço de estomaterapia em um hospital público.

\section{METODOLOGIA}

Estudo descritivo, com abordagem qualitativa, desenvolvido em um hospital público da Secretaria Estadual de Saúde do Ceará. Trata-se de uma unidade de saúde terciária, especializada nos atendimentos clínico-cirúrgico e ambulatorial de pessoas com patologias cardiovasculares e pulmonares. $\mathrm{O}$ hospital possui um serviço que se iniciou em 2002 como Comissão de Curativos e, em 2009, tornou-se serviço de estomaterapia, composto por cinco enfermeiras estomaterapeutas.

Os participantes do estudo foram enfermeiras que atenderam ao seguinte critério de inclusão: estar atuando como gerente de enfermagem em alguma unidade de internação do referido hospital, tais como enfermaria e Unidade de Terapia Intensiva.

A coleta de dados foi realizada com 11 gerentes, durante uma reunião ordinária mensal, em 24 de setembro de 2013. Com anuência da gerente geral de enfermagem, concedeu-se espaço nesta reunião para a explanação a respeito dos objetivos da pesquisa e orientação quanto ao preenchimento do Termo de Consentimento Livre e Esclarecido.

Para obtenção dos dados, optou-se por utilizar um questionário composto de perguntas fechadas sobre dados pessoais, com o propósito de caracterizar os sujeitos da pesquisa; e de questões subjetivas sobre a atuação do serviço de estomaterapia: como ocorre a atuação do serviço de estomaterapia em sua unidade? Sua unidade/equipe está necessitando de algum treinamento específico em nossa área? Se sim, qual/quais? Você teria alguma sugestão a fornecer para a melhoria do serviço?

O questionário foi entregue individualmente, lido e explicado. Por solicitação das entrevistadas, acordou-se um prazo de sete dias para a sua devolução à pesquisadora.
A análise, por sua própria natureza e subjetividade, foi fundamentada na abordagem qualitativa, tendo sido sistematizada conforme a técnica de análise de conteúdo, mais especificamente a análise temática. Para a operacionalização desse método, propõem-se três etapas: pré-análise; exploração do material e tratamento dos resultados; inferência e interpretação ${ }^{4}$.

A fase de pré-análise consistiu na organização propriamente dita, momento em que se organizou o material e formularam-se hipóteses ou questões norteadoras. No caso dos questionários, estes foram devidamente transcritos e sua reunião constituiu o corpus da pesquisa. A exploração do material foi a etapa seguinte, ou seja, o momento da codificação, em que os dados brutos foram transformados de forma organizada e agregados em unidades, as quais permitem uma descrição das características pertinentes do conteúdo. A codificação compreendeu a escolha das unidades de registro, a seleção das regras de contagem e a escolha de categorias. Unidade de registro (UR) é a unidade de significação a codificar, que pode ser o tema, a palavra ou a frase. A frequência com que aparece uma UR denota importância ${ }^{4}$.

Neste estudo, o corpus foi constituído por 11 entrevistas, tendo sido definida como UR a frase e, como unidade de contexto, o parágrafo. Esta, por sua vez, serve de unidade de compreensão para codificar a unidade de registro e corresponde ao segmento da mensagem, cujas dimensões (superiores às da unidade de registro) são ótimas para que se possa entender a significação exata da UR ${ }^{4}$.

A etapa seguinte consistiu na categorização. Categorias são rubricas ou classes que reúnem um grupo de elementos (URs) em razão de características comuns. Por último, procedeu-se ao tratamento dos resultados obtidos e à interpretação. Nesse momento, foi preciso voltar atentamente aos marcos teóricos, pertinentes à investigação, pois eles dão o embasamento e as perspectivas significativas para o estudo. A relação entre os dados obtidos e a fundamentação teórica é que dá sentido à interpretação.

Os resultados foram discutidos com a literatura referente à temática. Para garantir o anonimato das entrevistadas, as gerentes foram codificadas com a letra ' $G$ ' seguida de numeral arábico, conforme a ordem em que os questionários foram sido devolvidos.

A pesquisa obteve aprovação do Comitê de Ética em Pesquisa (CEP) do hospital onde se desenvolveu a investigação, recebendo parecer favorável, conforme número $397.529 / 2013$ 


\section{RESULTADOS}

O estudo contou com a participação de 11 enfermeiras gerentes, com idade média de 51 anos, mínima de 28 anos e máxima de 60 anos.

Quanto ao perfil profissional, foram encontrados profissionais experientes na área de atuação. Tal resultado é constatado quando se verifica $91 \%$ com mais de 10 anos de graduação e $55 \%$ com mais de cinco anos na gerência da unidade atual. Quanto às unidades, havia seis gerentes de unidades de internação/enfermarias e cinco de Unidades de Terapia Intensiva.

Com relação à qualificação, $73 \%$ possuíam especialização em diferentes áreas, porém apenas uma gerente era especializada em Gestão Hospitalar. Duas possuíam mestrado, uma em Cuidados Clínicos em Enfermagem e Saúde e outra em Planejamento e Políticas Públicas de Saúde.

No que diz respeito ao vínculo empregatício, seis eram funcionárias da Secretaria de Saúde do Estado; uma possuía vínculo com o Ministério da Saúde; duas eram vinculadas ao Ministério e à Secretaria de Saúde e duas eram terceirizadas.

Os resultados oriundos da exploração do material empírico correspondem à percepção das enfermeiras gerentes acerca do trabalho do serviço de estomaterapia. $\mathrm{O}$ corpus das informações coletadas dos 11 questionários resultou em 98 URs temáticas. Apresenta-se, na Tabela 1, o resultado da análise de conteúdo, na qual foram identificadas duas categorias temáticas e sete subcategorias.

Após uma organização criteriosa dos dados, as seguintes categorias temáticas emergiram: competências das enfermeiras do serviço de estomaterapia e apreciação crítica do serviço de estomaterapia.

Observa-se que houve destaque à categoria 2 , em que se reuniram $60 \%$ das URs.

\section{Competências das enfermeiras do serviço de estomaterapia}

\section{Visitaçáo e elaboração de pareceres}

As gerentes entrevistadas relataram como as especialistas organizavam as visitas nas unidades de internação, mostrado a seguir:

As visitas [às unidades] acontecem semanalmente (G 1).

[Ocorrem] visitas periódicas [na unidade] previamente programadas (G 11).

As estomaterapeutas do hospital de estudo realizam visitas programadas nas unidades de internação, por meio de um cronograma semanal. Cada unidade tem um dia específico para a visitação, sendo também chamada de busca ativa, como relata a gerente:

[As estomaterapeutas fazem] busca ativa em visitas às unidades (G 5).

Outra forma de atendimento das especialistas é por solicitação de pareceres, como se mostra a seguir:

[As estomaterapeutas] atendem as solicitações de "parecer" das enfermeiras do setor quando encaminhado (G 4).

$\mathrm{Na}$ realidade do hospital em estudo, o parecer a ser emitido pela estomaterapeuta pode ser solicitado pelo profissional médico, pela gerente de enfermagem ou pela enfermeira assistencial, o qual é preenchido em duas vias. Destas, uma consta no prontuário do paciente e a outra no serviço de estomaterapia para avaliação. Os pedidos de pareceres devem ser respondidos em tempo hábil, no prazo máximo

Tabela 1. Distribuição das categorias temáticas, subcategorias e respectivas frequências sobre o atendimento do serviço de estomaterapia. Fortaleza (CE), setembro de 2013, n=98.

\begin{tabular}{lccc}
\hline Categorias & $\mathbf{n}(\%)$ & Subcategorias & $\mathbf{n}(\%)$ \\
\hline $\begin{array}{l}\text { 1. Competências das } \\
\text { enfermeiras do serviço } \\
\text { de Estomaterapia }\end{array}$ & $39(39,8)$ & 1.1 Visitação e elaboração de pareceres & $18(46,2)$ \\
& & 1.2 Prevenção e tratamento de feridas & $17(43,6)$ \\
& & 1.3 Educaçãa permanente no serviço & $4(10,3)$ \\
$\begin{array}{l}\text { 2. Apreciação crítica do } \\
\text { serviço de estomaterapia }\end{array}$ & $59(60,2)$ & 2.3 Quantitativo/frequência restrita de visitas & $11(18,6)$ \\
& & 2.4 Estruturas física e humana e material inapropriado & $10(16,9)$ \\
\hline
\end{tabular}


de 24 horas. As enfermeiras estomaterapeutas priorizam este atendimento, sendo uma maneira de otimizar o serviço e estabelecer um vínculo e confiança com os profissionais.

Quanto à operacionalização, as visitas iniciam-se às oito horas da manhã. Cada estomaterapeuta se dirige às unidades escaladas naquele dia, conversam com a enfermeira do plantão e leem os prontuários, com o intuito de adquirir maiores conhecimentos sobre os pacientes, tais como: idade, sexo, diagnóstico, dieta, exames laboratoriais, medicamentos, os quais podem interferir no processo de cicatrização ou serem fatores potenciais para adquirir lesão cutâneas.

\section{Prevenção e tratamento de feridas}

As gerentes relataram como é a atuação das enfermeiras estomaterapeutas em suas unidades, durante as visitas programadas ou em respostas a pareceres:

[Elas fazem] indicações adequadas para uso dos curativos biológicos de acordo com as características e estágios da ferida (G 1).

[É] avaliada a presença de úlceras [por pressão] através da visualização durante os banhos (G 8).

A avaliação da enfermeira estomaterapeuta deve ser cautelosa, visto que o tratamento de feridas é um processo complexo e dinâmico. Somente na Unidade de Terapia Intensiva, o exame físico e a troca de curativos, geralmente, são realizados durante o banho no leito. Contudo, em função da grande demanda de pacientes, a profissional avalia os casos mais complexos. Os casos já investigados são reavaliados, as feridas são desbridadas, e executa-se o registro do atendimento nos prontuários de maneira detalhada, priorizando a evolução da lesão, do tamanho, das características de exsudato, dos sinais de infecção, do tecido viável ou inviável. São, então, sugeridas condutas de coberturas interativas, além da realização de orientações para a equipe sobre os cuidados prestados.

No depoimento a seguir, expõe-se essa necessidade diante do atendimento de feridas complexas:

Nos casos mais complexos, a própria estomaterapeuta acompanha a evolução da ferida diariamente (G 1).

Devido ao tipo de atendimento realizado no hospital do estudo, existem pacientes com lesões que evoluem para mediastinite, com indicação de limpeza exaustiva da ferida no esterno e aplicação de cobertura específica. $\mathrm{O}$ atendimento das feridas complexas é responsabilidade da estomaterapeuta, visto que, por sua gravidade e altas taxas de mortalidade, estas necessitam de maior atenção, preparos técnico e científico, conhecimentos específicos de anatomia e fisiologia da cicatrização.

Algumas feridas complexas necessitam de intervenção cirúrgica. Em tais casos, o trabalho da estomaterapeuta é árduo, ela prepara o leito da ferida para posteriormente receber a intervenção cirúrgica. Esta preparação é realizada de acordo com suas características, atentando para a escolha de coberturas que promovam a limpeza, o desbridamento, o controle do odor e a exsudação, a cessação da infecção e a redução de complicações.

\section{Educaçáo permanente no serviço}

A importância da educação permanente para a enfermagem merece atenção diferenciada, no sentido de preparar os trabalhadores para a prática. As gerentes apontaram as especialistas como articuladoras de educação permanente e em serviço.

[As estomaterapeutas] tiram dúvidas no dia-a-dia (G 7).

[...] há um treinamento prático quando os profissionais [estomaterapeutas] passam na unidade realizando os pareceres e os atendimentos (G 11).

\section{Apreciação crítica do serviço de estomaterapia}

\section{Capacitação e treinamento necessários/insuficientes}

Nesta subcategoria, as gerentes relatam seu desejo relacionado a treinamentos e estudos de caso na área de estomaterapia. Tal afirmativa é exemplificada nos relatos abaixo:

[Seria importante] manter sempre cursos de capacitações com profissionais atualizados (G 2).

Acredito que se fosse realizado um estudo de caso quinzenalmente com as unidades presentes seria muito positivo ( $\mathrm{G} 11)$.

Neste contexto, a gerente faz uma observação relevante a respeito da assistência dos enfermeiros no período noturno, que é relacionada à capacitação e ao treinamento: 
Sempre necessitamos [de capacitação]. Principalmente os enfermeiros que trabalham mais no serviço noturno e não renovam curativo com a mesma frequência que os enfermeiros diurnos (G 7).

No hospital analisado, a atuação do serviço de estomaterapia ocorre somente no período diurno. Para a gerente entrevistada, os enfermeiros do serviço noturno ficam prejudicados por não haver interação do serviço de estomaterapia na promoção de educação permanente.

Outra preocupação emergente do depoimento das pesquisadas é a falta de atualização e padronização das ações a fim de operacionalizar o serviço, o que denota a necessidade da criação de protocolos que ajudarão à equipe a uniformizar as suas condutas, de forma sistematizada, contribuindo para uma melhorar a assistência ao cliente. É preciso investir em protocolos e no treinamento para o uso destes, conforme relata esta gerente:

Promover reciclagem com os enfermeiros das unidades sobre novos protocolos (G 1).

Ainda com relação ao tema de capacitações e treinamentos, observou-se a variabilidade das temáticas citadas pelas gerentes na área de estomaterapia, questões consideradas relevantes e sugeridas por elas:

[Necessidade de treinamento] sobre prevenção de úlcera por pressão (G 5).

[Treinamento sobre] produtos mais recentes e que ainda não tivemos a oportunidade de conhecer ou usar (G 7).

[Treinamento sobre] técnicas de realização dos curativos devido ao uso, digo, gasto elevado de produtos, fixações exageradas, ampla (G10).

\section{Atuação satisfatória}

Nesta subcategoria, as gerentes ressaltam suas opiniões favoráveis acerca do serviço, identificadas nos seguintes discursos:

Existe bom relacionamento entre as profissionais da estomaterapia com as unidades (enfermeiras/médicos) (G 5).

A interação entre estomaterapeutas e gerentes é feita de maneira satisfatória (G 5).
A equipe [de estomaterapia é] bem atuante, acessível, muito harmônica (G 11).

\section{Quantitativo/frequência restrita de visitas}

Nesta, as gerentes enfatizaram a insatisfação com relação à quantidade de visitas, deixando claro o desejo de que estas fossem aumentadas:

Só um dia [de visita] é pouco para a quantidade de pacientes (G 4).

[São necessárias] visitas [da estomaterapeuta] duas vezes por semana (G 6).

[É necessário] aumentar a frequência de visita à unidade (G 10).

\section{Estruturas física e humana e material inapropriado}

Nesta subcategoria, as gerentes, inicialmente, relatam as dificuldades sobre dimensionamento de pessoal, a partir dos discursos:

A equipe [de estomaterapia é] pequena para a grande demanda existente (G 7).

[Existe] pouco pessoal na equipe de estomaterapia, o que deixa a desejar (G 10).

Por diversas vezes, as especialistas encontram-se sobrecarregadas, realizam visitas em três unidades em apenas um dia, porém existem unidades, como emergência e terapia intensiva, que requerem maior tempo e disponibilidade. Essa sobrecarga ocorre por meio do acompanhamento de diversos pacientes, dos pareceres para serem respondidos, dentre outras atividades, tais como atendimento ambulatorial e atividades burocráticas. No entanto, somente um dia e uma especialista para cada setor, muitas vezes, não atenderão às necessidades.

Em relação ao espaço físico, destacam-se os relatos a seguir:

Devido à dimensão do serviço de estomaterapia, penso que deveria ter um espaço físico próprio onde pudessem realizar atendimento aos pacientes externos ( $\mathrm{G} 1)$.

Gostaríamos que a equipe de estomaterapia tivesse uma sala adequada para desempenhar com tranquilidade e segurança a excelência do seu trabalho (G 9). 
Nesta mesma subcategoria, são mencionadas dificuldades referentes à dispensação dos materiais de curativo:

Sabemos das dificuldades financeiras da instituição, mas ressaltamos que a escassez de material para curativo em pediatria tem um impacto considerável na qualidade da assistência de enfermagem (G 9).

\section{DISCUSSÃO}

Ao analisar o perfil das entrevistadas, verificou-se que as enfermeiras gerentes das unidades de internação e de terapia intensiva do hospital em estudo representam um quadro de profissionais experientes, tanto na categoria profissional quanto no tempo de atuação no serviço. Esse perfil demonstra que tais enfermeiras possibilitaram uma avaliação crítica do serviço de estomaterapia ao relatarem as competências e os aspectos positivos e negativos de sua atuação. Desse modo, suas opiniões foram consideradas de relevância significativa para o desenvolvimento e o planejamento das ações do serviço de estomaterapia.

$\mathrm{Na}$ categoria 1 , no que diz respeito às competências do serviço de estomaterapia, as gerentes destacaram a visitação e a elaboração de pareceres.

Autores afirmam que as visitas da estomaterapeuta devem ser destinadas aos pacientes com lesões cutâneas já instaladas ou em potencial para desenvolvê-las. Contudo, essa estratégia é uma excelente maneira para o levantamento de dados epidemiológicos, dados de incidência e prevalência. O real número de pacientes com úlceras por pressão, no Brasil, ainda é desconhecido, o que se deve à ausência de registro do agravo e a não obtenção da taxa de ocorrência (prevalência e incidência) de forma rotineira ${ }^{5}$.

Quanto aos pareceres, é extremamente importante que, durante os atendimentos nas unidades de internação, estes sejam realizados de maneira correta e rotineira pela equipe de estomaterapia, a fim de efetivar o levantamento de dados estatísticos dos índices de lesão de pele da instituição, buscando promover estratégias para diminuir as taxas de incidência.

Borges et al. ${ }^{6}$ afirmam que os pareceres são exemplos de ferramentas primordiais e essenciais para o profissional enfermeiro implementar sua autonomia e buscar subsídios para a sua prática, com todo respaldo ético-legal, dispondo ao paciente com ferida qualidade e segurança.
A análise sobre a prevenção e o tratamento de feridas permite lembrar que existem fatores intervenientes no processo de cicatrização fisiológica e que devem ser ressaltados pelo estomaterapeuta na tomada de decisões em conjunto com a equipe assistencial, a saber: sistêmicos, como tabagismo, idade, estado nutricional, doenças crônicas do tipo insuficiência renal e vascular e diabetes e uso de drogas, principalmente aquelas que atuam no sistema imunológico ${ }^{6}$. Daí, ressalta-se a importância de uma avaliação criteriosa pelo profissional estomaterapeuta.

No Brasil, apenas médicos e enfermeiras especialistas em estomaterapia, em dermatologia ou treinados em cursos preparatórios, estão autorizados a realizar o desbridamento de feridas, já que tal procedimento exige conhecimento científico, competência e habilidade prática ${ }^{7}$.

$\mathrm{O}$ enfermeiro desempenha um papel fundamental na avaliação da ferida e no acompanhamento e tratamento do sujeito com lesão. Essa assistência torna-se ainda mais necessária quando nos deparamos com lesões graves, exigindo conhecimento teórico e prática para tratá-las ${ }^{8}$.

Quanto aos casos mais complexos, é preciso reconhecer a origem de tais lesões para que o seguimento adequado ocorra de forma efetiva. Ferida complexa é o termo utilizado para identificar as feridas difíceis, crônicas e algumas agudas, que desafiam equipes médicas e de enfermagem em sua cicatrização e que, às vezes, não respondem à terapia de curativo convencional. Atualmente, elas têm um grande impacto socioeconômico e devem ser tratadas por equipes multidisciplinares em centros hospitalares especializados, seguem alguns exemplos: feridas diabéticas, úlceras por pressão, úlceras venosas, gangrenas de tecidos moles, vasculites, dentre outras ${ }^{9}$.

Outro exemplo de ferida complexa é a mediastinite, que se caracteriza por uma infecção profunda da ferida operatória pós-cirurgia cardíaca, com evidência clínica e/ou microbiológica de comprometimento do espaço retroesternal, podendo estar associada à osteomielite do esterno, com ou sem a sua instabilidade ${ }^{10}$.

Destaca-se a importância da educação permanente dos profissionais das unidades por parte dos enfermeiros estomaterapeutas, os quais têm dupla responsabilidade: a primeira destina-se a promover cuidados especializados aos indivíduos com necessidades específicas; e a segunda para compartilhar conhecimentos e habilidades com colegas de profissões da área de saúde ${ }^{11}$. 
Nesta perspectiva, a especialista tem o dever de repassar seus conhecimentos para a equipe, seja durante a realização de curativo ou nas sugestões de condutas, garantindo um atendimento contínuo por parte dos enfermeiros assistenciais. Torna-se necessário interação com o serviço e interesse no aprendizado. Muitas vezes, deparamo-nos com enfermeiros assistenciais desinteressados no assunto e, também, sobrecarregados em suas atividades, não acompanhando a estomaterapeuta no atendimento ao paciente ou lendo o parecer escrito no prontuário, o que pode ocasionar uma assistência insegura e não continuada.

Todavia, é necessário qualificar os profissionais não especialistas, por meio da prática de educação permanente, elaboração de protocolos, estabelecimento de indicadores e programas para a prevenção de lesões cutâneas, a fim de melhorar a qualidade da assistência. O déficit de conhecimento, juntamente com as práticas inadequadas da equipe de enfermagem, contribui para o surgimento de feridas.

Faz-se necessário, ainda, dar ênfase aos indivíduos ensinando, capacitando e motivando, por meio de treinamentos, para que, além de realizarem o trabalho, também melhorem seus comportamentos e relacionamentos. Nesse sentido, o treinamento desenvolve as pessoas, não somente para atingir economicamente os objetivos, mas também para os crescimentos pessoal e profissional ${ }^{12}$.

Foi possível também identificar a maioria das URs encontradas nos depoimentos das gerentes de enfermagem, o que significa que houve maior enfoque à apreciação crítica do serviço, em seus aspectos positivos e negativos.

Inicialmente, a capacitação e o treinamento foram assuntos preponderantes entre as entrevistadas, as quais consideraram-nos insuficientes. Destaca-se o relato da G 11, a qual afirma a necessidade de trabalhar com estudos de caso para melhorar o conhecimento sobre a avaliação da pele do paciente.

O estudo de caso facilita o processo ensino-aprendizagem, sendo uma estratégia de investigação, na qual explora-se profundamente um evento, processo ou indivíduos ${ }^{13}$. Nos hospitais, esta modalidade de ensino-aprendizagem se faz necessária devido à complexidade e incorporação de novas tecnologias e tratamentos das diversas patologias encontradas.

Percebe-se a necessidade de um maior investimento em capacitação profissional, por meio da educação permanente em serviço, bem como na construção e implantação de protocolos para prevenção e tratamento de lesões, sendo estas responsabilidades da equipe de enfermagem; consequentemente, os protocolos são uma estratégia que poderá reduzir a incidência de úlcera por pressão ${ }^{14}$.

Um estudo realizado em 2009 mostra que 75\% (n=16) dos enfermeiros entrevistados consideraram ter pouco conhecimento sobre curativos, mesmo com metade deles afirmando já terem realizado algum curso sobre feridas ${ }^{15}$. Dessa forma, é imprescindível que o profissional seja habilitado, com conhecimentos apropriados e atualizados, a fim de prestar uma assistência eficiente.

Corroborando com este ponto de vista, o serviço de estomaterapia se faz primordial na capacitação de enfermeiros generalistas. Um estudo realizado no município de Belém (PA) revela que o serviço de estomaterapia possui uma função importante na reabilitação das pessoas, além de elaborar cursos e/ou palestras de capacitação dos profissionais de enfermagem. Também relata que o serviço exerce um papel essencial na vida das pessoas, demandando ainda melhorias e investimentos dos gestores de saúde do estado ${ }^{16}$.

A atuação satisfatória do serviço foi destacada pelos depoimentos das gerentes. Desse modo, percebe-se a autonomia e a valorização do trabalho das enfermeiras que compõem o serviço de estomaterapia no hospital analisado, considerando que, durante as visitas, ocorre um momento de interação significativa e troca de experiências e informações entre o enfermeiro estomaterapeuta, a equipe multiprofissional e os pacientes.

A enfermeira especialista dialoga e conhece o perfil de cada profissional, paciente e unidade visitada, facilitando a sua atuação e o desenvolvimento de estratégias comunicacionais para o atendimento. Quando a visita ocorre mais frequentemente, crescem a confiança, o vínculo e o cuidado humanizado.

Autores reiteram que a conquista da autonomia por parte do enfermeiro se faz pela busca da coletividade, o que envolve capacidades inatas, habilidades, atitudes, desejos, autoconfiança, aptidão, conhecimento, espaço político, tomadas de decisão e escolhas. É preciso estar preparado para a autonomia, pois ela exige embasamento de conhecimentos técnico e científico, além das responsabilidades éticas ${ }^{17}$.

Além disso, pelo grande interesse entre os enfermeiros em expandirem seus conhecimentos na área do tratamento de feridas, a estomaterapia destaca-se como uma especialidade que, a cada dia, exige mais multiplicidade de conhecimento e versatilidade na atuação. Assim, para o enfermeiro prestar uma assistência autônoma, é preciso objetivar, otimizar e padronizar os procedimentos de prevenção e tratamento 
de feridas. Isso deve ser feito mediante protocolos técnicos que garantam respaldo legal, técnico e científico ao profissional, a fim de melhorar a assistência, e dispondo ao paciente com feridas qualidade e segurança ${ }^{17}$.

Com relação à frequência restrita de visitas das estomaterapeutas às unidades assistenciais, esta percepção das gerentes é um dado relevante, visto que o trabalho da estomaterapia está sendo bem reconhecido por elas. A importância deste reconhecimento motiva a atuação do serviço de estomaterapia e, consequentemente, melhora a assistência prestada aliada à satisfação dos trabalhadores.

Em outro estudo, 93,7\% dos enfermeiros consideraram importante o trabalho multiprofissional no tratamento de feridas, seguido de $87,5 \%$ deles que acreditavam que a presença de um profissional qualificado, como o estomaterapeuta, possibilitava mais segurança aos trabalhos assistenciais com as feridas ${ }^{16}$. Nos hospitais, o estomaterapeuta ocupa uma função importante, uma vez que pode proporcionar a sistematização no tratamento de feridas, pois está preparado para tomar decisões nessas áreas ${ }^{15}$.

Quanto às estruturas física e humana e material inapropriado, percebeu-se, de maneira evidente, um desejo de melhorias por parte do atendimento do serviço aos pacientes externos, visto que o atendimento ambulatorial era realizado três vezes por semana, no período da manhã, por uma enfermeira estomaterapeuta e uma técnica de enfermagem, em uma pequena sala, inadequada para a realização de curativos. Esse local não era exclusivo do serviço de estomaterapia, o que gerava conflitos em alguns momentos.

Com relação à dispensa de materiais, outro estudo também abordou a problemática, em que foi apontada a deficiência de recursos materiais e a falta de protocolos específicos como importantes dificuldades para promover uma assistência de enfermagem eficaz e de boa qualidade ${ }^{18}$.

As instituições hospitalares, em geral, não dispõem de produtos variados para o tratamento de feridas, limitando-se a pomadas enzimáticas ou soro fisiológico, devido ao elevado custo dos produtos. Entretanto, quando considerada a relação custo-benefício, há uma economia dos materiais de consumo e recursos humanos, tendo em vista a aceleração do processo de cicatrização, a redução do período de hospitalização e a otimização das horas de trabalho dos profissionais ${ }^{19}$.

O conhecimento desses produtos e a sua utilização correta são imprescindíveis, visto que os gastos financeiros com lesões são elevados, além dos prejuízos para a saúde, causando também ansiedade para o paciente e a família e desgaste para toda a equipe. É mister que o melhor tratamento ainda é a prevenção.

Existem estudos que mostram depoimentos de enfermeiros acerca das dificuldades de aquisição dos recursos humanos e materiais. Nesse aspecto, ressalta-se que a provisão de qualidade no cuidado ao paciente é uma prioridade que está relacionada à promoção de condições adequadas de trabalho, seja referente ao quantitativo de pessoal, à qualificação dos profissionais ou à disponibilização de recursos físicos e materiais para prestar a assistência. Em contrapartida, é possível se deparar com profissionais desmotivados no trabalho e uma prática laboral distante das reais necessidades do paciente ${ }^{20}$.

Assim, ressalta-se que o primeiro passo na busca de articulação entre enfermeiros assistenciais, gerentes de unidades e estomaterapeutas deve levar em consideração os aspectos supracitados, evidenciados pelas fragilidades a serem trabalhadas e melhorias a serem implementadas, considerando a qualidade da assistência como produto final.

Portanto, o bom relacionamento interpessoal que as gerentes tem com o serviço de estomaterapia deverá ser preservado para alcançar tais resultados. $\mathrm{O}$ fato das estomaterapeutas estarem sempre disponíveis gera um bom relacionamento com os profissionais da assistência e da gerência das unidades. Isto faz com que o serviço, mesmo com as suas dificuldades, consiga realizar um atendimento de excelência, buscando assistência segura e humanizada aos pacientes.

O presente estudo apresentou limitação importante quanto ao quantitativo de profissionais entrevistados e devido ao fato de envolver apenas um hospital e um serviço de estomaterapia, o que impossibilita a generalização dos resultados. No entanto, como observado, foi expressiva, nos relatos das participantes, uma visão geral do atendimento prestado pelo serviço de estomaterapia.

Como contribuições, o estudo pode promover a disseminação do conhecimento adquirido, principalmente às organizações que já apresentam em sua estrutura um serviço de estomaterapia ou para aqueles que estão em construção. Há necessidade de sensibilização por parte dos mesmos quanto às fragilidades da assistência prestada pelo serviço de estomaterapia e as dificuldades expostas pelas gerentes de enfermagem em suas unidades. O serviço necessita de maior investimento para que possa atuar em sua especialidade de maneira satisfatória, em alguns aspectos. 


\section{CONSIDERAÇÕES FINAIS}

Este estudo propiciou conhecer a percepção das gerentes de enfermagem acerca do serviço de estomaterapia existente em um hospital público terciário, na cidade de Fortaleza (CE)

A respeito dos dados referentes às competências do serviço, as entrevistadas descreveram que as especialistas realizavam visitas semanais, programadas, em suas unidades de internação e respondiam pareceres quando solicitados. Porém, enfatizaram que, em função da elevada demanda de pacientes e pouco pessoal na equipe de estomaterapia, o atendimento tornava-se inviável para alguns pacientes.

Com relação aos procedimentos, as gerentes discorreram que o serviço era responsável por realizar os curativos de feridas consideradas complexas, pela emissão de pareceres, pela educação em serviço, dentre outros. Quanto à educação permanente, demonstraram sua importância e a necessidade de maior atenção por parte do serviço no quesito capacitação e treinamento, sugerindo diversos temas relacionados à área.

Com base nos achados sobre recursos materiais, as entrevistadas ressaltaram escassez, principalmente relacionadas às coberturas, as quais poderiam dificultar a assistência prestada. Todavia, mesmo diante das dificuldades, as gestoras demonstraram satisfação em seus discursos sobre a atuação do serviço em suas unidades, principalmente a respeito da comunicação e do relacionamento.

Neste prisma, no desenvolvimento desta pesquisa, buscou-se reunir, discutir e analisar a atuação do serviço de estomaterapia em um hospital público, em relação à percepção de suas gerentes. Desse modo, contribuiu-se para conhecer as facilidades e dificuldades e buscar caminhos alternativos para otimizar o serviço.

\section{REFERÊNCIAS}

1. Yamada BF, Ferrola EC, Azevedo GR, Blanes L, Rogenski NM, Santos VL. Competências do Enfermeiro Estomaterapeuta (ET) ou do Enfermeiro Pós-graduado em Estomaterapia (PGET). Rev Estima. 2008;6(1)33-43.

2. Associação Brasileira de Estomaterapia. [Internet] [citado 2014 Nov]. Disponível em: http://www.sobest.com.br/index. php?option=com_content\&task=view\&id=9

3. Malagutti W. Feridas: conceitos e atualidades. São Paulo: Martinari; 2015.

4. Bardin L. Análise de conteúdo. 7. ed. São Paulo: Edições 70; 2011.

5. Borges EL, Fernandes FP. Prevenção de Úlcera por Pressão. In: Domansky RC, Borges EL. Manual para prevenção de lesões de pele. Recomendações baseada em evidencias. Rio de Janeiro: Rubio; 2014. p. 151-218.

6. Borges EL, Saar SR, Magalhães MB, Gomes FS, Lima VL. Feridas: como tratar. Belo Horizonte: Coopmed; 2008.

7. Carvalho ES, Pinheiro RF. Limpeza e desbridamento das feridas: aspectos técnicos e operacionais. In: Carvalho ES. Como cuidar de pessoas com feridas: desafios para a prática multiprofissional. Salvador: Atualiza; 2012, p. 83-112.

8. Silva CC, Rogenski NM. Uso da papaína: conhecimentos de enfermeiros em um hospital da cidade de são Paulo. Rev Estima. 2010;8(1):12-7.

9. Ferreira MC, Tuma Jr. P, Carvalho VF, Kamamoto F. Complexwounds. Clinics. 2006;61(6):571-8.

10. Sá MP, Silva DO, Lima EN, Lima RC, Silva FP, Rueda FG, et al. Mediastinite no pós-operatório de cirurgia cardiovascular. Análise de 1038 cirurgias consecutivas. Rev Bras Cir Cardiovasc. 2010;25(1):19-24.

11. Cesaretii IU, Leite MG. Bases para o cuidado em Estomaterapia. In: Santos VL, Cesaretii IU. Assistência em estomaterapia: cuidando do ostomizado. São Paulo: Atheneu; 2005.

12. Almeida EL, Oliveira IG, Santos MA. Desenvolvimento e Capacitação de Pessoas. Revista Visão Acadêmica. 2011;3:89-101.

13. Creswell JW. Projeto de pesquisa. Métodos qualitativos, quantitativo e misto. 3. ed. Porto Alegre: Artmed; 2010.

14. Silva ML, Caminha RT, Oliveira SH, Diniz ER, Oliveira JL, Neves VS. Úlcera por pressão em unidade de terapia intensiva: análise da incidência e lesões instaladas. Rev Rene. 2013;5(14):938-44.

15. Moreira RA, Queiroz TA, Araújo MF, Araújo TM, Caetano JA. Condutas de enfermeiros no tratamento de feridas numa unidade de terapia intensiva. Rev Rene. 2009;10(3):83-9.

16. Silva AC, Silva NS, Cunha RR. Caracterização de Pessoas Estomizadas atendidas em Consulta de Enfermagem do Serviço de Estomaterapia do Município de Belém-PA. Rev Estima. 2012;10(1):12-9

17. Ferreira AM, Bogamil DD, Tormena PC. O enfermeiro e o tratamento de feridas: em busca de autonomia do cuidado. Arq Cienc Saúde. 2008;15(3):105-9.

18. Rios LC, Veloso IB. Cuidados de enfermagem na prevenção de ulcera por pressão em um hospital público de feira de Santana, Bahia. Rev Estima. 2010;8(2):20-7.

19. Melo EM, Fernandes VS. Avaliação do conhecimento do enfermeiro acerca das coberturas de última geração. Rev Estima. 2011;9(4):12-20

20. Rolim JA, Vasconcelos JM, Caliri MH, Santos IB. Prevenção e tratamento de úlceras por pressão no cotidiano de enfermeiros intensivistas. Rev Rene. 2013;1(14):148-57. 


\title{
Implantação de uma Comissão de Cuidados com a Pele em um Hospital de Ensino*
}

Implementation of a Skin Care Commission in a University Hospital

\author{
Implementación de una Comisión de Cuidado de la Piel en un Hospital Universitario
}

Tereza Cristina Caron Krause?, Gisela Maria Assis², Mitzy Tannia Reichembach Danski³

\begin{abstract}
RESUMO
Objetivo: Foi descrever as fases de implantação de uma Comissão de Cuidados com a Pele em um hospital de ensino. Método: Pesquisa descritiva documental, realizada no período de fevereiro de 2012 a março de 2014, por meio de consulta a documentos institucionais. Resultados: A implantação foi descrita nas seguintes fases por fins didáticos: negociação - apresentação da proposta à Diretoria de Enfermagem, Direção Geral e seus respectivos colegiados; estruturação - formação do núcleo estruturador, com reuniões periódicas para deliberações quanto aos membros e ao funcionamento da Comissão; documentação - elaboração de projeto, regimento, ofícios, solicitações de padronização, instrumentos de avaliação, relatórios, entre outros; implementação - funcionamento de reuniões, capacitações, avaliações e acompanhamento dos pacientes. Conclusão: Considera-se efetiva a estratégia utilizada para implantação da Comissão de Cuidados com a Pele e sugere-se a participação multiprofissional na sua composição. Destaca-se a importância da criação de comissões para a implementação do plano de segurança do paciente.
\end{abstract}

DESCRITORES: Estomaterapia. Comitê de Profissionais. Ferimentos e lesões. Segurança do paciente.

\begin{abstract}
Objective: It was to describe the implementation phases of a Commission for Skin Care in a university hospital. Method: Documentary, descriptive study conducted from February 2012 to March 2014, through consultation with institutional documents. Results: The implantation was described in the following phases for teaching purposes: negotiation - presentation of the proposal to the Board of Nursing, General Direction and their respective collegiate; structuring - formation of structuring core with regular meetings for deliberations as Members and functioning of the Commission; documentation - project design, regiment, crafts, requests for standardization, assessment tools, reports, etc.; implementation - running meetings, training, evaluations and monitoring of patients. Conclusion: It is considered effective the strategy used to implement the Skin Care Commission and it is suggest the multidisciplinary participation in its composition. Highlights on the importance of creating committees for the implementation of the security plan of the patient.
\end{abstract}

DESCRIPTORS: Stomatherapy. Professional Staff Committees. Wounds and injuries. Patient safety.

\footnotetext{
'Enfermeira, Mestre em Enfermagem pelo Programa de Pós-Graduação Mestrado Profissional em Enfermagem da Universidade Federal do Paraná (UFPR); Membro do Núcleo Estruturador da Comissão de Cuidados com a Pele do Hospital de Clínicas de Curitiba da UFPR - Curitiba (PR), Brasil Endereço para correspondência: Rua Herculano Carlos Franco de Souza, 550, apto 604 A - CEP: 80240-290 - Curitiba (PR), Brasil - E-mail: terezakrause@onda.com.br Enfermeira; Mestre em Tecnologia em Saúde pelo Programa de Pós-Graduação em Enfermagem da Pontifícia Universidade Católica (PUC) do Paraná; Coordenadora da Comissão de Cuidados com a Pele do Hospital de Clínicas de Curitiba da UFPR - Curitiba (PR), Brasil.

${ }^{3}$ Enfermeira, Doutora em História; Professora Adjunta da Graduação e Programa de Pós-Graduação do departamento de Enfermagem da UFPR Curitiba (PR), Brasil.

*Extraído da dissertação "Implantação de uma Comissão de Cuidados com a Pele em Hospital de Ensino". Programa de Pós-Graduação em Enfermagem Mestrado Profissional da Universidade Federal do Paraná em 2013.

Artigo recebido em: 01/04/2015 - Aceito para publicação em: 22/04/2015
} 


\section{RESUMEN}

Objetivo: Fue describir las fases de la implementatión de una Comisión para Cuidado de la piel en un hospital universitario. Método: Documental, estudio descriptivo realizado entre febrero 2012 y marzo 2014 , a través de consultas con los documentos institucionales. Resultados: La implantación se describe en las siguientes fases con fines didácticos: negociación - presentación de la propuesta a la Dirección de Enfermería, Dirección General y sus respectivos colegiados; Estructuración - formación de núcleo de estructuración con reuniones periódicas para las deliberaciones de miembros y funcionamiento de la Comisión; documentación - diseño de proyectos, regimiento, la artesanía, las solicitudes de normalización, herramientas de evaluación, informes, etc.; implementación - ejecución de reuniones, formación, evaluación y seguimiento de los pacientes. Conclusión: Se considera efectiva la estrategia utilizada para implementar la Comisión y se sugieren la participación multidisciplinaria en su composición. Se destaca la importancia de la creación de comités para la ejecución del plan de seguridad del paciente.

DESCRIPTORES: Estomaterapia. Comités de Profesionales. Heridas y traumatismos. Seguridad del paciente.

\section{INTRODUÇÃO}

A segurança do paciente é um assunto de interesse internacional, considerado pela Organização Mundial da Saúde um princípio fundamental do cuidado à saúde, pois no processo de cuidar existe certo grau de insegurança. Cuidados de saúde inseguros geram uma exposição maior a riscos resultando em acréscimo da morbidade e mortalidade evitáveis e em gastos adicionais com a manutenção dos sistemas de saúde ${ }^{1}$. As exigências de segurança e de controle nos serviços de saúde crescem com a evolução tecnológica, despertando cada vez mais nos profissionais de saúde a preocupação com a segurança dos pacientes ${ }^{2}$.

Dessa forma, evidencia-se a necessidade do uso de indicadores de qualidade em consonância com a política de segurança nacional, impactando na qualidade da assistência de Enfermagem ${ }^{3}$.

Ressalta-se a necessidade de evitar que a assistência prestada resulte em dano ao paciente. Para tanto, deve-se trabalhar na prevenção dos eventos adversos, que ocorrem quando o cuidado é prestado sem seguir os padrões estabelecidos para a prevenção e o tratamento de uma condição específica, como a úlcera por pressão, lesão por umidade, lesão por adesivo, lesão por fricção, entre outros ${ }^{4}$.

As lesões de pele constituem um problema de saúde, com graves consequências na qualidade de vida dos pacientes, no tempo da assistência de Enfermagem e na utilização e custos dos recursos materiais, sendo um grande desafio para os enfermeiros ${ }^{5}$.

O tratamento do paciente com ferida deve ser dinâmico e precisa acompanhar a evolução científica e tecnológica, visando à avaliação do paciente, indicação do tratamento, organização e sistematização da assistência. Portanto, faz-se necessário para o profissional de Enfermagem que trabalha com prevenção e tratamento de feridas o conhecimento da fisiologia da pele, da cicatrização, dos fatores de risco e das etapas do processo, como também dos produtos disponíveis no mercado e sua correta indicação ${ }^{6}$.

Diariamente, em um hospital de ensino de grande porte de Curitiba, diversos pacientes com feridas complexas ou alto risco para lesões de pele são atendidos ou internados, entre eles pacientes com insuficiências vasculares, diabetes, lesão medular, neoplasias e outras enfermidades. Ambulatorialmente, a demanda é atendida pelo ambulatório de tratamento de feridas, porém não existe nenhuma forma de assistência sistematizada aos pacientes internados no que diz respeito à prevenção ou ao tratamento de feridas e outras alterações de pele, tampouco encaminhamento desses pacientes para continuidade da assistência necessária.

Com esta publicação, que objetivou descrever os passos de implantação de uma Comissão de Cuidados com a Pele, pretende-se auxiliar profissionais da saúde no caminho para soluções similares, para que cada vez menos pacientes estejam expostos aos riscos de uma assistência não sistematizada.

\section{MÉTODO}

Trata-se de uma pesquisa descritiva documental, realizada em um hospital de ensino de grande porte, de média e alta complexidade, com 510 leitos distribuídos em 25 unidades 
de internação nas áreas clínica, cirúrgica, pediátrica e maternidade, totalizando 59 especialidades, na cidade de $\mathrm{Curitiba}^{7}$.

A coleta de dados foi realizada no período de fevereiro de 2012 a março de 2014 por meio de consulta autorizada a documentos institucionais relacionados produzidos nesse período.

Foram utilizados como fonte: atas do grupo de trabalho da Comissão de Feridas (anterior à alteração de nome da Comissão), do núcleo estruturador da Comissão, de reuniões gerais da Comissão, dos subgrupos de feridas crônicas, feridas agudas, estomias e cateteres e drenos, atas de reuniões ordinárias do Colegiado Assessor Técnico da Diretoria de Enfermagem, colegiado gestor, pré-projeto e projeto de implantação da Comissão, regimento interno, portaria de nomeação dos membros, ofícios internos, fluxogramas, procedimentos operacionais padrão descritos, instrumentos de avaliação e acompanhamento de pacientes, relatório de atividades e fichas de solicitação de padronização de materiais.

$\mathrm{O}$ projeto de pesquisa foi aprovado pelo Comitê de Ética em Pesquisa em Seres Humanos do Setor de Ciências da Saúde da Universidade Federal do Paraná, sob o registro No CONEP/CAAE: 07555012.8.0000.0102.

\section{RESULTADOS}

A implantação da Comissão encontra-se descrita em quatro fases - negociação, estruturação, documentação e implementação - , para melhor compreensão, porém vale salientar que em diversos momentos mais de uma fase esteve em andamento concomitantemente.

\section{Negociação}

A ideia de implantação da Comissão nasceu em orientação de mestrado profissional, no grupo de pesquisa de Tecnologia e Inovação em Saúde, no qual uma das autoras estava inserida como mestranda. A proposta inicial era de implantação de um Comitê de Prevenção e Tratamento de Úlceras por Pressão, aprovada por unanimidade na reunião do Colegiado Assessor Técnico da Diretoria de Enfermagem do hospital de ensino deste estudo em 6 de dezembro de 2011.

A proposta da Comissão inicial foi ampliada para Comissão de Prevenção e Tratamento de Feridas, por sugestão da Diretora de Enfermagem, observando-se a necessidade institucional. Essa proposta foi aprovada pela Direção Geral do Hospital.

A partir da ampliação da abrangência de atuação da Comissão, a então mestranda mobilizou alguns enfermeiros para formar um grupo de trabalho interno no referido hospital. Participaram desse grupo, além da mestranda, a Assessora da Diretoria de Enfermagem, outra mestranda que estava trabalhando a temática e uma enfermeira estomaterapeuta, mestre em Tecnologias em Saúde.

\section{Estruturação}

$\mathrm{Na}$ etapa de estruturação, o grupo de trabalho passou a ser denominado Núcleo Estruturador, que a partir de então passou a realizar reuniões periódicas quinzenais a fim de estruturar a Comissão a ser implantada. Essa fase aconteceu entre junho e outubro de 2012. Nela couberam as deliberações quanto à definição do nome da Comissão, à organização em subgrupos específicos, à definição dos componentes e ao planejamento de trabalho.

O nome da Comissão foi alterado de Comissão de Prevenção e Tratamento de Feridas para Comissão de Cuidados com a Pele (CCP). Optou-se por formar quatro subgrupos, cada um com a coordenação de uma das enfermeiras do núcleo estruturador, sendo eles: úlceras crônicas, feridas agudas e cirúrgicas, estomias e cateteres e drenos. Para cada subgrupo, foram convidadas mais três enfermeiras que atuavam na assistência nas áreas relacionadas. A reunião dos quatro subgrupos passou a ser chamado de "Grande Grupo da CCP”.

Foram definidas reuniões quinzenais dos subgrupos, nas quais deveria ser definida a lesão prioritária naquela área, para estudo e elaboração de estratégias de prevenção e/ou tratamento.

O Grande Grupo se reuniria uma vez por mês, com duração de duas horas. Nessa reunião, seria repassado o andamento do trabalho dos subgrupos e tomadas decisões que competiam a todos, e haveria uma aula ou palestra para capacitação do grupo. Cada encontro seria de responsabilidade de um subgrupo.

Ainda na fase de estruturação, o núcleo estruturador realizou um levantamento dos produtos, para prevenção e tratamento de feridas, já padronizados no hospital por outros serviços, solicitando aumento de cota daqueles que poderiam ser utilizados para as lesões de maior prevalência nos pacientes internados. 
Além de aumento de cota de produtos padronizados, foram chamados representantes e assessores técnicos das empresas que fabricam ou comercializam curativos especiais, que apresentaram ao núcleo estruturador toda a sua linha de produtos. Foram selecionados produtos com potencial de padronização no âmbito técnico e financeiro para serem utilizados e avaliados. Depois de um período de utilização, foram realizadas algumas solicitações de padronização.

Com o auxílio da equipe do setor de Faturamento e Informática, criou-se uma Unidade Executante para a CCP, inserida no Sistema de Informação Hospitalar, e elaborou-se uma lista de códigos compatíveis com os procedimentos que seriam realizados pelos membros $\mathrm{da}$ $\mathrm{CCP}$. Esses códigos seriam registrados para servir de base de dados para pesquisas, levantamento de produção e cobrança pelos procedimentos.

Procedimentos operacionais e o fluxograma padrão foram desenvolvidos e inseridos no software de gerenciamento de documentos, descrevendo os passos da primeira avaliação de um paciente pelos membros da Comissão, bem como seu acompanhamento. Tais procedimentos ficaram disponíveis para consulta por todos os serviços.

\section{Documentação}

A documentação está descrita como uma etapa, por motivos didáticos, porém ocorreu desde a fase de negociação e continua acontecendo após a fase de implantação, fazendo parte de um processo dinâmico.

O projeto de implantação da Comissão foi o primeiro documento elaborado, com base no pré-projeto apresentado à Diretoria de Enfermagem. Foi elaborado segundo normas institucionais, contendo objetivos, justificativa, resultados esperados e propostas de ações. Depois de elaborado pelo núcleo estruturador, foi apresentado aos membros da Comissão, em reunião para alterações e aprovação. O projeto foi aprovado pela Diretoria de Enfermagem e posteriormente pela Direção Geral, que, a partir da aprovação, emitiu a portaria de nomeação dos membros.

O regimento da Comissão também foi elaborado pelo núcleo estruturador. Tendo como modelo outros regimentos da instituição, regulamenta as finalidades, composição da $\mathrm{CCP}$ e atribuições de seus membros.

Ainda na documentação, foram preenchidos impressos de solicitação de padronização de materiais, realizados ofícios solicitando aumento de cotas e abertura de uma unidade executante no Sistema de Informação Hospitalar, registrados os procedimentos no sistema, gerados relatórios de produtividade, produzidos materiais para os meios de comunicação institucionais, entre outros.

\section{Implementação}

Considerou-se implementação o funcionamento da CCP. Como citado nas outras etapas, ele não aconteceu somente depois das fases anteriores, mas concomitantemente a elas.

Pode-se citar nesta fase a concretização dos cronogramas de reuniões do Grande Grupo, dos subgrupos e do núcleo estruturador e, concomitante a elas, os atendimentos realizados, a partir de pedidos de consulta, a pacientes com lesões ou em risco.

As reuniões do núcleo estruturador se mantiveram para determinação do andamento da $\mathrm{CCP}$, e as reuniões do Grande Grupo seguiram com apresentação das atividades dos subgrupos, com capacitações e discussões quanto ao andamento.

Os atendimentos foram iniciados de maneira não sistematizada, por meio de pedidos informais da equipe de Enfermagem e médica, para avaliação de pacientes com feridas complexas, que eram realizados pela enfermeira estomaterapeuta do núcleo estruturador. Na sequência, após desenvolvimento de fluxograma e procedimento operacional padrão, os atendimentos passaram a ser realizados por uma das enfermeiras do núcleo estruturador, por meio de pedidos de consulta, registrados no Sistema de Informação Hospitalar e evoluídos no prontuário do paciente. Além disso, as enfermeiras deixavam orientações por escrito afixadas próximo ao leito do paciente e orientavam a equipe de Enfermagem, o paciente e o acompanhante.

Durante um ano de funcionamento da CCP, os membros se dividiam entre suas atribuições nas unidades de lotação e as avaliações e os acompanhamentos de pacientes. Depois desse período, por necessidade institucional, observada pela demanda de atendimentos, foi aberta uma vaga para enfermeiro de dedicação exclusiva à CCP. Por meio de processo seletivo interno, a enfermeira estomaterapeuta do núcleo estruturador passou a ocupar essa vaga.

A partir da observação de demanda no primeiro ano de funcionamento da CCP, algumas modificações foram realizadas: os instrumentos de avaliação das lesões deixaram de ser utilizados, dando lugar à evolução sistematizada na 
ficha de evolução clínica do prontuário do cliente, a fim de fortalecer a Sistematização da Assistência de Enfermagem, também em fase de implementação.

Para fortalecimento do Grande Grupo, tendo em vista que as demandas de atendimento para cada subgrupo eram muito diferenciadas, cancelaram-se suas reuniões e aumentou-se a periodicidade de reuniões gerais, inserindo nelas as discussões de todas as áreas.

Entre as atividades relevantes da implementação da CCP, pode-se citar a seleção de Diagnósticos de Enfermagem da NANDA para problemas relacionados às lesões de pele e complicações periestomais, com suas respectivas prescrições de Enfermagem e inserção no Sistema de Informação Hospitalar.

Outra atividade importante foi a campanha denominada "HC livre de UP", que teve por objetivo a conscientização de toda a equipe de saúde quanto às medidas preventivas de úlceras por pressão, por meio de capacitação nas unidades de internação, com distribuição de materiais informativos, além de encontro científico com o tema "Úlceras por Pressão: Impacto e Prevenção” e auditorias.

A adoção de úlceras por pressão como prioridade de atuação preventiva da CCP baseia-se na prevalência delas, que pode ser observada pelos dados de atendimento descritos na sequência.

Nos últimos seis meses de atuação da CCP, a partir da lotação exclusiva de uma enfermeira na Comissão, foram solicitadas 184 avaliações por meio de pedidos de consulta. Grande parte dos pacientes avaliados apresentava mais de uma ferida e todos eles foram acompanhados semanalmente até a alta hospitalar, óbito, cicatrização completa da lesão ou redução de risco. Nesse período, 131 lesões avaliadas foram úlceras por pressão, em todos os estágios, com predominância para estágios III, IV e inclassificável.

\section{DISCUSSÃO}

Para a efetiva implantação da Comissão, foi de fundamental importância esta ter sido proposta como projeto de dissertação do mestrado profissional vinculado à mesma universidade que a instituição. $\mathrm{O}$ mestrado profissional tem como objetivo a intervenção da prática profissional, visando melhorar a eficácia e a eficiência das instituições por meio da solução de problemas, do desenvolvimento e da aplicação de processos de inovação apropriados à instituição ${ }^{8}$.
Vale ressaltar a linha e o grupo de pesquisa ao qual o tema da dissertação citada foi vinculado - Tecnologia e Inovação em Saúde (TIS) -, mesma área de mestrado de outra enfermeira do núcleo estruturador. Ocorreu assim a integração da academia com a prática, ou seja, universidade e unidade hospitalar, contribuindo para a melhoria do cuidado baseado nas melhores evidências .

A implantação de uma Comissão de Cuidados com a Pele relaciona-se com os três tipos de tecnologias definidas por Merhy como tecnologia dura, dura-leve e leve. Segundo o autor, tecnologia dura é todo tipo de equipamentos e medicamentos utilizados em intervenções terapêuticas, como coberturas especiais, bolsas coletoras e outros produtos. A tecnologia dura-leve é o olhar do profissional de saúde sobre o usuário, fundamentado em saberes bem definidos, como o conhecimento acerca das fases de cicatrização para guiar a definição da terapêutica adequada. A tecnologia leve é a que permite a produção de relações envolvidas no encontro trabalhador-usuário mediante a escuta, o interesse e a construção de vínculos que possibilita captar a singularidade ${ }^{10}$.

Segundo autores, as comissões devem ser um grupo técnico com caráter normativo e consultivo para desenvolver, organizar e coordenar atividades relacionadas à assistência, educação permanente e pesquisa no que se relaciona à prevenção e ao tratamento de lesões de pele ${ }^{11}$.

Considera-se imprescindível o envolvimento inicial da alta gestão da instituição, sem a qual não teriam sido possíveis os próximos passos dados em direção à aprovação dela nos colegiados institucionais.

A ampliação de abrangência de atuação de uma Comissão de Prevenção e Tratamento de Feridas para uma Comissão de Cuidados com a Pele possibilitou a cobertura de atendimento a pacientes com problemas referentes a estomas intestinais e urinários, assim como complicações em locais de inserção de drenos e cateteres de alimentação e eliminação, empregando assim o conhecimento e a atuação da enfermeira especialista em Estomaterapia que faz parte do núcleo estruturador.

Conforme descreve o estatuto da Associação Brasileira de Estomaterapia, o estomaterapeuta é um enfermeiro especialista, com conhecimento e prática voltada para a assistência de pessoas com estomias, fístulas, tubos, cateteres e drenos, feridas agudas e crônicas, e incontinências anal e urinária, em seus aspectos preventivos, terapêuticos e de reabilitação, em busca da melhoria da qualidade de vida ${ }^{12}$. 
Além do exposto, o nome da Comissão facilitou o entendimento dos profissionais da instituição para a abrangência de atuação dela, que passou a ser chamada não somente para atendimento de pacientes com feridas complexas mas também para avaliação de alterações como hiperemias e descamações, podendo atuar assim na prevenção de situações mais severas.

Autores ressaltam a importância da abordagem preventiva na assistência do enfermeiro, incentivando o uso de estratégias eficazes de prevenção como ferramenta no gerenciamento do cuidado, evitando que a assistência prestada resulte em dano ao paciente ${ }^{4}$.

Para garantir um atendimento de qualidade pela CCP, foi fundamental o engajamento de profissionais com experiência clínica e conhecimento científico em seu núcleo estruturador. Entre esses, destacam-se a idealizadora da Comissão, que desenvolveu sua dissertação com o objetivo de implantar a Comissão e que tem experiência de 18 anos na prevenção e no tratamento de feridas, tendo atuado na implantação, estruturação e assistência dos ambulatórios de Tratamento de Feridas e de Pé Diabético, e uma enfermeira com especialização em Estomaterapia.

Segundo pesquisadores, os profissionais escolhidos para compor a Comissão devem estar envolvidos e cientes de suas responsabilidades na prevenção e tratamento de lesões de pele, sendo necessário que pelo menos um dos componentes seja especialista na área ${ }^{13}$.

A organização de um núcleo estruturador, um número pequeno de membros engajados e capacitados que trabalharam na estruturação da Comissão antes de propor o funcionamento desta, foi válida para garantir a otimização dos tempos de reuniões e outras atividades realizadas para que a implantação fosse possível. Se todas as discussões tivessem sido propostas em reunião geral, com participação de todos os membros sugeridos, certamente o processo teria sido mais moroso, com divergência de ideias e sem o mesmo nível de comprometimento de todos os envolvidos, tendo em vista interesses pessoais, profissionais e demanda de trabalho.

O envolvimento dos profissionais do núcleo estruturador e a periodicidade frequente das reuniões iniciais favoreceram para que a negociação e a estruturação acontecessem em um período de quatro meses para início efetivo das atividades da Comissão.

A CCP foi inicialmente estruturada com a formação de subgrupos específicos. Com o andamento da Comissão, observou-se um enfraquecimento do "Grande Grupo" em decorrência da demanda científica de trabalho dos subgrupos. As reuniões dos subgrupos eram quinzenais, enquanto a geral era mensal. Houve faltas frequentes às reuniões gerais, as demandas dos subgrupos foram desiguais e os membros ficavam com conhecimento limitado à sua área. Por essas razões, a estrutura de subgrupos foi desfeita e as reuniões gerais passaram a ser quinzenais, com abordagem de temas referentes a todas as áreas, de acordo com a demanda institucional.

Fica a possibilidade de reestruturação em subgrupos para o momento em que houver uma Comissão fortalecida, com membros conhecedores de todas as suas áreas de abrangência e com clareza sobre a sua preferência de atuação para atender à demanda específica daquela área. É importante também maior divulgação na instituição sobre as áreas de abrangência da Comissão, para que a demanda seja estendida para todos os subgrupos.

Outra adequação percebida como necessária a partir do andamento da Comissão foi o instrumento de avaliação inicial e acompanhamento dos pacientes deixar de ser utilizado, dando lugar à evolução clínica sistematizada no prontuário do paciente em folha de evolução de uso multiprofissional.

Essa decisão foi tomada a fim de fortalecer a implantação da Sistematização da Assistência de Enfermagem na instituição, que padronizou a avaliação subjetiva e objetiva do paciente, os Diagnósticos de Enfermagem por áreas e prescrições relacionadas. Salientamos que essa alteração possibilitou maior visibilidade da Comissão por outros profissionais, uma vez que o registro de avaliação e acompanhamento das lesões passou a ser realizado no prontuário do paciente na folha de evolução de uso multiprofissional, que é uma ferramenta efetiva de comunicação entre as categorias.

De qualquer maneira, a elaboração dos instrumentos de avaliação, pela Comissão, foi uma fase importante de capacitação, para que todos os membros interiorizassem uma sequência clara de avaliação, passando essa a ser automática para a evolução sistêmica adotada.

No âmbito da capacitação, todas as discussões e explanações foram de fundamental importância para a formação dos membros, no sentido de estimular raciocínio clínico na área e padronizar condutas que embasarão a elaboração de protocolos institucionais.

Autores citam que a eficácia da prevenção e do tratamento de feridas depende do conhecimento dos profissionais quanto à fisiologia da pele, ao processo de cicatrização 
e à utilização de protocolos adequados e consistentes e da orientação e educação do paciente, familiar e/ou cuidador, tornando-os participantes ativos do processo $^{14}$.

Entre os assuntos necessários a serem inseridos em programas de capacitação de comissões que envolvem tratamento e prevenção de feridas, está o conhecimento de produtos disponíveis no mercado e suas particularidades. Faz-se necessário o conhecimento da tecnologia disponível para questionar seus benefícios e diferenciais, assim como ter embasamento científico para discussão de padronizações baseada na necessidade institucional.

Sabe-se da necessidade de realização de estudos comparativos entre os períodos anterior e posterior à implantação da Comissão para demonstrar a efetividade de tal medida no que diz respeito ao processo cicatricial das lesões crônicas, prevenção de feridas evitáveis e complicações de lesões intencionais (incisões cirúrgicas, estomas, drenos, entre outras). Até a elaboração do estudo, não houve tempo hábil para a realização de tais estudos em razão da demanda de estruturação, acompanhamento de pacientes e ações educativas, porém foi possível verificar, por meio de observação documentada de residentes de Enfermagem, um aumento no percentual de adesão dos profissionais às medidas de prevenção de úlceras por pressão.

O investimento financeiro por parte da instituição foi possível respeitando a burocracia processual e a limitação de recursos de um hospital público. Estudos de custo e efetividade foram necessários para demonstrar o benefício institucional com o encaminhamento dos processos de padronização.

\section{CONCLUSÃO}

Considera-se efetiva a estratégia utilizada para implantação de uma Comissão de Cuidados com a Pele descrita neste estudo. Sua efetividade pode ser observada atualmente pelo impacto positivo dela na instituição, pelo número crescente de pedidos de consultas por diversas categorias profissionais, inclusive para prevenção de lesões, pela evolução favorável das lesões, pelo uso adequado da tecnologia disponível e pelo envolvimento de profissionais de diversas áreas na campanha de prevenção de úlceras por pressão.

Pode-se destacar como ganho institucional a elaboração de protocolos que orientam condutas padronizadas, com o uso racional e adequado da tecnologia disponível, evitando gastos desnecessários e riscos aos pacientes. Além do citado, o enfoque em prevenção de lesões evitáveis e a utilização adequada de tecnologias estão em consonância com o movimento mundial de segurança do paciente.

Sugere-se que a formação de grupos específicos em uma Comissão seja discutida após solidificação de um grande grupo, com membros comprometidos que possam atuar em suas áreas de preferência. Reforça-se a importância de capacitação dos membros em todas as áreas da Comissão.

Como sugestão para estratégias similares, destaca-se a importância de participação de membros de outras categorias profissionais em Comissões de Cuidados com a Pele, como nutricionistas, fisioterapeutas, médicos, psicólogos, terapeutas ocupacionais e assistentes sociais, a fim de enriquecer as discussões de condutas e torná-las mais resolutivas.

\section{REFERÊNCIAS}

1. World Health Organization. World Alliance for Patient Safety, Taxonomy. The conceptual framework for the international classification for patient safety. Version 1.1. Final Technical Report. WHO: Geneva; 2009.

2. Lima LF, Leventhal LC, Fernandes MPP. Identificando os riscos do paciente hospitalizado. Einstein. 2008;6(4):434-8.

3. Oliveira RM, Leitão IMTA, Silva LMS, Figueiredo SV, Sampaio RC, Gondim MM. Estratégias para promover segurança do paciente: da identificação dos riscos às práticas baseadas em evidências. Esc Anna Nery. 2014;18(1): 122-9.

4. Domansky RC. Introdução. In: Domansky RC, Borges EL (orgs). Manual para prevenção de lesões de pele: recomendações baseadas em evidências. Rio de Janeiro: Rubio; 2012. p. 1-8.
5. Ferreira AM, Bogamil DDD, Tormena PCO. O enfermeiro e o tratamento de feridas: em busca da autonomia do cuidado. Arq Ciênc Saúde. 2008;15(3):105-9.

6. Salomé GM. Avaliando lesão: práticas e conhecimento dos enfermeiros que prestam assistência ao indivíduo com ferida. Rev Saúde Coletiva. 2009;6(35);280-7.

7. Hospital de Clínicas da Universidade Federal do Paraná [Internet]. Curitiba [cited 2012 Nov 13]. Available from: http://www.hc.ufpr.br/?q=node/65

8. Portaria Normativa/MEC $n^{0} 17$, de 28 de dezembro de 2009. Dispõe sobre o mestrado profissional no âmbito da Fundação Coordenação de Aperfeiçoamento de Pessoal de Nível Superior-CAPES. Brasília (DF): Diário Oficial da República Federativa do Brasil, 29 dez 2009: Seção 1: 20. 
9. Johann DA, Mingorance P, De Lazzari LSM, Pedrolo E, Almeida TQR, Danski MTR. Elaboração de diretriz clínica: integração entre universidade e unidade hospitalar. Cogitare Enferm. 2012;17(2):377-80.

10. Merhy EE. Saúde: a cartografia do trabalho vivo. $2^{a}$ ed. São Paulo: Hucitec; 2005.

11. Sodevilla-Agreda JJ, Garcia-Fernandes FP. Comisiones de Úlceras por Presión. Serie Documentos de Posicionamento GNEAUPP $n^{\circ}$ 1. (Segunda Edición). Grupo nacional para el Estudio y Asesoramiento em Úlcera por Presíon y Heridas Crónicas. Logroño. 2012.
12. Associação Brasileira de Estomaterapia: estomias, feridas e incontinências. Competências do Enfermeiro Estomaterapeuta (ET) ou do Enfermeiro Pós-graduado em Estomaterapia (PGET). Estima. 2008;6(1):33-43.

13. Declair V. Comissão de curativos estruturação de serviço de prevenção e tratamento de feridas em uma instituição hospitalar [Internet] [cited 2014 Fev 11]. Available from: http://www.vdeclair.com.br/doc/comissao_curativos

14. Carneiro CM, Sousa FB, Gama FN. Tratamento de feridas: assistência de enfermagem nas unidades de atenção primária à saúde. Rev Enfermagem Integrada. 2010;3(2):495-505. 


\title{
Caracterização de Pacientes com Feridas Neoplásicas
}

\section{Characterization of Patients with Neoplastic Wounds}

\author{
Caracterización de los Pacientes con Heridas Neoplásicas
}

Isabel Neves Duarte Lisboa ${ }^{1}$, Marilia Perrelli Valença ${ }^{2}$

\begin{abstract}
RESUMO
Objetivo: Identificar e discutir o perfil sociodemográfico e de saúde de pacientes que apresentam feridas neoplásicas. Métodos: Trata-se de um estudo quantitativo, transversal e observacional, aprovado pelo Comitê de Ética em Pesquisa, realizado no Hospital do Câncer de Pernambuco (HCP) no período de junho a agosto de 2013. O instrumento de coleta de dados abordou informações clínicas e epidemiológicas do paciente, dados específicos da lesão e do tratamento tópico. Resultados: Participaram do estudo 51 pacientes com ferida neoplásica; dentre eles, 60,8\% eram homens entre 40 e 60 anos. Conclusão: Os participantes apresentavam feridas localizadas, em sua maioria, na região da cabeça e do pescoço (52,8\%), apresentando estadiamento 3 em 52\% das lesões. Os produtos utilizados na instituição foram colagenase e ácidos graxos essenciais.
\end{abstract}

DESCRITORES: Estomaterapia. Serviço hospitalar de oncologia. Cicatrização. Qualidade de vida.

\begin{abstract}
Objective: Identify and discuss the profile sociodemographic and health of patients with neoplastic wounds. Methods: This is a quantitative, cross-sectional observational study, was approved by the Research Ethics Committee, held at the Hospital do Câncer de Pernambuco (HCP) in the period June to August 2013. The instrument for data collection addressed: epidemiological and clinical patient information, specific data of the lesion and topical treatment. Results: The study included 51 patients with neoplastic wounds, 60.8\% were men aged 40-60 years. Conclusion: Participants had wounds mostly located in the head and neck (52.8\%), with stage 3 in 52\% of lesions. The products used in the institution were collagenase and essential fatty acids.
\end{abstract}

DESCRIPTORS: Stomatherapy. Oncology sevice, hospital. Wound healing. Quality of life.

\section{RESUMEN}

Objetivo: Identificar y analizar el perfil sociodemográfico y la salud de los pacientes con heridas neoplásicas. Metodos: Se trata de un estudio observacional cuantitativo, transversal, fue aprobado por el Comité de Ética de la Investigación, que se celebró en el Hospital del Cáncer de Pernambuco (HCP) en el período de junio a agosto de 2013. El instrumento de recolección de datos abordar: la información del paciente epidemiológica y clínica, los datos específicos de la lesión y el tratamiento tópico. Resultados: El estudio incluyó a 51 pacientes con heridas neoplásicas, 60,8\% eran hombres de entre 40 a 60 años. Conclusión: Los participantes tenían heridas en su mayoría localizados en la cabeza y el cuello (52,8\%), con la etapa 3 en el 52\% de las lesiones. Los productos utilizados en la institución fueron colagenasa y ácidos grasos esenciales.

DESCRIPTORES: Estomaterapia. Servicio de oncología en hospital. Cicatrización de heridas. Calidad de vida.

'Enfermeira pela Universidade Federal do Rio Grande do Norte (UFRN). Pós-graduada em Cancerologia pela Universidade de Pernambuco (UPE) - Recife (PE) Brasil. Endereço para correspondência: Campus Universitário - Avenida Senador Salgado Filho, 3.000 - CEP 59078-970 - Lagoa Nova - Natal (RN), Brasil - E-mail: bebelisboa@gmail.com

Mestre em Ciências da Saúde pela Faculdade de Ciências Médicas da UPE - Recife (PE), Brasil.

*Artigo baseado em monografia apresentada em 19 de dezembro de 2013 no Hospital Universitário Oswaldo Cruz (HUOC/UPE).

Artigo recebido em: 27/10/2014 - Aceito para publicação em: 24/04/2015 


\section{INTRODUÇÃO}

Conhecido há muitos séculos, o câncer foi amplamente considerado como uma doença dos países desenvolvidos e com grandes recursos financeiros. Há aproximadamente quatro décadas, a situação vem mudando e a maior parte do ônus global do câncer pode ser observada em países em desenvolvimento, principalmente aqueles com poucos e médios recursos ${ }^{1}$.

As causas de câncer são variadas, podendo ser externas ou internas ao organismo, estando ambas inter-relacionadas. As causas externas relacionam-se ao meio ambiente e aos hábitos ou costumes próprios de um ambiente social e cultural. As causas internas são, na maioria das vezes, geneticamente predeterminadas, estando ligadas à capacidade do organismo de se defender das agressões externas. Esses fatores causais podem interagir de várias formas, aumentando a probabilidade de transformações malignas nas células normais².

O tratamento oncológico é baseado em cinco pilares fundamentais: cirurgia, quimioterapia, radioterapia, imunoterapia e hormonioterapia. O diagnóstico correto e o estadiamento são atitudes clínicas fundamentais no processo de tomada de decisão. $\mathrm{O}$ tratamento pode ser de objetivo curativo; entretanto, mesmo com todos os avanços, não se pode dizer que essa doença seja sempre curável, e, nos casos mais avançados, o cuidado paliativo é a meta ${ }^{3,4}$.

As feridas neoplásicas são formadas pela infiltração das células malignas do tumor nas estruturas da pele. Nesse caso, ocorre a quebra da integridade do tegumento em decorrência da proliferação celular descontrolada que o processo de oncogênese induz, levando à formação de uma ferida evolutivamente exofítica ${ }^{3}$. Essas feridas podem ocorrer por extensão do tumor primário, por uma metástase, bem como pela implantação acidental de células na pele durante um procedimento cirúrgico ou diagnóstico, ou ainda pela invasão de linfonodos próximos ao tumor primário. São caracterizadas principalmente por progressão rápida e inviabilidade de cicatrização, hemorragias, odor fétido, exsudato abundante, alto risco para infecção, alto risco para miíase, presença de necrose tecidual, dor, prurido e agressão do tecido saudável perilesional ${ }^{4,5}$.

Não há um consenso sobre a nomenclatura dessas feridas. As denominações mais utilizadas são "feridas neoplásicas" ou "feridas tumorais". De acordo com o aspecto da ferida, podem ser utilizados os termos: "feridas ulcerativas malignas" (quando estão ulceradas e formam crateras rasas), "feridas fungosas malignas ulceradas" (união do aspecto vegetativo e partes ulceradas), "feridas fungosas malignas" (quando são semelhantes à couve-flor) ou ainda "feridas neoplásicas vegetantes". Além disso, elas também podem ser classificadas pelo seu estadiamento, de acordo com a evolução e as características de coloração, exsudato, odor, dor e invasão tecidual ${ }^{1,6,7}$.

É possível observar que o paciente com feridas neoplásicas ainda representa um desafio para o enfermeiro no que concerne ao manejo dos sinais e sintomas físicos e psicológicos que essas feridas impõem. Desse modo, a qualidade desses cuidados pode se tornar o fator mais significativo na determinação da qualidade de vida desses pacientes. Não obstante, existe a consciência da grande lacuna que permanece em relação à base concreta do conhecimento que gera esse cuidado, o qual, ao longo do tempo, estrutura-se sobre bases empíricas, desprovido de estudos clínicos específicos ${ }^{3}$.

Diante das dificuldades que envolvem a prática do cuidar de pacientes com feridas neoplásicas e na intenção da contínua melhoria da qualidade da assistência de enfermagem, este estudo teve como base a seguinte questão norteadora: quem são os pacientes com ferida neoplásica? Como estão sendo tratados atualmente na instituição?

Diante de tal reflexão, elencamos como objetivo deste estudo identificar e discutir o perfil sociodemográfico e de saúde de pacientes com feridas neoplásicas.

\section{MÉTODOS}

Trata-se de um estudo quantitativo, tipo corte transversal e observacional, realizado em pacientes com ferida neoplásica internados no Hospital do Câncer de Pernambuco (HCP).

$\mathrm{O}$ HCP é referência estadual em Oncologia. Está inserido no Sistema Único de Saúde (SUS) e é uma instituição de saúde sem fins lucrativos e de reconhecida utilidade pública. Seus serviços buscam prestar assistência médica especializada aos portadores de neoplasia, oferecendo tratamentos para os seguintes tipos de tumores: sólidos, de mama, pulmão, cabeça e pescoço, dos aparelhos digestivo e ginecológico, de próstata, ósseos e de partes moles, pele, dentre outros. A Oncologia Clínica do HCP proporciona assistência e tratamentos de quimioterapia, hormonioterapia, imunoterapia, suporte oncológico, cardiologia/unidade de terapia intensiva (UTI), hemoterapia e clínica médica. 
A amostra deste estudo se deu por conveniência e correspondeu a 51 pacientes acometidos por feridas neoplásicas que atenderam aos critérios de inclusão e exclusão.

Os critérios de inclusão foram: ter mais de 18 anos, possuir ferida neoplásica e concordar em participar da pesquisa, assinando o Termo de Consentimento Livre e Esclarecido (TCLE). Os critérios de exclusão foram: pacientes portadores de outras lesões não caracterizadas como neoplásicas e ter idade inferior a 18 anos. A coleta de dados se deu no período de junho a agosto de 2013 por meio de um instrumento de pesquisa composto por roteiro de entrevista com questões objetivas.

Os dados foram organizados em uma planilha do Microsoft Excel 2007 e tabulados em relação a variáveis sociodemográficas, características das feridas e tratamentos utilizados. Posteriormente, foi realizada a análise estatística utilizando o software STATA/SE 12.0.

O projeto de pesquisa foi aprovado pelo Comitê de Ética em Pesquisa do Hospital Universitário Oswaldo Cruz, sob o CAE no 13369213400005192. Os participantes foram orientados quanto aos objetivos do trabalho e concordaram em participar assinando o TCLE.

\section{RESULTADOS E DISCUSSÃO}

Do total de 51 indivíduos, 24 (47,1\%) possuíam câncer primário na região de cabeça e pescoço, seguido por câncer de mama, com 12 pessoas $(23,4 \%)$. Nesse caso, sugere-se que a região de cabeça e pescoço seja a responsável pelos maiores índices de ferida neoplásica. A maioria dos pacientes com câncer de cabeça e pescoço apresenta doença avançada ao diagnóstico. O prognóstico sombrio se deve, por vezes, ao diagnóstico tardio, o qual ocorre, aproximadamente, em 60\% dos pacientes ${ }^{8,9}$. Além disso, o carcinoma epidermoide apresenta-se como a histologia mais comum entre as neoplasias de cabeça e pescoço ${ }^{10}$, podendo tornar esse local o mais suscetível ao aparecimento de lesões neoplásicas, devido à sua proximidade com o tecido subcutâneo. $\mathrm{O}$ câncer de mama é considerado de bom prognóstico quando diagnosticado e tratado precocemente. Entretanto, o atraso no diagnóstico vem impedindo que as pacientes sejam beneficiadas pelos procedimentos terapêuticos que poderiam, de fato, reverter o curso clínico da doença $a^{11}$. Sugere-se que a localização tumoral adjacente à epiderme também possa predispor o tecido mamário ao desenvolvimento de lesões neoplásicas à medida que a patologia se torna avançada (Tabelas 1 e 2).

Trinta e um participantes $(60,8 \%)$ eram do sexo masculino, e 20, do feminino (39,2\%). Relaciona-se essa diferença a maior incidência de câncer de cabeça e pescoço como doença primária nesses indivíduos. No Brasil, a incidência desse câncer ultrapassa 20 por 100.000 habitantes e é mais comum em homens ${ }^{9}$. Todavia, evidencia-se o alcance de índices cada vez maiores entre a população feminina, diminuindo, portanto, essa diferença, uma vez que houve nos últimos anos algumas mudanças no estilo de vida e, consequentemente, nos hábitos relacionados ao consumo de álcool e tabaco por parte dessa população ${ }^{8}$. É importante ressaltar a incidência de câncer de mama em segundo lugar dentre a amostra, tornando a porcentagem relacionada ao sexo feminino ainda mais significativa.

Tabela 1. Perfil do paciente com ferida neoplásica.

\begin{tabular}{|c|c|c|}
\hline Variáveis & $\mathrm{n}$ & $\%$ \\
\hline \multicolumn{3}{|l|}{ Sexo } \\
\hline Masculino & 31 & 60,8 \\
\hline Feminino & 20 & 39,2 \\
\hline \multicolumn{3}{|l|}{ Idade (anos) } \\
\hline$<40$ & 4 & 7,8 \\
\hline $40-60$ & 30 & 58,9 \\
\hline$\geq 60$ & 17 & 33,3 \\
\hline \multicolumn{3}{|l|}{ Escolaridade } \\
\hline Analfabeto & 20 & 39,2 \\
\hline Ensino fundamental incompleto & 24 & 47,1 \\
\hline Ensino fundamental completo & 2 & 3,9 \\
\hline Ensino médio incompleto & 4 & 7,8 \\
\hline Ensino superior incompleto & 1 & 2,0 \\
\hline \multicolumn{3}{|l|}{ Comorbidades } \\
\hline $\operatorname{Sim}$ & 14 & 27,5 \\
\hline Não & 37 & 72,5 \\
\hline \multicolumn{3}{|l|}{$\mathrm{HAS}$} \\
\hline $\mathrm{Sim}$ & 13 & 25,5 \\
\hline Não & 38 & 74,5 \\
\hline \multicolumn{3}{|l|}{ Antecedentes pessoais } \\
\hline $\operatorname{Sim}$ & 38 & 74,5 \\
\hline Não & 13 & 25,5 \\
\hline \multicolumn{3}{|l|}{ Tabagismo } \\
\hline Sim & 34 & 89,5 \\
\hline Não & 4 & 10,5 \\
\hline \multicolumn{3}{|l|}{ Etilismo } \\
\hline Sim & 32 & 84,2 \\
\hline Não & 4 & 10,5 \\
\hline
\end{tabular}

HAS: hipertensão arterial sistêmica.

Fonte: HCP, 2013. 
Houve uma incidência maior de ferida neoplásica na faixa etária entre 40 e 60 anos de idade. Isso reflete também a incidência geral do acometimento do câncer no estudo em questão, tendo em vista o fato de serem patologias presentes em faixas etárias mais avançadas. Evidências epidemiológicas mostram que a incidência do câncer de cabeça e pescoço aumenta com a idade, assim como o câncer de mama, que tem maior acometimento em mulheres acima de 50 anos $^{8-11}$.

No quesito escolaridade, a maioria das pessoas possuía o ensino fundamental incompleto $(47,1 \%)$, seguida por analfabetos $(39,2 \%)$. Deduz-se que a baixa escolaridade reflete diretamente no acometimento da ferida neoplásica, visto que o paciente mais instruído tem melhores condições de esclarecimento quanto ao tratamento adequado. $\mathrm{O}$ baixo nível de instrução dos pacientes pode levar a um atraso na percepção da doença e na procura por assistência médica e, consequentemente, para o diagnóstico, diminuindo suas possibilidades terapêuticas 9 . A ferida tumoral surge em processos avançados de carcinogênese, tendo, assim, forte associação com o conhecimento deficiente do paciente.

Em relação aos antecedentes pessoais, do total de 51 pessoas, $38(74,5 \%)$ possuíam algum precedente. Dos 38, 34 (89,5\%) eram tabagistas, e 32 (84,2\%), etilistas. Esse dado reflete a suma relevância do consumo de tabaco e de álcool sobre a incidência do câncer. Além disso, sugere-se que tais hábitos também sejam determinantes para o desenvolvimento

Tabela 2. Características clínicas dos pacientes com ferida neoplásica.

\begin{tabular}{|c|c|c|}
\hline Variáveis & $\mathrm{n}$ & $\%$ \\
\hline \multicolumn{3}{|l|}{ Câncer primário } \\
\hline Cabeça e pescoço & 24 & 47,0 \\
\hline Mama & 12 & 23,4 \\
\hline Interrogado & 2 & 3,9 \\
\hline Linfoma & 3 & 5,9 \\
\hline Ovário & 1 & 2,0 \\
\hline Partes moles & 1 & 2,0 \\
\hline Pele & 2 & 3,9 \\
\hline Região perianal & 4 & 7,9 \\
\hline Sarcoma & 1 & 2,0 \\
\hline Útero & 1 & 2,0 \\
\hline \multicolumn{3}{|l|}{ Terapia antineoplásica } \\
\hline $\mathrm{Sim}$ & 32 & 62,7 \\
\hline Não & 19 & 37,3 \\
\hline \multicolumn{3}{|l|}{ Tipo de terapia } \\
\hline Quimioterapia & 24 & 75,0 \\
\hline Radioterapia & 20 & 62,5 \\
\hline Cirurgia & 13 & 40,6 \\
\hline
\end{tabular}

Fonte: HCP, 2013. e a progressão da ferida neoplásica. Sendo a cabeça e o pescoço as regiões de maior incidência neoplásica nesta pesquisa, é importante ressaltar que o álcool e o tabaco são os principais fatores de risco para o acometimento desse cân$\operatorname{cer}^{10}$. Além disso, o etilismo é um fator de risco importante no surgimento do câncer de mama ${ }^{11}$.

Das 51 pessoas entrevistadas, apenas 14 possuíam comorbidades. Desse contingente, $13(25,5 \%)$ eram hipertensos e apenas 1 indivíduo possuía diabetes mellitus. A ausência de comorbidades no paciente com ferida neoplásica nos chama a atenção, pois o câncer, apesar de ser uma doença que compromete e debilita o paciente das mais variadas formas, nem sempre se encontra associado a outras doenças, sejam elas transmissíveis ou não, como diabetes mellitus, hipertensão arterial e doenças virais.

Do total de 51 pacientes, 32 (62,7\%) já tinham sido submetidos a alguma terapia antineoplásica. Desse quantitativo, 24 (75\%) realizaram quimioterapia em algum momento, $20(62,5 \%)$ passaram por radioterapia, e $13(40,6 \%)$, por cirurgia. O câncer, em sua fase inicial, pode ser controlado e/ou curado por meio do tratamento cirúrgico, quando este for o tratamento indicado para o caso ${ }^{11}$. Considerando essas informações, sugere-se que grande parte dos pacientes já chega ao serviço médico em estágio avançado, fazendo-se necessária a associação com outras modalidades, como quimioterapia sistêmica ou radioterapia. Salienta-se aqui a porcentagem significativa de pacientes $(37,3 \%)$ que chegaram ao serviço com lesão sem o passado de terapêutica antineoplásica, reforçando o pensamento de que o paciente, em seu primeiro contato com o serviço,já se encontra em estágios avançados. A radioterapia e a quimioterapia também podem ser utilizadas na ferida neoplásica para controle do exsudato e do sangramento, reduzindo o tumor e diminuindo a dor ${ }^{5}$. Contudo, a lesão continuará a se desenvolver até que algum tratamento oncológico seja empreendido com sucesso. Isso implica dizer que também podem existir indivíduos na amostra que realizaram terapêutica quimioterápica ou radioterápica, porém com fins apenas paliativos (Tabelas 3 e 4).

Em relação à localização da lesão, das 51 pessoas, 27 (52,8\%) tinham lesão na região de cabeça e pescoço, seguida por região da mama, com 10 pessoas (19,6\%). As lesões neoplásicas podem surgir por extensão do tumor primário, por uma metástase, implantação acidental de células na pele durante um procedimento cirúrgico ou diagnóstico; além disso, também podem ocorrer por invasão de linfonodos próximos ao tumor primário ${ }^{5}$. Conclui-se que a ferida neoplásica pouco 
surge em decorrência de episódios metastáticos, visto que a localização da ferida praticamente se iguala com a localização da doença primária.

O estadiamento da lesão se apresentou predominantemente em grau 3 em 26 pacientes (52\%), seguido pelo estadiamento 4 , com 8 pacientes (16\%), de um total de 51 pacientes. O estadiamento 1 caracteriza-se por pele íntegra, tecido de coloração avermelhada ou violácea, nódulo visível e delimitado, assintomático. $\mathrm{O}$ estadiamento $1 \mathrm{n}$ constitui-se como uma ferida fechada ou com abertura superficial por orifício de drenagem de exsudato límpido, de coloração amarelada ou de aspecto purulento, tecido avermelhado ou violáceo, ferida seca ou úmida, dor ou prurido ocasionais e sem odor ${ }^{12,13}$.

O estadiamento 2 caracteriza-se por uma ferida aberta que envolve: derme e epiderme; ulcerações superficiais, por vezes, friáveis e sensíveis à manipulação; exsudato ausente ou em pouca quantidade (lesões secas ou úmidas), bem como intenso processo inflamatório ao redor da ferida. Por fim, destacamos dentre as características dor e odor ocasionais ${ }^{12,13}$.

O estadiamento 3 constitui-se como uma ferida espessa envolvendo o tecido subcutâneo. Possui profundidade regular, com

Tabela 3. Caracterização das lesões neoplásicas.

\begin{tabular}{|c|c|c|}
\hline Variáveis & $n$ & $\%$ \\
\hline \multicolumn{3}{|l|}{ Localização da lesão } \\
\hline Abdome & 1 & 2,0 \\
\hline Cabeça e pescoço & 27 & 52,8 \\
\hline Mama & 10 & 19,6 \\
\hline Sacra & 1 & 2,0 \\
\hline Região perianal & 6 & 11,8 \\
\hline Região torácica & 6 & 11,8 \\
\hline \multicolumn{3}{|l|}{ Tamanho } \\
\hline$<5 \mathrm{~cm}$ & 16 & 31,4 \\
\hline Entre 5 e $10 \mathrm{~cm}$ & 13 & 25,5 \\
\hline$>10 \mathrm{~cm}$ & 22 & 43,1 \\
\hline \multicolumn{3}{|l|}{ Sintomas } \\
\hline $\mathrm{sim}$ & 46 & 90,2 \\
\hline Não & 5 & 9,8 \\
\hline \multicolumn{3}{|l|}{ Tipos de sintomas } \\
\hline Dor & 41 & 89,1 \\
\hline Prurido & 22 & 47,8 \\
\hline Cefaleia & 10 & 21,7 \\
\hline \multicolumn{3}{|l|}{ Estadiamento } \\
\hline 1 & 2 & 4,0 \\
\hline 2 & 7 & 14,0 \\
\hline 3 & 26 & 52,0 \\
\hline 4 & 8 & 16,0 \\
\hline $1 \mathrm{n}$ & 7 & 14,0 \\
\hline
\end{tabular}

Fonte: HCP, 2013. saliência e formação irregular. É friável, ulcerada ou vegetativa, podendo apresentar tecido necrótico liquefeito ou sólido e aderido, com odor fétido e exsudato. Possui lesões satélites em risco de ruptura, tecido de coloração avermelhada ou violácea, porém o leito da ferida encontra-se predominantemente amarelado ${ }^{12,13}$.

No estadiamento 4 tem-se a invasão profunda de estruturas anatômicas. Destaca-se uma profundidade expressiva, onde, por vezes, não se visualiza o seu limite, sendo, em alguns casos, com exsudato abundante, odor fétido e dor. Possui tecido de coloração avermelhada ou violácea, porém o leito da ferida encontra-se predominantemente amarelado ${ }^{12,13}$.

Sugere-se que as lesões em estadiamento 1, 1n e 2 sejam menos frequentes pelo fato de serem passíveis de controle e regressão com terapêuticas, como quimioterapia e radioterapia, tendo em vista o fato de serem estágios iniciais de lesão. Sugere-se também que o estadiamento 4 estará mais

Tabela 4. Caracterização das lesões e do tratamento dos pacientes com feridas neoplásicas

\begin{tabular}{|c|c|c|}
\hline Variáveis & $\mathrm{n}$ & $\%$ \\
\hline \multicolumn{3}{|l|}{ Exsudato } \\
\hline $\mathrm{Sim}$ & 43 & 84,3 \\
\hline Não & 8 & 15,7 \\
\hline \multicolumn{3}{|l|}{ Tipo de exsudato } \\
\hline Purulento & 25 & 58,1 \\
\hline Sanguinolento & 24 & 55,8 \\
\hline \multicolumn{3}{|l|}{ Odor } \\
\hline $\mathrm{Sim}$ & 37 & 72,5 \\
\hline Não & 14 & 27,5 \\
\hline \multicolumn{3}{|l|}{ Odor } \\
\hline Grau 1 & 26 & 70,3 \\
\hline Grau 2 & 6 & 16,2 \\
\hline Grau 3 & 5 & 13,5 \\
\hline \multicolumn{3}{|l|}{ Coloração } \\
\hline Amarelado & 34 & 66,7 \\
\hline Avermelhado & 33 & 64,7 \\
\hline Violáceo & 5 & 9,8 \\
\hline Necrose & 9 & 17,6 \\
\hline \multicolumn{3}{|l|}{ Terapia tópica } \\
\hline $\operatorname{Sim}$ & 40 & 78,4 \\
\hline Não & 11 & 21,6 \\
\hline \multicolumn{3}{|l|}{ Tipo de terapia tópica } \\
\hline Soro fisiológico & 15 & 37,5 \\
\hline Colagenase & 13 & 32,5 \\
\hline Metronidazol & 1 & 2,5 \\
\hline $\mathrm{AGE}$ & 3 & 7,5 \\
\hline Sulfadiazina de prata & 4 & 10,0 \\
\hline Outras coberturas & 5 & 12,5 \\
\hline
\end{tabular}

AGE: ácidos graxos essenciais.

Fonte: HCP, 2013. 
presente em pacientes terminais em virtude de sua característica invasiva, atingindo outros órgãos em profundidade, sendo esse tipo menos encontrado também.

Em relação ao tamanho das feridas, a maioria apresentava-se maior do que $10 \mathrm{~cm}$ de comprimento (43,1\%), seguida por feridas com menos de $5 \mathrm{~cm}(31,4 \%)$. Observa-se que a invasão em planos mais profundos é uma característica mais presente na lesão neoplásica, já que a quantidade de lesões extensas e lesões pequenas não apresentou variação tão significativa. Foram encontradas lesões em comprimento extenso em grau 1, assim como lesões pequenas em grau 3 ou 4, porém com profundidade ou acometimento tecidual significativo.

Dos 51 pacientes, 46 (90,2\%) referiram alguma sintomatologia em relação à ferida. A dor estava presente em 41 indivíduos (89,1\%), seguida de prurido em 22 pessoas $(47,8 \%)$ e cefaleia em 10 participantes $(21,7 \%)$. Durante o seu processo de crescimento acelerado, o tumor pode exercer pressão e/ou invasão sobre estruturas e terminações nervosas, ocasionando dor pelo processo inflamatório que cursa com esse crescimento agressivo, ocorrendo a liberação de histaminas, responsáveis pelas frequentes queixas de prurido ao redor da ferida. A cefaleia mostra-se presente principalmente em pacientes com câncer de cabeça e pescoço, em que há envolvimento linfonodal ${ }^{7}$.

Em relação à exsudação da lesão, do total de 51, 43 pacientes $(84,3 \%)$ possuíam feridas exsudativas. Desses 43 , 25 pacientes $(58,1 \%)$ apresentavam exsudato purulento, e 24 $(55,8 \%)$, exsudato sanguinolento. $\mathrm{O}$ exsudato é atribuído à permeabilidade capilar aumentada no leito da ferida, como consequência da neovascularização débil do tumor e pela secreção adicional de fator de permeabilidade vascular pelo próprio tumor ${ }^{1}$. Associa-se a esse processo a formação adicional de exsudato decorrente do processo inflamatório adjacente. A monitoração do exsudato diminui o odor, aumenta o conforto e melhora a autoestima do paciente. $\mathrm{O}$ controle da infecção local e da quantidade de tecido necrótico pode diminuir o exsudato da ferida em alguns casos ${ }^{3}$.

Do total de lesões, 34 (66,7\%) possuíam coloração amarelada, e 33 (64,7\%), coloração avermelhada. A predominância das cores amarelada e avermelhada está relacionada às características teciduais de feridas de estadiamento 3, assim como à necrose em graus superiores, destacando a cor violácea, mais encontrada em graus iniciais de feridas (1 e 1n).

No que diz respeito ao odor, dos 51 pacientes, 37 $(72,5 \%)$ possuíam odor em sua ferida. Desses 37 , obtivemos 26 pacientes $(70,3 \%)$ com odor grau 1 , seguidos por 6 pessoas $(16,2 \%)$ com odor grau 2. O odor é uma característica importante na ferida tumoral, sendo encontrado principalmente em estadiamentos avançados. A infecção por micro-organismos anaeróbios e tecidos desvitalizados causa o odor fétido, o qual tem sido descrito como o responsável por desconforto, constrangimento e sofrimento, em decorrência da sensação de enojamento e isolamento social que imputa o paciente ${ }^{4-6}$. A variação entre graus também tenderá a variar pela quantidade de trocas de cobertura, higienização, quantidade de exsudação e cobertura adequada utilizada. O grau 1 é o odor sentido ao abrir o curativo; o grau 2 é sentido ao se aproximar do paciente sem abrir o curativo; o odor grau 3, definido como forte e/ou nauseante, é sentido no ambiente sem abrir o curativo ${ }^{12}$.

Das 51 pessoas, $40(78,4 \%)$ utilizavam algum tipo de terapia tópica. Dessas 40, 15 pessoas $(37,5 \%)$ utilizavam apenas soro fisiológico, seguidas por 13 pessoas (32,5\%) utilizando colagenase. Outras coberturas foram utilizadas em menor número, como metronidazol, sulfadiazina de prata e ácidos graxos essenciais (AGE). Os cuidados das lesões neoplásicas seguem os mesmos preceitos do curativo ideal: manter o meio úmido, evitar a aderência ao leito da lesão, evitar trauma durante a remoção, auxiliar no desbridamento do tecido necrótico, controlar a hemorragia, permitir as trocas gasosas, manter isolamento térmico, absorver e conter o exsudato, evitar irritação superficial, reestabelecer a simetria corpórea do paciente e ser esteticamente aceitável ${ }^{5}$. Todavia, as feridas neoplásicas possuem características peculiares que devem ser levadas em consideração no momento de se iniciar a conduta com o paciente. $\mathrm{O}$ objetivo é alcançar o controle de secreção, odor, sangramento, dor e prurido, e a meta é o curativo confortável, funcional e estético ${ }^{13}$. A conduta terapêutica deve ser ajustada às características da lesão, obedecendo aos princípios de cuidados com feridas. A meta principal dessas condutas deixa de ser a cicatrização - que é improvável - e passa a focar:

- $\quad$ o conforto do paciente com relação à ferida;

- a prevenção e o controle dos sintomas locais ${ }^{3-12}$.

Para o controle de sangramentos, podem ser utilizados: a aplicação de esponja hemostática (constituída à base de colágeno); a manipulação de cuidados com uso de irrigação com solução fisiológica (SF) 0,9\% ou água tratada ao retirar curativo anterior; a utilização de curativos não aderentes; a aplicação de adrenalina tópica diretamente sobre os pontos sangrantes; o uso de drogas coagulantes orais e radioterapia anti-hemorrágica ${ }^{5}$. 
No que concerne ao odor, estão indicados: o uso de curativo de carvão ativado (envolto em uma lâmina de gaze); hidróxido de alumínio; metronidazol sistêmico e/ou tópico ${ }^{2}$. Recomenda-se observar o padrão alimentar do paciente e elaborar um plano de cuidados que evite a troca de curativos próxima aos horários das refeições ${ }^{5}$.

Para o alívio da dor, é possível considerar: pré-analgesia pelo uso de dose de resgate; uso de anestésico tópico ao redor da ferida; aplicação de hidróxido de alumínio diretamente no sítio da lesão; manipulação cuidadosa do leito da ferida, evitando o esfregaço; revisão da analgesia sistêmica em curso; uso de radioterapia antiálgica ${ }^{5}$.

Para o controle do exsudato, podem ser utilizados curativos absortivos, como carvão ativado, alginato de cálcio e compressa/gaze como cobertura secundária. Em alguns casos, a falta de proteção à pele íntegra perilesional pode levar à irritação e, consequentemente, ao prurido. Atualmente, para o controle do prurido está indicada a aplicação de esteroides tópicos, como dexametasona creme a $0,1 \% \%^{5-13}$.

O soro fisiológico, quando utilizado exclusivamente, mantém a ferida úmida, favorece a formação do tecido de granulação, amolece os tecidos desvitalizados, estimula o desbridamento autolítico e absorve exsudato ${ }^{12}$. A conduta seria adequada para uma lesão passível de cicatrização. A colagenase atua como agente desbridante em lesões superficiais, promovendo a limpeza enzimática das áreas lesadas e retirando ou dissolvendo, enzimaticamente, necroses e $\operatorname{crostas}^{5-12}$. O desbridamento pode reduzir o odor e a exsudação presentes nessas feridas; todavia, o sangramento capilar comumente presente e as grandes massas de tecido necrótico contribuem para que essa seja uma prática evitada. É importante ressaltar que a conduta terapêutica para a ferida neoplásica não se centraliza na cicatrização, em que a colagenase seria um produto de maior utilidade.

A sulfadiazina de prata é um bactericida utilizado no tratamento de feridas com grande potencial de infecção generalizada, como queimaduras, úlceras varicosas e feridas cirúrgicas infectadas, e atua impedindo o aparecimento de uma vasta gama de bactérias e leveduras na pele danificada ${ }^{12-15}$. Não há dados na literatura que embasem o seu uso em feridas neoplásicas, visto que também se trata de um agente auxiliador na cicatrização, assim como os AGE, que age na hidratação preventiva, além de possuir propriedades emolientes que protegem a pele e auxiliam no processo de cicatrização de feridas.
O metronidazol é um antibiótico ativo contra bactérias anaeróbicas e protozoários, exercendo atividades antibacterianas, antiparasitárias e anti-helmínticas, sendo indicado para feridas neoplásicas com odor grau $3^{5,16,17}$.

É importante ressaltar que a instituição não possuía uma variedade grande de produtos, bem como um protocolo a ser seguido acerca do manejo de feridas neoplásicas.

\section{CONCLUSÃO}

Neste estudo foram avaliados 51 pacientes com feridas neoplásicas, a maioria era do sexo masculino, apresentando câncer primário e ferida, predominantemente, na região de cabeça e pescoço. Essa população tinha entre 40 e 60 anos de idade e possuía baixa escolaridade. A grande parte era constituída por tabagistas e etilistas, porém poucos indivíduos possuíam alguma comorbidade associada, sendo a hipertensão arterial a mais citada. A maioria dos pacientes já tinha sido submetida a alguma terapia antineoplásica, sendo a quimioterapia a mais realizada. As lesões encontravam-se, em sua maioria, no estadiamento 3, com mais de $10 \mathrm{~cm}$ de comprimento, exsudato predominantemente purulento e com odor grau 1. A cobertura mais utilizada foi a colagenase. A maioria dos pacientes relatava dor no local da lesão.

Este estudo possibilitou o conhecimento acerca do paciente com ferida neoplásica, seus aspectos epidemiológicos e o manejo da ferida. Caracterizar o paciente significa conhecer e analisar suas particularidades e os aspectos envolvidos em seu universo, possibilitando o planejamento de uma atenção individualizada e direcionada, premissa da qualidade da assistência de enfermagem.

Nos últimos anos, com a transição demográfica, ocorreram mudanças no envelhecimento da população, aumentando a prevalência de câncer e de outras patologias crônicas, o que torna este estudo relevante e exalta a necessidade constante de mais pesquisas acerca dos cuidados com o paciente com ferida neoplásica. Sendo o enfermeiro um membro ativo do processo de cuidar, é necessária a avaliação criteriosa do paciente com esse tipo de lesão e suas especificidades, o que determinará o cuidado adequado conforme as características clínicas de cada ferida, a fim de proporcionar qualidade de vida ao paciente. Conhecer mais - e melhor - , para atuar com foco, direcionamento e especificidade, gera melhorias no atendimento ao paciente. 
O conhecimento deficiente acerca do manejo das feridas neoplásicas ainda é uma realidade não só por parte do enfermeiro, mas da equipe multiprofissional como um todo, sendo esse tipo de ferida conduzida com base no empirismo e em conhecimentos de outros tipos de lesões. Recomenda-se, aqui, uma atualização e a capacitação contínua do profissional que está à frente do cuidado do paciente oncológico e, além disso, a valorização do enfermeiro especialista, melhorando, desse modo, a qualidade da assistência ao paciente que se encontra em processo de constante fragilidade.

Além da relevância para uma melhor assistência de enfermagem, espera-se que esta pesquisa possa subsidiar novos estudos, contribuindo para o enriquecimento científico da enfermagem oncológica.

\section{REFERÊNCIAS}

1. Instituto Nacional de Câncer (INCA). Incidência de câncer no Brasil. Rio de Janeiro: INCA; 2012.

2. Instituto Nacional de Câncer (INCA). Ações de enfermagem para o controle do câncer: uma proposta de integração ensino-serviço. $3^{\text {a }}$ ed. rev. Rio de Janeiro: INCA; 2008.

3. Firmino F. Pacientes portadores de feridas neoplásicas em Serviços de Cuidados Paliativos: contribuições para elaboração de protocolos de intervenções de enfermagem. Rev Bras Cancerol. 2005;51(4):347-59.

4. Academia Nacional de Cuidados Paliativos. Manual de cuidados paliativos. Rio de Janeiro: Diagraphic; 2009.

5. Santos CMC. Revisão sistemática sobre tratamentos tópicos de lesões vegetantes malignas [dissertação]. São Paulo: Escola de Enfermagem da Universidade de São Paulo; 2007.

6. Agra G, Fernandes MA, Platel ICS, Freire MEM. Cuidados Paliativos e Ferida Neoplásica. Rev Bras Cancerol. 2013;59(1):95-104.

7. Aguiar RM, Silva GRC. Os cuidados de enfermagem em feridas neoplásicas na assistência paliativa. Rev Hospital Universitário Pedro Ernesto. 2012;11(2):82-88.

8. Alvarenga LM, Ruiz MT, Pavarino-Bertelli EC, Ruback MJC, Maniglia JV, Goloni-Bertollo M. Avaliação epidemiológica de pacientes com câncer de cabeça e pescoço em um hospital universitário do noroeste do estado de São Paulo. Rev Bras Otorrinolaringol. 2008;74(1):68-73.

9. Dallagnol JC, Reksidler MA, Oliveira BV, Orlandi D, Silva RCA, Pedruzzi PAG. Perfil epidemiológico dos pacientes com câncer de cabeça e pescoço que evoluíram a óbito antes de receber tratamento. Rev Bras Cir Cabeça Pescoço. 2011;40(2):57-60

10. Sociedade Brasileira de Oncologia Clínica. Manual de Condutas. Câncer de Cabeça e Pescoço. Belo Horizonte: Sociedade Brasileira de Oncologia Clínica; 2011.

11. Brasil. Instituto Nacional de Câncer (INCA). ABC do câncer: abordagens básicas para o controle do câncer/Instituto Nacional de Câncer. Rio de Janeiro: INCA; 2011.

12. Brasil. Instituto Nacional de Câncer (INCA). Tratamento e controle de feridas tumorais e úlceras por pressão no câncer avançado. Rio de Janeiro: INCA; 2009. 42 p. (Série Cuidados Paliativos)

13. Junior JF, Fuly PSC. Análise de associação entre feridas neoplásicas, odor e tratamento: estudo transversal. Rev Enferm UFPE (Online). 2014;8(8):2938-40.

14. Firmino F. Feridas Neoplásicas: Estadiamento e Controle dos Sinais e Sintomas. Prática Hospitalar (Online). 2005;42:59-62.

15. Gomes IP, Camargo TC. Feridas tumorais e cuidado de enfermagem: buscando evidências para o controle de sintomas. Rev Enferm UERJ. 2004;12:211-6.

16. Leite AC. Feridas Tumorais: cuidados de enfermagem. Rev Científica do Hospital Central do Exército do Rio de Janeiro. 2007;2(2):36-40.

17. Pinto KCMS, Silva RMP, Pereira AL, Ribeiro DB. Produtos Utilizados no Tratamento de Lesões Neoplásicas Cutâneas. Rev Estima. 2009;7(1):39-43. 


\title{
Caracterização Sociodemográfica e Clínica de Pessoas com Estomia em Teresina
}

\section{Sociodemographic and Clinic Characterization of People with Ostomy in Teresina}

\author{
Caracterización Sociodemográfica y Clínica de Personas con Ostomía en Teresina
}

\author{
Sara Machado Mirandaํ, Maria Helena Barros Araújo Luz², Helena Megumi Sonobe, \\ Elaine Maria Leite Rangel Andrade ${ }^{4}$, Elaine Cristina de Carvalho Moura ${ }^{5}$
}

\begin{abstract}
RESUMO
O estudo teve por objetivo caracterizar o perfil sociodemográfico e clínico de pessoas cadastradas no Programa de Estomizados de Teresina (PI). Pesquisa exploratório-descritiva, transversal, com abordagem quantitativa, cujos dados foram coletados no período de junho a julho de 2013, sendo utilizado o programa Statistical Package for the Social Sciences (SPSS), versão 19.0, para análise estatística. A pesquisa foi aprovada pelo Comitê de Ética e Pesquisa (CEP) da Universidade Federal do Piauí (UFPI), sob CAAE nº 10487813.3.0000.5214. A amostra foi constituída por 107 estomizados, que atenderam aos critérios de inclusão. Houve predomínio de estomizados do sexo masculino (55,1\%); média de idade de 59,2 anos; casados (48,6\%); com filhos (86,9\%); católicos (81,3\%); renda familiar entre 1 e 3 salários mínimos (60,7\%); ensino fundamental incompleto (32,7\%); aposentados (57,0\%). As neoplasias constituíram a principal causa da estomia (71,0\%), seguidas de doenças inflamatórias intestinais (20,6\%); a maioria era colostomizada (74,8\%), permanente (48,6\%), há menos de um ano (39,3\%); apresentava efluente de consistência pastosa (74,8\%); utilizava bolsa coletora de peça única (94,4\%), sendo 100\% drenável, fornecida pelo Sistema Único de Saúde (SUS) (73,8\%). Dentre as 41 (38,3\%) complicações apresentadas pelos participantes, 30 (73,1\%) referiam-se à pele periestoma caracterizado, 29, ao eritema (96,7\%), e 11 (26,82 \%), ao estoma, sendo verificados prolapso, 10 (90,0\%), e sangramento, 1 (3,3\%). Os resultados obtidos mostraram aproximações e semelhanças em comparação com as literaturas nacional e internacional. Conclui-se que o conhecimento do perfil dessa clientela possibilitará a adequação do planejamento da assistência especializada e da provisão de equipamentos coletores e adjuvantes no contexto do Estado do Piauí.
\end{abstract}

DESCRITORES: Estomaterapia. Estomia. Enfermagem. Perfil de saúde. Neoplasias.

\begin{abstract}
The study aimed to characterize the sociodemographic and clinical profile of people registered in the ostomy program of Teresina (PI). Exploratory-descriptive, cross-sectional survey with a quantitative approach, whose data were collected between June and July 2013, by using the Statistical Package for the Social Sciences (SPSS) 19.0 software for statistical analysis. The study was approved by the Research Ethics Committee (CEP) of the Federal University of Piauí (UFPI) under CAAE n. 10487813.3.0000.5214. The sample consisted of 107 ostomy who met the inclusion criteria, through interviews using an instrument adapted from a previously developed. The results showed that the majority of ostomy (55.1\%) are male; mean age 59.2 years; married (48.6\%); with children (86.9\%); Catholic (81.3\%); family income
\end{abstract}

\footnotetext{
${ }^{1}$ Enfermeira. Mestre do Programa de Pós-Graduação em Enfermagem da Universidade Federal do Piauí (UFPI) - Teresina (PI), Brasil. Endereço para correspondência: Avenida Senador José Cândido Ferraz, 1770, Condomínio Pallazzo Maggiore 1603 - Jóquei Club - CEP: 64049-250- Teresina (PI), Brasil - E-mail: sarammiranda2@gmail.com

${ }^{2}$ Doutora em Enfermagem pela Escola de Enfermagem Anna Nery da Universidade Federal do Rio de Janeiro (UFRJ) - Rio de Janeiro (RJ), Brasil. Docente do Programa de Pós-Graduação em Enfermagem da UFPI - Teresina (PI), Brasil. Pós-graduada em Estomaterapia pela Universidade de São Paulo (USP) - São Paulo (SP), Brasil.

${ }^{3}$ Doutora em Enfermagem pela Escola de Enfermagem de Ribeirão Preto da Universidade de São Paulo (EERP-USP). Docente do Programa de Pós-Graduação Enfermagem Fundamental da EERP-USP - Ribeirão Preto (SP), Brasil. Pós-graduada em Estomaterapia pela USP - São Paulo (SP), Brasil. ${ }^{4}$ Doutora em Enfermagem pela EERP-USP - São Paulo (SP), Brasil. Docente do Programa de Pós-Graduação em Enfermagem da UFPI - Teresina (PI), Brasil. ${ }^{5}$ Doutora em Enfermagem Fundamental pela EERP-USP - Ribeirão Preto (SP), Brasil. Docente do Programa de Pós-Graduação em Enfermagem da UFPI - Teresina (PI), Brasil.

Artigo recebido em: 06/10/2014 - Aceito para publicação em: 02/07/2015
} 
between 1 and 3 minimum wages (60.7\%); have incomplete primary education (32.7\%) and retired (57.0\%). Neoplasms are the main cause of the stoma (71.0\%), followed by inflammatory bowel disease (20.6\%); colostomy (74.8\%), standing (48.6\%), with length of stay less than 1 year (39.3\%); present effluent pasty consistency (74.8\%); using one-piece pouch (94.4\%) draining (100\%) and supplied by SUS (73.8\%). Among the 41 (38.3\%) complications presented by the participants, $30(73.1 \%)$ referred to the peristoma skin characterized by erythema 29 (96.7\%) and 11 (26.82\%) to the stoma, prolapse and 10 (90.0\%) and bleeding 1 (3.3\%). The results show similarities and similarities in some aspects and differences in others, found in national and international literature. It is concluded that the knowledge produced reflects the state of health of the individual who undergoes surgery to make the stoma, the structure of the support services provided in the context of the State of Piauí.

DESCRIPTORS: Stomatherapy. Ostomy. Self-care. Nursing. Health profile. Neoplasms.

\section{RESUMEN}

El estudio tuvo como objetivo caracterizar el perfil sociodemográfico y clínico de las personas inscritas en el programa de ostomía de Teresina (PI). Encuesta exploratorio-descriptivo, transversal, con abordaje cuantitativo, cuyos datos fueron recogidos entre junio-julio de 2013, mediante el software Statistical Package for the Social Sciences (SPSS) 19.0 para el análisis estadístico. El estudio fue aprobado por el Comité de Ética en Investigación (CEP) de la Universidad Federal de Piauí (UFPI), bajo CAAE n 10487813.3.0000.5214. La muestra consistió de 107 ostomizados, según los criterios de inclusión. La mayoría de los participantes eran hombres (55,1\%); edad media de 59,2 años; casados (48,6\%); con los hijos (86,9\%); católica (81,3\%); renta familiar 1 hasta 3 sueldos mínimos (60,7\%); educación básica incompleta (32,7\%) y jubilados (57,0\%). Neoplasias son la causa principal del estoma (71,0\%), seguida de la enfermedad inflamatoria intestinal (20,6\%); colostomía (74,8\%), definitivo (48,6\%), convivio con estoma de menos de 1 año (39,3\%); con efluente pastoso (74,8\%); uso de equipo de una pieza (94,4\%), drenable (100\%) y suministrado por el Sistema Único de Salud (SUS) (73,8\%). Entre los 41 $(38,3 \%)$ las complicaciones presentadas por los participantes, 30 (73,1\%) se refirió a la piel peristoma caracterizado por eritema 29 (96,7\%) y 11 (26,82\%) al estoma, prolapso y 10 (90,0\%) y sangrado 1 (3,3\%). Los resultados son semejantes y diferentes comparados con literatura nacional y internacional. Se concluye que el conocimiento del perfil de esta clientela posibilita adecuar el planeamiento de la asistencia especializada y la provisión de equipos de ostomía y adyuvantes en el contexto del Estado de Piauí.

DESCRIPTORES: Estomaterapia. Ostomía. Autocuidado. Enfermería. Perfil de salud. Neoplasias.

\section{INTRODUÇÃO}

Nos últimos anos, as mudanças sociodemográficas, econômicas e epidemiológicas ocasionadas por urbanização acelerada, novos padrões de consumo, globalização do conhecimento, avanços científicos e tecnológicos promoveram grande impacto em âmbito nacional, com declínio da taxa de natalidade, aumento da expectativa de vida populacional e, consequentemente, da longevidade, paralelamente associado ao aumento de doenças crônicas não transmissíveis, elevado número de acidentes de trânsito e violência urbana, resultando no crescente aumento do número pessoas com estomias no Brasil, sendo que a cada ano são realizados, aproximadamente, 1 milhão e 400 mil procedimentos cirúrgicos com confecção de estomias ${ }^{1}$.

Na maioria das vezes, as estomias estão vinculadas às doenças crônicas intestinais e urinárias, como os cânceres colorretal e de bexiga, às doenças inflamatórias, como doença de Crohn, retocolite ulcerativa e diverticulite, e ao tratamento de enfermidades congênitas e trauma abdominal ${ }^{2}$. No Brasil, dentre as principais causas relacionadas à necessidade de estomia na população adulta e idosa, encontram-se as neoplasias, principalmente o câncer colorretal, cuja estimativa mais recente pelo Instituto Nacional de Câncer José Alencar Gomes da Silva (INCA) foi para o ano de 2014, com 32.600 casos, sendo 15.070 homens e 17.530 mulheres ${ }^{3}$.

Considerando o aumento da população estomizada, ressaltamos conquistas importantes em relação à assistência especializada e à implementação de políticas públicas para assegurar a acessibilidade para essa clientela, como o movimento, na década de 1970, marcado pela forte presença dos estomizados, com o apoio dos profissionais de saúde, especialmente médicos coloproctologistas e enfermeiros, a criação da primeira associação de estomizados, em 1975, em Fortaleza (CE), e, em 1990, a implementação do primeiro curso de especialização em estomaterapia no Brasil, visando formar enfermeiros para prestar assistência avançada em resposta às reivindicações da clientela. Posteriormente, em 1992, foi criada a Associação Brasileira de Estomaterapia: estomias, feridas e incontinências (SOBEST), que fortaleceu ainda mais o movimento ${ }^{4}$. 
Houve a criação e a implementação de políticas públicas governamentais específicas para as pessoas com estomia, como a Portaria SAS/MS no 400, de 16 de novembro de 2009, que estabeleceu diretrizes nacionais para a Atenção à Saúde de pessoas estomizadas no âmbito do Sistema Único de Saúde (SUS) e definiu os três níveis de atenção prestados às pessoas com estoma, além das responsabilidades com a promoção da saúde, a assistência, a reabilitação e as respectivas atribuições. Além disso, propõe modelos de estruturas físicas adequadas para realizar o atendimento e a descrição dos materiais e equipamentos coletores necessários ao cuidado integral às pessoas com os estomas pelo SUS, por uma equipe interdisciplinar, e os fluxos para os serviços de referência e contrarreferência ${ }^{5,6}$.

A assistência de enfermagem às pessoas com estomias perpassa pela necessidade de integração dos diferentes níveis de atendimento à saúde, como as instituições hospitalares $\mathrm{e}$ os ambulatórios de especialidades, pelas repercussões físicas e psicossociais do processo de estomização e pela necessidade de aprendizagem do autocuidado com a estomia, equipamentos coletores e adjuvantes, que são aspectos cruciais durante o seguimento no Programa de Ostomizados para a reabilitação dessas pessoas. Com a aprendizagem do autocuidado, a pessoa com estomia adquire maior autonomia, maior capacidade de desempenhar atividades necessárias à saúde, além de enfrentar e conviver com as repercussões e limitações resultantes das alterações de saúde ${ }^{1}$.

No Programa de Ostomizados, o enfermeiro realiza avaliação clínica da estomia e da região periestoma para realizar a indicação do equipamento e adjuvante adequados para cada pessoa, considerando aspectos físicos, atividades diárias desenvolvidas por estas e capacidade para o autocuidado, o que previne desenvolvimento de lesões periestomas, proporciona maior segurança e favorece a adaptação à nova condição, gerando, dessa forma, melhor custo-benefício ao sistema público de saúde local ${ }^{1,6}$.

Apesar de muitos avanços em relação à implementação de políticas públicas específicas para essa clientela, o desafio nesse programa de saúde é atender à demanda de necessidades de cuidados especializados, assim como a previsão e a provisão de equipamentos coletores e adjuvantes, para potencializar o alcance de melhores resultados ${ }^{1,6}$

Assim, acreditamos que para a operacionalização dessas políticas é necessário conhecer as características sociodemográficas e clínicas dessa clientela, para otimizar os recursos humanos e materiais.

\section{OBJETIVO}

Caracterizar o perfil sociodemográfico e clínico de pessoas cadastradas no Programa de Atenção às Pessoas com Estomia de Teresina (PI).

\section{MÉTODOS}

Trata-se de um estudo descritivo com abordagem quantitativa dos dados acerca da caracterização do perfil sociodemográfico e clínico de pessoas com estomias cadastradas no Programa de Atenção às Pessoas com Estomia de Teresina (PI).

A amostra foi não probabilística, constituída por 107 pessoas cadastradas no programa até junho de 2013, sendo que 97 apresentavam estomia intestinal, e 10, estomia urinária. A coleta de dados ocorreu no período de junho a julho de 2013 por meio de entrevistas previamente agendadas, em que se utilizou formulário semiestruturado, com perguntas abertas e fechadas, preenchidas pelo entrevistador com os estomizados que atenderam aos critérios de inclusão: estar cadastrado no Centro Integrado de Saúde Lineu Araújo (CISLA), ter idade acima de 18 anos, ambos os sexos, residir no município de Teresina e aceitara participar da pesquisa assinando o Termo de Consentimento Livre e Esclarecido. As entrevistas foram digitadas no Microsoft ${ }^{\circledR}$ Excel e transportadas para o programa Statistical Package for the Social Sciences (SPSS), e, em seguida, foi realizada a análise descritiva dos dados. A pesquisa foi aprovada pelo Comitê de Ética e Pesquisa (CEP) da Universidade Federal do Piauí (UFPI), sob CAAE no 10487813.3.0000.5214, de acordo com a Resolução 466/12 do Conselho Nacional de Saúde.

\section{RESULTADOS}

A caracterização sociodemográfica dos 107 estomizados participantes do estudo mostra que a maioria, $59(55,1 \%)$, é do sexo masculino, cuja faixa etária predominante foi de 60 a 80 anos, com 47 (43,9\%), apresentando média de 59,3 anos de idade, casada/em união estável, 52 (48,6\%), e possuía um ou mais filhos, 93 (86,9\%). 
Predominaram os que possuíam ensino fundamental incompleto, 35 (32,7\%), renda familiar de 1 a 3 salários mínimos, 65 (60,7\%), condição previdenciária como aposentados, 61 (57,0\%), moravam em casa própria, 88 (82,2\%), e se declararam católicos, 87 (81,3\%).

Quanto à causa básica que resultou na construção da estomia, verificou-se que a maioria, $76(71,0 \%)$, foi por neoplasias, sendo 80 colostomias (74,8\%), 15 (14\%) ileostomias e $10(9,3 \%)$ urostomias, e $2(1,9 \%)$ possuíam dois tipos de estoma (colostomia e urostomia).

Em relação à coloração do estoma, a maioria, 104 (97,2\%), apresentou cor róseo-avermelhada, com forma redonda, $63(58,9 \%)$, protrusa, 75 (70,1\%), plana, 23 (21,5\%), e retraída, $9(8,4 \%)$. Quanto ao tempo de permanência, a maioria, $52(48,6 \%)$, apresentou estomia permanente, com localização da estomia no quadrante inferior esquerdo, $56(52,3 \%)$, $40(37,4 \%)$ no quadrante inferior direito, $3(2,8 \%)$ no quadrante superior esquerdo e $8(7,5 \%)$ no quadrante superior direito, sendo observado que a maioria, $80(74,8 \%)$, apresentou efluente pastoso, seguido por $24(22,4 \%)$ com forma líquida e 3 (2,8\%) com consistência sólida.

Por outro lado, o tipo de equipamento coletor utilizado pela maioria dos estomizados, 101 (94,4\%), era bolsa com peça única e apenas 6 (5,6\%) utilizavam dispositivo de duas peças; quanto à abertura, $100 \%$ das bolsas eram drenáveis ou abertas.

Verificou-se que dos 107 participantes, 41 (38,31\%) apresentaram complicações no estoma ou na pele periestoma, sendo $11(26,82 \%)$ complicações de estoma, 10 (90,0\%) apresentaram prolapso e $1(9,0 \%)$ com sangramento. Dos $30(73,1 \%)$ estomizados que apresentaram complicações na pele periestoma, 29 (96,7\%) tiveram eritema, e 1 (3,3\%), outra complicação.

\section{DISCUSSÃO}

Em relação à análise das variáveis sociodemográficas e econômicas dos estomizados participantes da pesquisa, pode-se verificar o predomínio de pacientes do sexo masculino, idosos, casados, com filhos, aposentados, católicos, cuja formação educacional foi o ensino fundamental incompleto, com renda de até 3 salários mínimos e que residiam em casa própria, o que corrobora resultados de outros estudos que indicam constituição familiar nuclear e condição socioeducacional e econômica predominante na população brasileira, com a maioria composta por estomizados do sexo masculino $(52,6 \%)$ e média de idade de 61,6 anos $^{7,8}$. Isso pode ser decorrente do aumento da violência urbana e dos acidentes de trânsito, associados ao uso de drogas lícitas e ilícitas, tornando o sexo masculino mais exposto a riscos de trauma abdominal, outras doenças e agravos. Ainda, a população masculina utiliza com menor frequência os serviços de saúde e as medidas preventivas, o que leva tal população a procurar o atendimento médico tardiamente, quando apresenta manifestações do agravamento das doenças. Além disso, o sexo masculino possui certa invisibilidade nos serviços de atenção primária, fator que faz com que os homens se privem de medidas de promoção da saúde e prevenção de doenças, o que pode torná-los mais vulneráveis a agravos e complicações, por isso o diagnóstico em estágio avançado ${ }^{9,10}$.

Apesar de a maioria ser casada, a confecção da estomia e a convivência com o equipamento coletor geram sentimentos conflituosos, bem como alterações sexuais, que podem desgastar os relacionamentos afetivos, em decorrência de negação, diminuição da autoestima, sensação de mutilação e rejeição própria e dos familiares ${ }^{11}$.

No que diz respeito ao nível de escolaridade, assim como em outros estudos com a mesma clientela, predominou ensino fundamental incompleto ${ }^{7,12}$. Tal resultado revela um perfil preocupante em relação à cidadania e aos direitos, pois quanto mais baixa a escolaridade, maior a dificuldade para questionar os profissionais a respeito do problema de saúde e realizar os cuidados necessários, além de comprometer a implementação de ações educativas de autocuidado ${ }^{1}$.

O baixo nível de escolaridade pode ser um fator preponderante para a não prevenção do câncer colorretal, uma das principais causas básicas para a confecção das estomias, devido à ausência de conhecimento sobre a necessidade de realizar exames de rotina para a detecção precoce do câncer, e manutenção de hábitos prejudiciais, como etilismo, tabagismo, sedentarismo, maus hábitos alimentares, fatores intimamente ligados ao surgimento de neoplasias malignas ${ }^{13}$.

Em relação à renda familiar, este estudo coincide com o percentual encontrado em outras regiões, nas quais a média salarial é compreendida entre 1 e 2 salários mínimos $(66,51 \%)^{12}$.

No tocante à religião, o predomínio de católicos foi semelhante aos resultados de outros estudos ${ }^{7,14}$. É sugestivo que os estomizados busquem nas atividades espirituais subsídios para o enfrentamento dos seus problemas físicos e psicológicos, vinculados ao estoma.

Em relação à condição previdenciária, a maioria encontra-se inativa, fato que pode ser observado não somente pelo 
uso da estomia, mas também pela faixa etária dos participantes ( $>60$ anos), podendo estes pacientes ser aposentados pela idade, e não pela presença da estomia.

Verifica-se que é comum, depois da cirurgia, o paciente aposentar-se, deixando de ser provedor da família e tornando-se dependente em relação ao seu cuidado. Os limites ou a perda da capacidade para o trabalho são definidos, na maioria das vezes, pelo próprio estomizado, que se classifica como alguém que está impossibilitado de ser útil à sociedade ${ }^{14}$.

No que diz respeito ao tipo de moradia, a grande maioria afirmou residir em casa própria. Pode-se observar que, mesmo com a maior parte dos entrevistados apresentando baixo poder aquisitivo, entre 1 e 3 salários mínimos, os pacientes possuem casa própria, fato que amplia a visibilidade da política nacional de habitação, que beneficia as pessoas de baixa renda.

Verificou-se que as neoplasias são a maior causa de estomia, seguidas das doenças inflamatórias. Um estudo realizado recentemente em Minas Gerais corrobora os resultados desta pesquisa, em que as neoplasias malignas representaram $(75 \%)$ das causas de estomia ${ }^{8}$. No que diz respeito às doenças inflamatórias, uma pesquisa feita também em Teresina, no ano de 2009, apontava que $10,5 \%$ das estomias eram por essa causa ${ }^{7}$.

Pode-se observar que as causas das estomias condizem com a diversidade de idades dos estomizados do estudo, que engloba jovens, adultos e idosos. Entre os jovens e adultos, evidencia-se maior frequência de doenças inflamatórias intestinais, tais como a doença de Crohn e a retocolite ulcerativa, além de traumas decorrentes da violência urbana. Entre os idosos, verifica-se a predominância de quadros clínicos obstrutivos relacionados ao câncer colorretal e a doenças inflamatórias intestinais, como diverticulite e volvo.

No tocante ao tipo de estomia realizada, houve predominância de colostomia, seguida de ileostomia. Em um estudo realizado também em Teresina foram obtidos resultados semelhantes, em que a colostomia foi de $84,1 \%$ e ileostomia foi de $15,7 \%{ }^{7}$. A colostomia é a intervenção cirúrgica geralmente realizada nos casos em que o paciente tem neoplasia intestinal ${ }^{10}$.

Em relação à coloração da estomia, a maioria foi rósea, com formato de estoma redondo, seguido pelo formato irregular. O formato redondo diminui as complicações, principalmente por favorecer a adaptação do equipamento coletor e evitar extravasamento de efluentes.
Os estomas com aparência normal devem apresentar formato regular, coloração róseo-avermelhada, brilhante, úmido, com pele periestoma íntegra. A umidade e a coloração indicam fluxo sanguíneo adequado para a área ${ }^{15}$.

Em relação ao tipo de implantação na pele, a maior parte foi composta pelo modelo protruso, seguido pelo plano. A protrusão recomendada de um estoma é de $3 \mathrm{a} 5 \mathrm{~cm}$, para evitar lesões de pele por vazamento de efluente. No Reino Unido, em 2005, foi realizada uma auditoria em estomaterapia que estabeleceu que a altura mínima para a confecção de estomias era de $5 \mathrm{~mm}$ para colostomia e de $20 \mathrm{~mm}$ para ileostomia, para evitar complicações ${ }^{15,16}$.

Quanto à temporalidade da estomia, a maioria foi permanente. A permanência ou não das estomias está diretamente relacionada com o diagnóstico de indicação de sua confecção. A definitiva está associada frequentemente aos cânceres colorretal e urogenital, e a temporária, aos traumas. Em outros estudos, foram observados resultados semelhantes, pois $51,24 \%$ apresentaram estomia permanente e $48,76 \%$ possuíam estomia temporária ${ }^{12}$.

No tocante à localização, a maioria dos estomas localizava-se no quadrante inferior esquerdo, seguida por quadrante inferior direito. Somando as estomias localizadas nos quadrantes do lado esquerdo obtém-se a maioria, fato que explica a predominância do diagnóstico oncológico e do tipo de efluente pastoso.

A consistência do efluente varia conforme a localização de confecção do estoma; assim, colostomias sigmoide e descendente apresentam efluentes sólidos não corrosivos; colostomia transversa tem efluente de consistência semissólida não corrosiva; colostomia ascendente tende a apresentar efluentes semilíquidos e corrosivos. Vale ressaltar que a emissão de gases e odores tende a aumentar em colostomias transversas e ascendentes ${ }^{8}$.

Quanto à abertura da bolsa coletora, predominaram o tipo drenável e o equipamento de uma peça, em decorrência da padronização de equipamentos realizada nesse do serviço, limitando o processo de licitação da compra e o fornecimento de outros modelos de equipamentos coletores, sendo mais recomendado o modelo de duas peças, com protetor de pele, para prevenção de complicações.

Outros estudos que abordaram o uso de equipamentos coletores corroboram esta pesquisa, em que $66,6 \%$ dos participantes usavam bolsa coletora drenável, e 91,6\%, sistema de uma peça ${ }^{15}$. A bolsa deve ser esvaziada quando atingir um terço do conteúdo ou, no máximo, metade de 
sua capacidade, pois a durabilidade e a adesividade da base da bolsa coletora à pele serão maiores ${ }^{17,18}$.

A indicação de equipamentos e adjuvantes aos pacientes depende do tipo de estoma e da consistência do efluente, assim como da confecção cirúrgica, além da presença de complicações, nível de protrusão, capacidade para o autocuidado, tipo de atividade do paciente, barreira de proteção ou protetores cutâneos disponíveis ${ }^{19}$.

Das complicações apresentadas no estoma e na pele periestoma, a maioria foi composta por prolapso e eritema. Em estudos semelhantes, 50,6\% dos pacientes apresentaram complicações, predominando as dermatites, com $28,7 \%$, fato que diverge das características deste estudo ${ }^{10}$.

O prolapso é uma complicação nos estomas terminais, com maior frequência nos estomas em alça, em decorrência de exteriorização do segmento intestinal móvel, distante dos pontos de fixação anatômicos (ângulo hepático, ângulo esplênico, ângulo descendente-sigmoide $)^{17}$. Tal situação decorre de dificuldades para a confecção da estomia e anomalia da estrutura abdominal, gerando grande desconforto abdominal e dificuldade no manejo da estomi ${ }^{20}$.Já as lesões de pele periestoma, como as dermatites, são ocasionadas por uso ou indicação inadequada dos equipamentos, corte excessivo do orifício da barreira protetora, deixando a pele exposta à ação do efluente ${ }^{21}$.

Destacamos a importância do uso do cinto para a prevenção do prolapso em pacientes com abdômen globoso ou que realizam atividade física e no tratamento daqueles que apresentam prolapso, para evitar o agravamento. Em relação ao eritema, deve-se enfatizar a proteção da pele, o ensino do autocuidado e a avaliação periódica. Essas adequações de indicações de equipamentos somente é possível com a caracterização do perfil de saúde dessa clientela, para otimizar a gestão especializada dos recursos materiais e humanos.

O aparecimento das complicações é consequência de consultas pré-operatórias precárias, em especial da falta de demarcação de estoma no pré-operatório, pois a má localização dificulta o autocuidado, a visualização da pele e a troca de equipamentos. A má adaptação da base do equipamento à pele deve-se principalmente à escolha inadequada do local de confecção da estomia na parede abdominal, ou seja, proximidade às depressões, pregas cutâneas, proeminências ósseas, entre outros acidentes anatômicos que poderão resultar em vazamento do conteúdo drenado pela estomia ou impossibilidade de adesividade da base do equipamento na pele ${ }^{22}$.

As limitações deste estudo estão relacionadas com a deficiência nos registros de informações, a falta de organização e a atualização do banco de dados no programa de saúde, além da falta de equipamento coletor para distribuição e dificuldade de deslocamento das pessoas com estoma intestinal, que, para terem acesso aos equipamentos, enviavam terceiros para recebê-los e cuja ausência nas reuniões aumenta a prevenção de complicações como eritema e prolapso, identificadas neste estudo.

\section{CONCLUSÃO}

Com o perfil sociodemográfico e clínico das pessoas estomizadas residentes em Teresina (PI), identificamos que a maioria era composta por pacientes do sexo masculino, com idade ente 60 e 80 anos, casados ou mantinham união estável, possuíam ensino fundamental incompleto ou eram analfabetos, renda familiar de até 3 salários mínimos, praticantes do catolicismo, aposentados e residiam em casa própria.

No que diz respeito à causa básica que deu origem às estomias, verificou-se que a maioria das cirurgias estomas foi ocasionada pela neoplasia.

A maioria possuía colostomia, sendo permanente localizada no quadrante inferior esquerdo, com efluente pastoso, de formato redondo, coloração róseo-avermelhada e implantação protrusa na pele, fazia uso de equipamento coletor drenável e de peça única.

Acredita-se que este estudo trouxe maior visibilidade sobre a clientela estomizada atendida para o poder público e para os profissionais de saúde, o que possibilitará traçar estratégias mais eficientes para prevenção, tratamento e reabilitação, com melhoria da qualidade de vida desses pacientes, além da contribuição para o dimensionamento de equipamentos e adjuvantes nesse programa. 


\section{REFERÊNCIAS}

1. Lenza NFB, Sonobe HM, Buetto LS, Santos MG, Lima MS. O ensino do autocuidado aos pacientes estomizados e seus familiares: uma revisão integrativa. Rev Bras Promoção a Saúde. 2013;26(1):139-45.

2. Silva AC, Silva GNS, Cunha RR. Caracterização de pessoas estomizadas atendidas em consulta de enfermagem do serviço de estomoterapia do município de Belém-PA. Rev. ESTIMA. 2012;10(1):20-7.

3. Instituto Nacional de Câncer (INCA) [Internet]. [cited 2014 Apr 10]. Available from: http://www2.inca.gov.br/wps/wcm/ connect/tiposdecancer/site/home/colorretal/definicao+

4. Geraldi I. Associação Brasileira de Estomaterapia - SOBEST. Campinas: Editora Pinti; 2012.

5. Brasil. Ministério da Saúde. Secretaria de Atenção à Saúde. Política Nacional de Saúde da Pessoa com Deficiência. 1 a ed. Brasília: Ministério da Saúde; 2010.

6. Brasil. Ministério da Saúde. Secretaria de Atenção à Saúde. Portaria n 400, de 16 de novembro de 2009 [Internet]. Brasília: Ministério da Saúde; 2009. [cited 2013 May 23]. Available from: http://www.mprs.mp.br/areas/dirhum/ arquivos/p_sas_400_2009_ostomizados.pdf

7. Luz MHBA, Andrade DS, Amaral HO, Bezerra SMG, Benício CDAV, Leal ACA. Caracterização dos pacientes submetidos a estomas intestinais em um hospital público de Teresina-PI. Texto Contexto - Enferm. 2009;18(1):140-6.

8. Fernandes RM, Miguir ELB, Donoso TV. Perfil da clientela estomizada residente no município de Ponte Nova, Minas Gerais. Rev Bras Colo-proctol. 2010;30(4):385-92.

9. Figueiredo W. Assistência à saúde dos homens: um desafio para os serviços de atenção primária [Internet]. Ciênc Saúde Coletiva. 2005;10(1):104-9. [cited 2014 Feb 25]. Available from: http://www.scielo.br/scileo.php?script=sci_ arttext\&pid=\$1413-81232005000100017\&nrm=iso

10. Santos CHM, Bezerra MM, Bezerra FMM, Paraguassu BR. Perfil do paciente ostomizado e complicações relacionadas ao estoma. Rev Bras Colo-proctol. 2007;27(1):16-9.

11. Batista MRFF, Rocha FCV, Silva DMG, Silva FJG Jr. Autoimagem de clientes com ostomia em relação à bolsa coletora [Internet]. Rev Bras Enferm. 2011;64(6):1043-7. [cited 2014 Mar 01]. Available from: http://www.scielo.br/pdf/reben/v64n6/v64n6a09.pdf
12. Silva AC, Silva GNS, Cunha RR. Caracterização de pessoas estomizadas atendidas em consulta de enfermagem do serviço de estomoterapia do município de Belém-PA. Rev. ESTIMA. 2012;10(1):20-7.

13. Guarisi M. Rastreamento, Diagnóstico e tratamento das lesões Precursoras e do câncer Invasor do Colo Uterino no município de Franco da Rocha, SP [Internet]. Rev Bras Cancerol. 2004;50(1):7-15. [cited 2014 Apr 23]. Available from: http://www.inca.gov.br/rbc/n/n_50/v01/pdf/ ARTIGO01.pdf

14. Sonobe HM, Barichello E, Zago MMF. A visão do colostomizado sobre o uso da bolsa de colostomia. Rev Bras Cancerol. 2002;48(3):341-8.

15. Vujnovich A. Pre and post-operative assessment of patient with a stoma [Internet]. Nursing Standart. 2001;22:121-9. [cited 2013 Oct 20]. Available from: http://rcnpublishing. com/doi/abs/10.7748/ns2008.01.22.19.50.c6315

16. Cottam J, Richards K. National audit of stoma complications within 3 weeks of surgery [Internet]. Gastrointestinal Nursing. 2006;4(8):34-9. [cited 2013 Oct 20]. Available from: http://www.internurse.com/cgibin/go.pl/library/article.cgi?ui d=22084; article=gn_4_8_34_39;format=pdf

17. Crema E, Silva R. Estomas: uma abordagem interdisciplinar. Uberaba: Editora Pinti; 1997.

18. Netina SMB. Prática de enfermagem. 7a ed. Rio de Janeiro: Guanabara Koogan; 2007.

19. Cesaretti, IUR. Dermatite Periostomal: da etiologia ao tratamento e assistência de enfermagem. Acta Paul Enferm. 1997;10(2):80-7.

20. Dukes S. Considerations when caring for a person with a prolapsed stoma. Br J Nurs. 2011;19(17):1-5.

21. Williams J. Evaluating skin care problems in people with stomas [Internet]. Br J Nurs. 2010;19(17):6-15. [cited 2014 Feb 10]. Available from: http://ncbi.nlm.nih.gov/ pubmed/20871505

22. Manjoubi B, Goodarki, KK, Mohammad-Sadegui H. Quality of life in stomas patients: appropriate and inappropriate stomas sites [Internet]. World J Surg. 2010;34(1):147-52. [cited 2013 Apr 22]. Available from: http://www.ncbi.nlm.nih. gov/pubmed/19936980 


\title{
Ações Preventivas para Úlcera por Pressão em Idosos com Declínio Funcional de Mobilidade Física no Âmbito Domiciliar*
}

\author{
Preventive Actions against Pressure Ulcers in Elderly with Functional Decline of \\ Physical Mobility at Home Environment
}

\section{Acciones Preventivas a las Úlceras por Presión en Ancianos con Declino Funcional de la Movilidad Física en el Entorno Familiar}

Josefa Danielma Lopes Ferreira', Elizabeth Souza Silva de Aguiar², Carla Lidiane Jácome de Lima',
Karen Krystine Gonçalves de Brito ${ }^{3}$, Marta Miriam Lopes Costa', Maria Júlia Guimarães Oliveira Soares

\begin{abstract}
RESUMO
As úlceras por pressão são complicações possíveis de ocorrer em pessoas em situação de fragilidade, principalmente naquelas com restrição de mobilidade e idade avançada. Este estudo teve como objetivo investigar as medidas preventivas para úlceras por pressão, utilizadas em idosos com declínio funcional de mobilidade física que vivem em domicílio. Trata-se de um estudo transversal com abordagem quantitativa, tipo inquérito domiciliar. A amostra foi composta por 25 idosos domiciliados no município de João Pessoa, na Paraíba. Foi aprovado pelo Comitê de Ética e Pesquisa do Centro de Ciências da Saúde da Universidade Federal da Paraíba, sob protocolo 124/11. Dos pesquisados, 72\% eram do sexo feminino, com faixa etária prevalente (64\%) de 80 anos ou mais; dos entrevistados, 19 (72\%) eram cuidadores informais, 6 (24\%) eram formais e apenas 1 (4\%) foi o próprio idoso. As medidas preventivas incluíram manter a pele limpa (84\%); examinar a pele diariamente (64\%); usar redistribuidores de pressão (52\%), aplicar hidratante (56\%) e usar colchão de espuma (60\%). Neste estudo, embora fossem praticadas algumas ações preventivas para úlceras por pressão, a dinâmica domiciliar encontrada apontou a necessidade de as Equipes de Saúde da Família e os serviços de atendimento domiciliares atuarem melhor quanto à prevenção de agravos, como as úlceras por pressão e suas complicações.
\end{abstract}

DESCRITORES: Estomaterapia. Enfermagem. Idoso. Úlcera por pressão. Prevenção.

\begin{abstract}
Pressure ulcers are possible complications that occur in people on fragility situations, especially those with restricted mobility and advanced age. This study aimed at investigating the preventive measures against pressure ulcers that were used in elderly people with functional decline of physical mobility who live at home. This is a cross-sectional study with a quantitative approach, of household survey type. The sample consisted of 25 elderly living in the city of João Pessoa, Paraíba state, Brazil. It was approved by the Research Ethics Committee of the Health Sciences Center from Universidade Federal do Paraíba, under protocol 124/11. A total of 72\% of the respondents was women; the most prevalent age group (64\%) was 80 years or older; 19 (72\%) of the respondents were informal caregivers, 6 (24\%) were formal and only 1 (4\%) was the elder himself. The preventive measures included keeping the skin clean (84\%), examining the skin daily (64\%), using pressure relievers (52\%), using moisturizer (56\%) and a foam mattress (60\%). In this study, although some preventive actions against pressure ulcer were taken, household dynamics pointed to the need for better performance of Family Health Teams and home care services regarding prevention of injuries, such as pressure ulcer and its complications.
\end{abstract}

DESCRIPTORS: Stomatherapy. Nursing. Elderly. Pressure ulcers. Prevention.

*Trabalho de conclusão de curso apresentado à Universidade Federal da Paraíba (UFPB) como requisito para obtenção do título de Bacharel e Licenciatura em Enfermagem, março de 2013 - João Pessoa (PB), Brasil.

'Enfermeira; Mestranda do Programa de Pós-Graduação em Enfermagem, Universidade Federal da Paraíba (UFPB) - João Pessoa (PB), Brasil. Endereço para correspondência: Rua Haroldo Monteiro Freire, 77 - José Américo de Almeida - CEP: $58073-597$ - João Pessoa (PB), Brasil -

E-mail: danielma_jp@hotmail.com

Enfermeira; Especialista em Estomaterapia; Mestre em Enfermagem pela UFPB - João Pessoa (PB), Brasil.

Enfermeira; Mestre em Enfermagem pela UFPB - João Pessoa (PB), Brasil.

4Enfermeira; Professora Doutora da Graduação e do Programa de Pós-Graduação em Enfermagem, UFPB - João Pessoa (PB), Brasil.

Artigo recebido em: 14/11/2013 - Aceito para publicação em: 09/06/2015 


\section{RESUMEN}

Las úlceras por presión son las posibles complicaciones que ocurren en personas en situaciones de fragilidad, especialmente aquellos con movilidad reducida y edad avanzada. Este estudio tuvo como objetivo investigar las medidas preventivas contra la úlcera por presión utilizadas en ancianos con declive funcional de la movilidad física, que viven en domicilios. Se trata de un estudio transversal, con abordaje cuantitativa, tipo encuesta domiciliar. La muestra se compuso por 25 ancianos que viven en la ciudad de João Pessoa, Paraíba, Brasil. El estudio fue aprobado por el Comité de Ética y Pesquisa del Centro de Ciencias de la Salud de la Universidade Federal da Paraíba, con el protocolo $124 / 11$. Los $72 \%$ de los encuestados eran mujeres, el grupo de edad más frecuente (64\%) era de 80 y más años, 19 de los encuestados (72\%) eran cuidadores informales, 6 (24\%) eran formales y sólo 1 (4\%) fue el propio anciano. Las medidas preventivas incluyeran mantener la piel limpia (84\%), examinar la piel todos los días (64\%), usar aliviadores de la presión (52\%), aplicarse la crema hidratante (56\%) y usar el colchón de espuma (60\%). En este estudio, aunque algunas acciones preventivas contra la úlcera por presión fuesen practicadas, la dinámica domiciliar encontrada señaló la necesidad de un mejor desempeño de los Equipos de Salud Familiar y los servicios de cuidado en domicilio en cuanto a la prevención de lesiones, como la úlcera por presión y suyas complicaciones.

DESCRIPTORES: Estomaterapia. Enfermería. Ancianos. Úlceras por presión. Prevención.

\section{INTRODUÇÃO}

O fato mais marcante para as sociedades atuais é o processo de envelhecimento populacional observado em todos os continentes. $\mathrm{O}$ aumento do número de idosos, tanto proporcional quanto absoluto, impõe mudanças nos modos de pensar e viver a velhice na sociedade. A longevidade alcançada pelo homem e, portanto, o aumento desta população são um tema de debates entre pesquisadores, gestores sociais e políticos de vários países do mundo ${ }^{1}$.

O Censo Populacional de 2010 do Instituto Brasileiro de Geografia e Estatística (IBGE) aponta que a sociedade brasileira caminha para o envelhecimento. Idosos com idade superior a 65 anos cresceram de 4,8\%, em 1991; 5,9\%, em 2000, para 7,4\%, em 2010. Segundo o IBGE, esse aumento é uma relação entre a ampliação da expectativa de vida e a redução abrupta da mortalidade infantil, portanto, há uma tendência a se evidenciarem mais pessoas idosas em detrimento dos mais jovens na população. Somado a esse fato, também ocorre que os brasileiros optam por constituir cada vez mais tarde menos filhos ${ }^{2}$.

O envelhecimento é um processo natural que ocorre durante o curso de vida do indivíduo e submete o corpo humano a inúmeras mudanças físicas e funcionais, com repercussões nas condições de saúde física e psicológica. Muitas dessas alterações são progressivas, como aquelas na estrutura da pele e dos músculos, as quais colocam o idoso em risco para o desenvolvimento das úlceras por pressão (UP) ${ }^{3}$.

As UP são complicações possíveis de ocorrer, principalmente, em pessoas com declínio de mobilidade física e idade avançada ${ }^{4}$. São consideradas como lesões teciduais que podem ser causadas por pressão constante, prolongada ou não, fricção, cisalhamento ou pela combinação deles. Portanto, além de a UP ocasionar dano tissular, pode provocar inúmeras dificuldades e agravar o estado clínico do paciente, especialmente naqueles com restrição na mobilização do corpo ${ }^{5}$.

Estudos nacionais relacionados à prevalência e incidência da UP apresentam índices variados quanto a sua ocorrência e/ ou presença, em função das diferentes metodologias empregadas, ao perfil dos sujeitos da amostra e aos diversificados cenários de pesquisa, tais como unidades de internação hospitalar, instituições de longa permanência para idosos e domicílios. Em um estudo realizado nas clínicas de um hospital universitário em São Paulo, identificou-se uma prevalência de 11,4\%, no primeiro momento, e 10,3\%, no segundo, o que corresponde a uma média de $10,9 \%$ de $\mathrm{UP}^{6}$. Pesquisas desenvolvidas nos domicílios de João Pessoa, na Paraîba, e Teresina, no Piauí, a partir da atenção primária com pessoas acamadas ou em cadeira de rodas, identificaram uma presença da UP de 10 e 23,52\%, respectivamente ${ }^{7}$. Ademais, as UP são consideradas problemas socioeconômico e educacional, pois o seu desenvolvimento representa um importante impacto financeiro para as instituições. Por essa razão, deve-se investir na prevenção, uma vez que os seus custos são inferiores àqueles demandados para o tratamento. O cuidado das UP ocupa o terceiro lugar em gastos em saúde, sendo ultrapassado somente por aqueles com tratamento de câncer e cirurgia cardíaca. Além disso, quando um paciente desenvolve uma UP, sua atenção demanda $50 \%$ a mais do tempo dispensado pela equipe de enfermagem, reforçando os benefícios dos cuidados preventivos tanto para o paciente e a equipe quanto pelo sistema de saúde em geral ${ }^{8}$. 
Considerando o poder incapacitante e o ônus das UP, algumas medidas de baixa tecnologia podem ser utilizadas tanto em ambientes hospitalares quanto domiciliares, tais como: promover a integridade da pele, deixando-a limpa, sem umidade e hidratada com óleos naturais ou loções hidratantes; utilizar fraldas absorventes; realizar constantemente o controle do excesso de pressão sobre as proeminências ósseas, efetivando a descompressão local e o reposicionamento com a mudança de decúbito em intervalos regulares e de forma sistemática; oferecer um adequado suporte nutricional, pois tal estado reduzido, além de prejudicar a elasticidade da pele, em longo prazo, desencadeia a anemia e reduz a oxigenação nos tecidos 9 .

Adicionalmente, é imprescindível empregar escalas de predição para o risco das UP, como as escalas de Norton, Gosnell, Waterlow e Braden, as quais são aplicadas para qualificar o diagnóstico obtido pelo raciocínio clínico, com base no de enfermagem?

De uma maneira geral, dado que compete aos serviços de saúde, por meio de suas equipes, prevenir e tratar as UP, os cuidados no processo de prevenção/tratamento/cicatrização devem ser uma preocupação constante dos profissionais e cuidadores, os quais precisam estar motivados para a busca de informações e novos recursos que permitam minimizar a morbimortalidade desencadeada por essas lesões e oferecer ao paciente a melhor assistência possível ${ }^{10}$.

Diante do exposto, partindo da continuidade de uma dissertação de Mestrado, surge a atual pesquisa, com vistas a colaborar para se repensar a assistência em saúde aos gestores e profissionais de saúde, no que concerne um planejamento adequado e uma implementação de ações para a prevenção de lesões cutâneas, tais como as UP, especialmente em pessoas idosas no âmbito domiciliar. Sendo assim, este estudo teve como objetivo investigar as medidas preventivas para UP, utilizadas em idosos com declínio funcional de mobilidade física que vivem em domicilio.

\section{MÉTODOS}

Estudo quantitativo, do tipo transversal, o qual representa a continuidade de uma investigação, mais especificamente uma dissertação de Mestrado, que foi desenvolvida na Universidade Federal da Paraíba (UFPB), sobre o risco de UP em idosos com declínio funcional de mobilidade física, residentes nos domicílios de João Pessoa, na Paraíba ${ }^{11}$. O presente estudo, portanto, refere-se à investigação das medidas preventivas para UP praticadas nesses idosos com declínio funcional de mobilidade física.
Vale destacar que tal dissertação integrou uma pesquisa maior chamada "Condições de vida e de saúde de idosos de Ribeirão Preto-SP e de João Pessoa-PB: um estudo comparado", que avaliou as condições de saúde dos idosos com idade igual ou superior a 60 anos, residentes na área urbana do município de João Pessoa, Paraíba.

$\mathrm{Na}$ busca de compreender melhor o universo amostral, haja vista que o presente estudo selecionou sua amostra partindo de outra pesquisa, a seguir, será descrito o processo desde a sua origem.

O processo amostral foi realizado por conglomerados de duplo estágio, o qual considerou a contagem da população pelo IBGE em 2007, visto que não foi possível utilizar as informações do Censo do IBGE de 2010, pois não haviam sido publicadas na ocasião do cálculo amostral. Para mensurar a amostra, foram adotados os seguintes parâmetros estatísticos: ela foi definida em 240 indivíduos, o que garantiu um erro máximo de 6,3\% com $95 \%$ de probabilidade, considerando uma população referência da cidade de João Pessoa de 61.281 idosos de 60 anos e mais $^{12}$. Para alcançar o valor de $n=240$, planejou-se o sorteio de 20 setores censitários entre os 617 existentes. Em seguida, foram visitados 12 idosos por cada um. Desses 240 sujeitos que fizeram parte do inquérito domiciliar, foram identificadas 51 pessoas com limitação física, 25 das quais apresentavam algum risco para UP, conforme a Escala de Braden, que é de risco para UP, incluindo seis parâmetros: percepção sensorial, umidade, atividade, mobilidade, nutrição, fricção e cisalhamento ${ }^{13}$. Assim, os 25 idosos citados perfizeram a amostra do presente estudo.

Os critérios de inclusão foram: pessoas com 60 anos ou mais; residentes na área urbana de João Pessoa, Paraíba; que apresentavam algum nível de risco para UP segundo a Escala de Braden; escore $\leq 18$ - índices iguais ou menores que 18 classificam as pessoas em níveis de risco para UP. Em suma, o não atendimento a um desses critérios implicou na não inclusão de idosos na amostra.

Durante abril e junho de 2011, transcorreu a coleta inicial dos dados, a qual identificou os idosos com declínio funcional de mobilidade física com algum risco para UP segundo a Escala de Braden aplicada; em seguida, entre outubro de 2011 a janeiro de 2012, as pesquisadoras retornaram aos domicílios para pesquisar as medidas preventivas para UP praticadas com os idosos estudados. Para tanto, utilizou-se a técnica de entrevista com o idoso e/ou cuidador, além de observação não participativa. Para essa etapa, utilizou-se um instrumento elaborado pelas pesquisadoras, que passou por pré-teste e abordou aspectos sociodemográficos e cuidados para a prevenção de UP. 
Os dados foram duplamente digitados e validados em uma planilha do programa Microsoft Excel, e os cálculos estatísticos foram realizados no software SPSS (Statistical Package for the Social Sciences), versão 20.0.

A pesquisa foi submetida à apreciação do Comitê de Ética e Pesquisa do Centro de Ciências da Saúde da UFPB, sob protocolo 124/11.

\section{RESULTADOS}

Dentre os 25 idosos pesquisados, a maioria dos investigados, 18 (72\%), era do sexo feminino; quanto à idade, 16 (64\%) estavam na faixa etária de 80 anos ou mais; seis deles (24\%) tinham de 70 a 79 anos, e apenas três (12\%) estavam com 60 a 69 anos. A cor da pele predominante foi a branca, com um total de 15 (64\%). Verificou-se que todos tinham cuidador domiciliar, sendo 19 (72\%) deles informais, como familiares, e seis (24\%) formais. A presença de tal profissional deve-se ao perfil desses idosos, visto que são pessoas com declínio de mobilidade física e a maioria dependente de cuidados, portanto se tratava de pessoas com dificuldades para deambular, usavam cadeiras de rodas ou ainda estavam totalmente acamadas.

Quanto às condições de saúde identificadas, merecem destaque: a doença neurológica (especificamente na maioria dos idosos com 80 anos ou mais), o acidente vascular encefálico, a incontinência urinária e/ou fecal, as osteoartrites, a hipertensão arterial sistêmica e a visão prejudicada.

Concernente às medidas preventivas implementadas no domicílio para evitar ou retardar o desenvolvimento de UP, as mais frequentes foram: manter a pele limpa (84\%), examinar a pele diariamente (64\%) e usar aliviadores de pressão (52\%), conforme a descrição na Tabela $1^{14}$.

Os idosos acamados e em uso das cadeiras de rodas, ou aqueles incapazes de se posicionarem, são mais propensos para a formação da UP, portanto devem receber atenção específica e sistemática a fim de evitar fatores adicionais de riscos que resultem em lesões nos tecidos. Logo, no presente estudo, 21 (84\%) não realizavam a movimentação dos membros inferiores (MMII), 21 (84\%) não efetivavam a descompressão local, 20 (80\%) não faziam o reposicionamento da pessoa sentada ou em uso cadeiras de rodas.

Com relação aos produtos utilizados após a higienização da pele, os mais citados foram as loções hidratantes, utilizadas por 14 (56\%), como mostra a Tabela 2.

Também foi possível investigar as superfícies de suporte utilizadas pelos idosos pesquisados, conforme apresentado na Tabela 3 , em que se destaca o uso do colchão de espuma por 15 participantes (60\%).

Tabela 1. Medidas preventivas utilizadas para úlcera por pressão nos idosos que vivem em domicílios (n-=25). João Pessoa, Paraíba, 2011/2012.

\begin{tabular}{|c|c|c|c|c|}
\hline \multirow{2}{*}{ Variável } & \multicolumn{2}{|c|}{ Sim } & \multicolumn{2}{|c|}{ Não } \\
\hline & $\mathrm{n}(\%)$ & IC95\% & $\mathrm{n}(\%)$ & IC95\% \\
\hline Massagem de conforto** & $1(4)$ & $0-12$ & $24(96)$ & $88-100$ \\
\hline Elevação da cabeceira a $30^{\circ}$ & $3(12)$ & $0-28$ & $22(88)$ & $72-100$ \\
\hline Lençóis sem rugas, pregas ou sujidade & $8(32)$ & $16-48$ & $17(68)$ & $52-84$ \\
\hline $\begin{array}{l}\text { Uso de lençol móvel ou forro da cama para } \\
\text { movimentar o idoso acamado }\end{array}$ & $1(4)$ & $0-12$ & $24(96)$ & $88-100$ \\
\hline Alimentação equilibrada & $5(20)$ & $4-36$ & $20(80)$ & $64-96$ \\
\hline Pele limpa & $21(84)$ & $68-96$ & $4(16)$ & $4-32$ \\
\hline Uso dos redistribuidores de pressão & $13(52)$ & $32-72$ & $12(48)$ & $28-68$ \\
\hline Exame da pele diariamente & $16(64)$ & $44-84$ & $9(36)$ & $16-56$ \\
\hline Elevação dos membros inferiores & $4(16)$ & $4-32$ & $21(84)$ & $68-96$ \\
\hline Levantar para descompressão local & $4(16)$ & $4-28$ & $21(84)$ & $72-96$ \\
\hline Mudança de decúbito & $1(4)$ & $0-12$ & $24(96)$ & $88-100$ \\
\hline $\begin{array}{l}\text { Reposicionamento da pessoa sentada ou em cadeiras } \\
\text { de rodas }\end{array}$ & $5(20)$ & $4-40$ & $20(80)$ & $60-96$ \\
\hline
\end{tabular}

IC: intervalo de confiança; *Embora essa ação esteja apresentada na tabela, destacamos que ela é contraindicada sobre as proeminências ósseas e/ou áreas hiperemiadas, na presença de inflamação aguda e onde existe a possibilidade de vasos sanguíneos danificados ou pele frágil ${ }^{14}$. 
Tabela 2. Uso de soluções para manter a integridade da pele em idosos que vivem em domicílios (n=25). João Pessoa, Paraíba, 2011/2012.

\begin{tabular}{|c|c|c|c|c|}
\hline \multirow{2}{*}{ Variável } & \multicolumn{2}{|c|}{ Sim } & \multicolumn{2}{|c|}{ Não } \\
\hline & n (\%) & IC95\% & $\mathrm{n}(\%)$ & IC95\% \\
\hline Óleos vegetais & $6(24)$ & $8-40$ & $19(76)$ & $60-92$ \\
\hline $\begin{array}{l}\text { Loções } \\
\text { hidratantes }\end{array}$ & $14(56)$ & $36-76$ & $11(44)$ & $24-64$ \\
\hline Outros* & $7(28)$ & $12-48$ & $18(72)$ & $52-88$ \\
\hline
\end{tabular}

*Pomadas, soluções caseiras, pasta d'água; IC: intervalo de confiança.

Tabela 3. Superfícies de suporte utilizadas pelos idosos. João Pessoa, Paraíba, 2011/2012.

\begin{tabular}{|c|c|c|c|c|}
\hline \multirow{2}{*}{ Variável } & \multicolumn{2}{|c|}{ Sim } & \multicolumn{2}{|c|}{ Não } \\
\hline & n (\%) & IC95\% & n (\%) & IC95\% \\
\hline & $15(60)$ & $40-80$ & $10(40)$ & $20-60$ \\
\hline Colchão de ar* & $2(8)$ & $0-20$ & $23(92)$ & $80-100$ \\
\hline $\begin{array}{l}\text { Colchão de } \\
\text { água }\end{array}$ & $1(4)$ & $0-12$ & $24(96)$ & $88-100$ \\
\hline $\begin{array}{l}\text { Colchão de } \\
\text { caixa de ovo }\end{array}$ & $6(24)$ & $8-40$ & $19(76)$ & 60-92 \\
\hline Rede ${ }^{\star \star}$ & $1(4)$ & $0-12$ & $24(96)$ & $88-100$ \\
\hline
\end{tabular}

*A superfície citada refere-se ao colchão de ar estático; **Culturalmente usadas por sertanejos no Nordeste; IC: intervalo de confiança.

\section{DISCUSSÃO}

Estudos nacionais apontam o sexo feminino como o grupo de maior sobrevida em detrimento do masculino, em virtude do autocuidado, especialmente com a saúde, praticado por elas ${ }^{15,16}$. Os homens não têm a cultura da prevenção, uma vez que não procuram os serviços de saúde com a mesma frequência que as mulheres, pois é um costume masculino não demonstrar a necessidade de cuidados, já que, de forma consciente ou inconsciente, essa é uma característica fraca, e como tal, não combina com a concepção masculina de homem forte e viril ${ }^{17}$.

Quanto à idade, verificaram-se diferenças percentuais nas faixas etárias, com o maior risco para UP entre os idosos octogenários ou com mais de 80 anos. Pesquisas referem que existe um relacionamento linear entre o aumento da idade dos pacientes e da ocorrência de UP, pois, além da própria fisiologia do envelhecimento, a prevalência das condições crônicas que ocorrem nessa época da vida leva à diminuição da capacidade funcional nos idosos, e essas situações somadas contribuem para elevar o risco de UP ${ }^{15,16}$.

Cuidar de um idoso no domicílio é uma tarefa árdua. $\mathrm{Na}$ maioria das vezes, é um papel desempenhado por familiares, especialmente do gênero feminino, como esposa, filha, neta ou irmã. Em um estudo realizado em Pelotas, no estado do Rio Grande do Sul, os familiares eram responsáveis pelo cuidado domiciliar com os idosos, desempenhado, principalmente, pelo esposo/a. Estudos mostram que é crescente a sua necessidade, sendo que, entre os cuidadores, prevalecem os familiares (cônjuge, filhos, irmãos etc.), também chamados de informais, em detrimento dos cuidadores formais ${ }^{18}$.

Vale destacar que cuidadores são aqueles que prestam cuidados ao idoso dependente e podem ou não ter vínculo familiar. Existem dois tipos: o cuidador formal e o informal. O primeiro é um profissional preparado em uma instituição de ensino para prestar cuidados no domicílio, segundo as necessidades do idoso. Por outro lado, o informal advém da dependência e necessidade de cuidados de um familiar, amigo, vizinho ou outros grupos de pessoas, o qual não é economicamente remunerado pela atenção desenvolvida ${ }^{19}$.

Neste estudo, também foram encontrados problemas de saúde, como déficits cognitivos determinados pela senilidade e pelas doenças de base, além de distúrbios cardiovasculares, neurológicos e degenerativos que trazem diversas consequências, desde a inabilidade de autocuidado até perdas sensitivas e de mobilidade física, as quais, juntas, predispõem a pessoa ao risco de UP, assim como o surgimento de complicações, uma vez que a lesão representa uma porta de entrada para infecções ${ }^{11}$. As medidas preventivas têm custos, porém os gastos com a hospitalização ou o prolongamento do tempo de tratamento das lesões são superiores. Várias medidas preventivas podem ser adotadas para evitar o desenvolvimento da UP, bem como o emprego dos instrumentos de avaliação e predição de risco, tais como as várias escalas validadas, a exemplo a Escala de Braden, utilizada no presente traba1 ho ${ }^{9}$. Partindo desse princípio, existem medidas preventivas que podem ser realizadas no domicílio do idoso em risco de UP, algumas apresentadas na Tabela 1 , as quais foram investigadas e serão discutidas adiante.

Dentre as ações de prevenção encontradas, houve maior prevalência nas medidas relacionadas à manutenção de higiene cutânea (84\%) e ao exame físico cutâneo (64\%). A pele seca pode ser um sinal de desidratação, que se caracteriza pela diminuição de água, perda de eletrólitos totais do organismo, pele com elasticidade diminuída e pouca tolerância ao calor, à fricção e à pressão, tornando-a suscetível à 
ruptura. Assim, examinar a pele e manter a sua higienização adequada são medidas simples que podem diminuir o risco de UP. Hidratar a pele seja com produtos utilizados após o banho ou a troca de fraldas ou o simples ato de ingerir água também ajudam ${ }^{18}$. Um estudo com abordagem de caráter qualitativo, realizado em uma Unidade de Terapia Intensiva (UTI) adulto de um hospital público do município de Chapecó, em Santa Catarina, mostra que o banho é o melhor momento para examinar a pele e avaliar a eficácia de outras medidas preventivas 9 .

No que se refere à elevação da cabeceira a $30^{\circ}$, a manutenção dos lençóis sem rugas, pregas ou sujidade e ao uso de lençol móvel ou forro da cama para movimentar o idoso acamado, poucos, respectivamente 12,32 e $4 \%$, empregavam essas medidas no cotidiano. Outros estudos indicaram que atos importantes, como o uso do lençol móvel, a elevação da cabeceira a $30^{\circ}$ e a manutenção dos lençóis limpos, sem pregas ou rugas, também foram pouco utilizados pelos idosos pesquisados ${ }^{16}$. Não se deve elevar o leito da cabeceira da cama acima dos $30^{\circ}$ por dificultar os retornos dos fluxos sanguíneos e linfáticos e favorecer a fricção e/ou o cisalhamento da pele ${ }^{14}$.

Quanto à mudança de decúbito, à descompressão local, ao reposicionamento de pessoa sentada ou em cadeiras de rodas e à elevação dos MMII, também foram ações poucos efetivadas pelos pesquisados. Estudos apresentam que a mudança de decúbito é uma conduta importante para a prevenção de UP, que deve ser realizada a cada duas horas em indivíduos acamados. Essas são importantes para diminuir-se o risco. Já para os que permanecem sentados por períodos longos, o reposicionamento deve ser realizado a cada hora e com a proteção de almofadas de gel ou ar, porém dispositivos do tipo roda d'água não devem ser empregados, pois as mudanças de posição frequentes e o uso de almofadas reduzem a pressão em proeminências ósseas ${ }^{20,21}$.

O reposicionamento de pessoa sentada ou em cadeiras de rodas, por sua vez, alterna ou alivia a pressão sobre áreas suscetíveis e diminui o risco do desenvolvimento de UP. Travesseiros e coxins são materiais facilmente disponíveis e que podem ser utilizados para auxiliar a redistribuição da pressão, por exemplo, na elevação dos MMII. Quando utilizados de forma apropriada, podem expandir a superfície que suporta o peso. Geralmente, a pele de pacientes com risco para UP rompe-se facilmente durante o reposicionamento, portanto, deve-se tomar cuidado com a fricção durante este procedimento ${ }^{14}$.
A alimentação estava pouco equilibrada nos idosos investigados, apenas $20 \%$ tinham essa preocupação. Sabe-se que a análise do índice de massa corporal (IMC) acima e abaixo da média representava risco para o desenvolvimento de UP. Em pacientes emagrecidos, em que a quantidade de gordura é mínima nas proeminências ósseas, é mais propensa a maior pressão sobre essas áreas. Porém, se o paciente é obeso, também se mantém um risco para o desenvolvimento da úlcera em função da restrição de mobilidade física ${ }^{16}$. Acrescente-se, ainda, a importância de proporcionar suporte nutricional adequado, pois o estado nutricional reduzido, além de prejudicar a elasticidade da pele em longo prazo, leva à anemia e diminuição de oxigênio nas células 9 .

No que diz respeito ao uso de soluções para manter a integridade da pele dos idosos (Tabela 2), as loções hidratantes foram as mais utilizadas (56\%). Os hidratantes devem ser aplicados suavemente, e a pele deve ser limpa frequentemente com água morna e um produto de limpeza neutro, sem sabonete, pois este provoca ressecamento da pele. Essas intervenções, como o ato de aplicar hidratante e examinar a pele durante o banho ou a troca de fralda, por exemplo, refletem o processo de estar atento e identificar precocemente fatores de risco para UP'. Durante a hidratação da pele, não devem ser massageadas áreas de proeminências ósseas ou hiperemiadas. A aplicação de hidratante deve ser realizada com movimentos suaves e circulares ${ }^{14}$.

Medidas como controle do excesso de pressão sobre as proeminências ósseas podem ser empregadas, protegendo-as com travesseiros e almofadas de espuma ou colchões de espuma, ar estático e dinâmico, gel e água, pois redistribuem o peso e reduzem a pressão. São também chamados de aliviadores de pressão, apresentados na Tabela 3. Neste estudo, o colchão de espuma foi o mais utilizado pelos idosos (60\%), sendo que, muitas vezes, estava associado ao uso do colchão de ar ou caixa de ovo. Superfícies de apoio específicas, como colchões, redistribuem a pressão que o corpo do paciente exerce sobre a pele e os tecidos subcutâneos. Se a mobilidade do paciente está comprometida e a pressão nessa interface não é redistribuída, esta poderá prejudicar a circulação, levando ao surgimento da úlcera ${ }^{14}$.

Esses resultados evidenciam as características do paciente e do processo de cuidar; entretanto, aspectos referentes à estrutura familiar e àquela oferecida pelos serviços para a assistência domiciliária precisam ser investigados mais atentamente, de forma a se compreender mais o problema. 


\section{CONCLUSÃO}

Nesta pesquisa, foram identificadas as seguintes ações prioritárias de medidas preventivas para prevenir as UP: manter a pele limpa, examiná-la e hidratá-la diariamente e utilizar redistribuidores de pressão. Ressalta-se que, dentre as diversas ações para prevenção de UP, houve predominância de três ações. Portanto, conclui-se que a maioria dos pesquisados não utilizava as medidas preventivas de forma eficaz, muito embora, neste estudo, $100 \%$ deles demonstrassem risco para desenvolver a lesão. Assim, infere-se que os cuidadores não tinham o preparo adequado para a realização dessas medidas, seja por falta de conhecimentos ou condições financeiras precárias.

Esse apontamento remete que, na dinâmica domiciliar, as Equipes de Estratégias de Saúde da Família e os serviços de atendimento domiciliares devem melhorar a sua atuação quanto à prevenção de agravos, como as UP e as suas complicações. Como é crescente a população de pessoas idosas que necessitam de cuidados especiais, é imprescindível que os profissionais de saúde, especialmente os enfermeiros, atuem na capacitação dos cuidadores, para evitar outros agravos à saúde dos idosos e conferir qualidade de vida melhor para eles.

\section{REFERÊNCIAS}

1. Brasil. Ministério da Saúde. Secretaria de Atenção à Saúde. Departamento de Ações Programáticas e Estratégicas. Atenção à saúde da pessoa idosa e envelhecimento. Brasília; 2010. 44p.

2. Brasil. Instituto Brasileiro de Geografia e Estatística. Sinopse do Censo Demográfico 2010. São Paulo: IBGE; 2011. [citado 21 jul. 2014]. Disponível em: http://www.ibge.gov.br/home/ estatistica/populacao/censo2010/tabelas_pdf/Paraiba.pdf

3. Lima AP, Delgado El. A melhor idade do Brasil: aspectos biopsicossociais decorrentes do processo de envelhecimento. Rev Ulbra Movimento. 2010;1(2):76-91.

4. Freitas MC, Medeiros AB, Guedes MV, Almeida PC, Galiza FT, Nogueira JM. Úlcera por pressão em idosos institucionalizados: análise da prevalência e fatores de risco. Rev Gaúcha Enfermagem. 2011;32(1):143-50.

5. European Pressure Ulcer Advisory Panel (EPUAP), National Pressure Ulcer Advisory Panel (NPUAP). New 2014 Prevention and Treatment of Pressure Ulcers: Clinical Practical Guideline. Europa; EUA; 2009. [citado 20 jul. 2014]. Disponível em: http://www.npuap.org/wp-content/ uploads/2012/02/Final_Quick_Prevention_for_web_2010.pdf

6. da Silva Cardoso JR, Blanes L, Augusto Calil J, Ferreira Chacon JM, Masako Ferreira L. Prevalence of pressure ulcers in a Brazilian Hospital: results of a cross-sectional study. Ostomy Wound Manage. 2010;56(10):52-7.

7. Ferreira JD, Aguiar ES, Soares MJ, Silva MA, Oliveira SH. Risco e prevalência de úlcera por pressão em usuários da rede básica de saúde. Rev Enferm UFPE Online. 2012;6(9):2045-51.

8. Serpa LF, Santos VL, Campanili TC, Queiroz M. Validade preditiva da Escala de Braden para o risco de desenvolvimento de úlcera por pressão em pacientes críticos. Rev Latino-Am Enfermagem. 2011;19(1):1-8.

9. Lise F, Silva LC. Prevenção de úlcera por pressão: instrumentalizando a enfermagem e orientando o familiar cuidador. Acta Sci Health Sci. 2007;29(2):85-9.

10. Mattia AL, Rocha AM, Barbosa MH, Guimarães MA, Borgato MO, Silva SR, Freitas Filho JP. Úlcera por pressão em UTI: fatores de risco e medidas de prevenção. Saúde Col. 2010;7(46):296-9

11. Aguiar ES, Soares MJ, Caliri MH, Costa MM, Oliveira SH. Avaliação da capacidade funcional de idosos associada ao risco de úlcera por pressão. Acta Paul Enferm. 2012;25(Número Especial 1):94-100.

12. Brasil. Instituto Brasileiro de Geografia e Estatística. Censo Demográfico 2007. São Paulo: IBGE; 2007. [citado 21 jul. 2014. Disponível em: http://www.ibge.gov.br/home/ estatistica/populacao/contagem2007/

13. Braden B, Bergstrom N. A conceptual schema for the study of the etiology of pressure sores. Rehab Nurs. 1987;12(1):8-12.

14. Brasil. Ministério da Saúde. Anvisa. Fiocruz. Protocolo para prevenção de úlcera por pressão. Brasília; 2013. [citado 30 jul. 2014]. Disponível em: http://www.hospitalsantalucinda. com.br/downloads/prot_prevencao_ulcera_por_pressao.pdf

15. Chayamiti EM, Caliri MH. Úlcera por pressão em pacientes sob assistência domiciliária. Acta Paul Enferm. 2010;23(1):29-34.

16. Fernandes MG, Costa KN, Santos SR, Pereira MA, Oliveira DS, Brito SS. Risco para úlcera por pressão em idosos hospitalizados: aplicação da Escala de Waterlow. Rev Enferm UERJ. 2012;20(1):56-60.

17. Fernandes LA. O enfermeiro atuando na prevenção das úlceras de pressão. Rev Eletrônica Cuatrimestral Enferm. 2009 [citado 10 jul. 2014];13. Disponível em: http//:www.um.es/eglobal/

18. Duca GF, Thumé E, Hallal PC. Prevalência e fatores associados ao cuidado domiciliar a idosos. Rev Saúde Pública. 2011;45(1):113-20.

19. Cruz DC, Loureiro HA, Silva MA, Fernandes MM. As vivências do cuidador informal do idoso dependente. Rev Enferm Referência. 2010;3(2):127-36.

20. Goes KS, Mabda M, Almeida DT. Úlcera por pressão: um desafio na prática profissional do enfermeiro de Unidade de Terapia Intensiva. Rev Estima. 2007;5(3):29-35.

21. Coêlho AD, Lopes MV, Melo RP, Castro ME. O idoso e a úlcera por pressão em serviço de atendimento domiciliar. Rev Rene. 2012;13(3):639-49. 


\title{
Cuidados de Enfermagem na Incontinência Urinária: um Estudo de Revisão Integrativa
}

\author{
Nursing Care in Urinary Incontinence: a Study of Integrative Review \\ Cuidados de Enfermería en la Incontinencia Urinaria: Estudio de Revisión Integral \\ Marilia Perrelli Valença', Andressa Ferreira Leite Ladislau Albuquerque², Gabriela Maria da Silva Rocha², \\ Ana Priscila Duarte de Aguiar ${ }^{2}$
}

\section{RESUMO}

Este estudo teve como objetivo verificar os principais cuidados de enfermagem na assistência ao paciente com incontinência urinária, fornecendo de forma sucinta conhecimentos fundamentais para esse cuidado à luz da literatura publicada. Realizou-se uma revisão integrativa da literatura a partir das Bases de Dados da Biblioteca Virtual em Saúde (BVS), no período de 2003 a 2013. Foram encontrados 13 publicações, e, após as exclusões pertinentes e leitura cuidadosa dos trabalhos na íntegra, a amostra constituiu-se de oito artigos. A pesquisa congregou cuidados relativos à promoção da educação em saúde, ações de apoio psicoemocional, tratamento comportamental com estratégias conservadoras e não invasivas de adaptação e reabilitação, além dos cuidados secundários ao planejamento da sistematização da enfermagem. Diante disso, destaca-se a necessidade de realizar pesquisas clínicas com metodologias de maior nível de evidência sobre o manejo da incontinência urinária por enfermeiros, fortalecendo o conhecimento a esta temática, baseado em evidências científicas que conduzam práticas mais especializadas.

DESCRITORES: Estomaterapia. Cuidados de enfermagem. Incontinência urinária. Revisão.

\begin{abstract}
This study aimed to verify the main nursing care in patient with urinary incontinence shortly providing fundamental knowledge for this care in the view of published literature. It was conducted as an integrative literature review from the databases of the Virtual Health Library (VHL) in the period 2003-2013. Thirteen publications were found, and after the relevant exclusions and a careful reading of the work in totaly, the sample consisted of eight items. The survey gathered care promotional health education, psycho-emotional support actions, behavioral treatment with conservative and noninvasive strategies for adaptation and rehabilitation, in addition to the planning side of the systematization of nursing care. Therefore, we highlight the need for clinical research methodologies with the highest level of evidence on the management of urinary incontinence by nurses, strengthening knowledge about this issue based on scientific evidence that lead more specialized practices.
\end{abstract}

DESCRIPTORS: Stomatherapy. Nursing care. Urinary incontinence. Review.

\footnotetext{
'Enfermeira Estomaterapeuta TiSOBEST. Professora Assistente da Faculdade de Enfermagem Nossa Senhora das Graças; Universidade de Pernambuco (UPE) - Recife (PE), Brasil. Endereço para correspondência: Rua Arnoldo Magalhães, 80, apto 602 - Casa Amarela - CEP: 52051 -280 Recife (PE), Brasil - E-mail: mariliaperrelli@gmail.com

Enfermeira Estomaterapeuta pela UPE - Recife (PE), Brasil

Artigo recebido em: 24/09/2014 - Aceito para publicação em: 25/05/2015
} 


\section{RESUMEN}

Este estudio tuvo como objetivo verificar los principales cuidados de enfermería en la atención al paciente con incontinencia urinaria, proporcionando, sucintamente, los conocimientos fundamentales para ese cuidado, basándose en la literatura publicada. Se llevó a cabo una revisión integradora de la literatura desde las bases de datos de la Biblioteca Virtual en Salud, en el período de 2003 hasta 2013. Fueron encontradas 13 publicaciones, y, después de las exclusiones pertinentes y de una cuidadosa lectura de la obra en su totalidad, la muestra se formó por ocho artículos. La investigación recopiló cuidados referentes a la promoción de educación en salud, acciones de apoyo emocional, tratamiento comportamental con estrategias conservadoras y no invasivas de adaptación y rehabilitación, además de los cuidados secundarios a la planificación de la sistematización de enfermería. Por lo tanto, destacamos la necesidad de nuevas investigaciones clínicas con metodologías de mayor nivel de evidencia sobre el maneo de la incontinencia urinaria por las enfermeras, con el fortalecimiento de los conocimientos con respecto a esa cuestión, basado en pruebas científicas que conduzcan prácticas más especializadas.

DESCRIPTORES: Estomaterapia. Cuidados de enfermería. Incontinencia urinaria. Revisión.

\section{INTRODUÇÃO}

\section{A Internacional Continence Society (ICS) define inconti-} nência urinária (IU) como uma condição na qual ocorre a perda involuntária de urina, que gera um problema social ou higiênico ${ }^{1}$. Traz ao individuo importantes repercussões físicas e sociais na forma como se manifesta. Contudo, nem todos que possuem incontinência procuram ajuda profissional. Estima-se que uma a cada três pessoas que sofrem de incontinência sinta-se constrangida em falar sobre o assunto com familiares, amigos ou com um profissional de saúde, convivendo com o problema por muitos anos, sem procurar ajuda, e considerando a situação normal. Sabe-se, no entanto, que tais distúrbios acabam por afetar diversos aspectos da vida, não só o físico, como também o social, psicológico, ocupacional, doméstico e sexual ${ }^{2}$.

A IU, de acordo com os sintomas, pode ser classificada em três tipos principais: a incontinência urinária de esforço, quando ocorre perda involuntária de urina durante o esforço ou exercício ou ao espirrar ou tossir; a hiper-reflexia detrusora idiopática, caracterizada pela queixa de perda involuntária de urina acompanhada ou imediatamente precedida por urgência; e a incontinência mista, quando há queixa de perda involuntária de urina associada à urgência e também aos esforços, exercícios, espirro ou tosse $\mathrm{e}^{3}$.

Diante de inúmeros tratamentos existentes para IU, surgiram como o passar dos anos, muitas denominações para definir os variados tipos. No intuito de uniformizar as denominações estão inclusos tratamentos não cirúrgicos, não farmacológicos para a função do trato urinário inferior, incluindo o treinamento do assoalho pélvico, biofeedback, e mudanças comportamentais ${ }^{4}$.
A terapia comportamental, em particular, é um método não invasivo de tratamento, de baixo risco, pouco dispendioso e que pode constituir-se numa estratégia de tratamento efetivo e conservadora na recuperação das funções fisiológicas, causando uma melhora da musculatura do assoalho pélvico. Ela consiste em estimular modificações comportamentais e mudanças dos hábitos do(a) incontinente que possam contribuir para piorar ou causar episódios de perdas urinárias, associando a isso um retreinamento da bexiga. Assim, entre as orientações necessárias, inclui-se alteração de hábitos alimentares, como minimização da ingestão cafeinados, excesso de líquidos antes de dormir, frutas ácidas, achocolatados e refrigerantes. Essas mudanças devem ser estimuladas, já que alguns desses produtos são considerados irritantes vesicais e podem de certa agravar os episódios de perdas urinárias, sobretudo nas situações de urge-incontinência ${ }^{5}$.

A literatura aponta intervenções de enfermagem que podem auxiliar no diagnóstico e controle da perda urinária contribuindo para melhorar a qualidade vida dessas pessoas. Exames simples podem ajudar a(o) enfermeira(o) a identificar os fatores de risco para a IU na população, assim como uma anamnese de enfermagem detalhada com a realização de uma simples pergunta: você perde urina quando tosse, espirra ou quando sente forte desejo de urinar?

Muitas vezes por falta de informação do profissional enfermeiro, ou de um exame físico completo, ou anamnese que identifique ao menos os fatores de risco, ou até de uma atenção sistematizada, surgem os obstáculos para o diagnóstico precoce da IU. Diante disso, este estudo tem como objetivo verificar, por meio de revisão integrativa da literatura as principais ações de enfermagem na assistência ao paciente com incontinência urinária 
fornecendo de forma sucinta conhecimentos fundamentais para esse cuidado à luz da literatura publicada.

\section{MÉTODO}

Trata-se de uma revisão integrativa da literatura sobre os cuidados de enfermagem na assistência ao paciente com incontinência urinária, a partir das Bases de Dados da Biblioteca Virtual em Saúde (BVS). Revisões integrativas da literatura são definidas como revisões sintetizadas dos estudos já realizadas em particular área de conhecimento. Trata-se de um método de pesquisa relevante, pois permite a síntese e conclusões gerais do estado do conhecimento, além de possibilitar suporte para a tomada de decisão e a melhoria da prática clínica, apontando as possíveis lacunas que implicam na realização de novos estudos na área temática em questão. Esse método contempla 5 etapas, a saber:

1. Identificação da questão norteadora do estudo,

2. Busca na literatura,

3. Avaliação dos dados,

4. Análise apresentação dos resultados relevantes,

5. Discussão à luz da literatura.

Utilizou-se a seguinte pergunta para guiar a revisão integrativa: quais os principais cuidados de enfermagem na assistência ao paciente com incontinência urinária?

A busca foi realizada no mês de junho de 2013 e, para o refinamento da pesquisa, foi definida uma amostra, obedecendo aos seguintes critérios de inclusão: Periódicos indexados na Bilblioteca Virtual de Saúde (no sítio www.bireme.br); artigos indexados pelos descritores DeCS/MeSH (Incontinência urinária, Cuidados de enfermagem); estudos com abordagem sobre o manejo da IU realizados por enfermeiros; artigos publicados em língua portuguesa - devido ao objetivo da pesquisa restringir-se a âmbito nacional; Textos completos disponíveis; Publicação no período de 2003 a 2013.

A escolha da Biblioteca Virtual em Saúde (BVS) se deu por sua relevância como a base distribuída do conhecimento científico e técnico em saúde registrado, organizado e armazenado em formato eletrônico acessível, eficiente e universal ${ }^{2}$. Foram considerados apenas estudos completos devido ao entendimento de que muitos resumos não expressam o conteúdo exato dos trabalhos.
A partir da pré-leitura de cada artigo selecionado na busca, foi possível avaliá-los e caracterizá-los quanto à autoria, ano de publicação, base de dados referente, tipo de incontinência abordada e nível de evidência do estudo.

Considerou-se estudos como de evidência forte (evidências oriundas de revisões sistemáticas ou meta-análise de relevantes ensaios clínicos - Nível I; e evidências derivadas de pelo menos um ensaio clínico randomizado controlado bem delineado - Nível II), evidência moderada (ensaios clínicos bem delineados sem randomização - Nível III, estudos de coorte e de caso-controle bem delineados - Nível IV; revisão sistemática de estudos descritivos e qualitativos - Nível $\mathrm{V}$ ), evidência fraca (Evidências derivadas de um único estudo descritivo ou qualitativo - Nível VI; Opinião de autoridades ou relatório de comitês de especialistas Nível VII), conforme o modelo para nível de evidência utilizado no estudo de Santos et al. ${ }^{6}$.

A partir da questão norteadora, iniciou-se a busca e seleção de produções bibliográficas que pudessem elucidar tais questionamentos.

Após a fase descrita, seguiu-se para a análise das publicações por meio de leitura crítica dos estudos selecionados, a fim de extrair informações relacionadas os cuidados de enfermagem, segundo os seus conteúdos e a reflexão à luz das recomendações da literatura. Assim, após agrupamento por semelhança de conteúdos, emergiram quatro categorias: educação em saúde, suporte psicoemocional, tratamento comportamental, sistematização da assistência de enfermagem.

\section{RESULTADOS E DISCUSSÃO}

$\mathrm{Na}$ primeira etapa, referente à busca em base de dados, foram encontrados 13 publicações indexadas; destas, duas estavam duplicadas em outra base de dados encontrada.

Após análise preliminar dos estudos selecionados na primeira etapa de busca, verificou-se que dois destes não atendiam à questão norteadora, sendo portanto desconsiderados assim como os artigos duplicados.

Apesar de estar publicado em periódico nacional, um artigo encontrava-se em texto disponível apenas na língua inglesa e, por isso, também foi desconsiderado. Ademais, a amostra deste estudo constituiu-se de oito artigos a serem analisados. 
A base de dados LILACS destacou-se com a indexação de seis dos periódicos selecionados. Os estudos de revisão foram predominantes, representando seis do total de oito artigos, com nível de evidência moderada. Metade dos artigos abordou a incontinência urinária (IU) de uma maneira geral, sem caracterização do tipo ou das queixas secundárias. Dentre os que fizerem alguma especificação, a incontinência urinária de esforço (IUE) foi a mais mencionada, conforme mostra o Quadro 1.

O Quadro 2 apresenta o detalhamento de cada categoria com seus respectivos cuidados e conclusões pertinentes. A categoria educação em saúde congregou o menor número de artigos, o que reflete a necessidade de um maior envolvimento com pesquisas relacionadas a essa temática, tendo em vista competir ao enfermeiro o desafio como educador, prestando cuidados além da técnica, elaborando um planejamento de cuidados e autocuidado em interação com os clientes incontinentes em busca de melhor qualidade de vida ${ }^{15}$.

A categoria suporte psicoemocional apresentou o melhor nível de evidência, com prevalência dos estudos qualitativos de abordagem reflexiva sobre qualidade de vida, grupos de apoio, relação enfermeiro-paciente, reconhecimento como "ser" incontinente, adaptação, enfrentamento, motivação e avaliação holística do individuo com incontinência. Estudos recentes apontam uma lacuna nos trabalhos da enfermagem quanto ao incentivo à participação de grupos como ação de suporte psicológico. Em pesquisa de revisão integrativa sobre os cuidados de enfermagem ao paciente pós-operatório de prostatectomia, foram identificados apenas dois artigos com referência a esse cuidado, demostrando necessidade da enfermagem agir mais ativamente na promoção de cuidados que propiciem a troca de experiências e vivências em busca do alívio das ansiedades e autoconfiança ${ }^{16}$.

Entende-se que apreensão e implementação das estratégias educativas e de suporte psicoemocional apresentadas possam auxiliar na aquisição de conhecimentos por parte do paciente incontinente e cuidador para a tomada de decisão quanto aos comportamentos e atitudes de saúde seguros e ajustados às necessidades geradas pela incontinência, além de subsidiar o planejamento

Quadro 1. Distribuição dos estudos selecionados segundo autor, periódico e ano de publicação, base de dados indexada, nível de evidência e tipo de incontinência urinária abordada. Recife, 2013.

\begin{tabular}{|c|c|c|c|c|c|c|}
\hline Id & Autores & Periódico/Ano & Base de dado & Método & NE & Tipo de IU \\
\hline$A$ & Lima et al. ${ }^{7}$ & $\begin{array}{l}\text { O Mundo da } \\
\text { Saúde SP } \\
\text { (2007) }\end{array}$ & LILACS & $\begin{array}{c}\text { Revisão } \\
\text { Bibliográfica }\end{array}$ & V & IUE \\
\hline B & $\begin{array}{l}\text { Bicalho e } \\
\text { Lopes }^{8}\end{array}$ & $\begin{array}{c}\text { Rev Esc Enferm } \\
\text { USP } \\
(2012)\end{array}$ & LILACS & $\begin{array}{l}\text { Revisão } \\
\text { Integrativa }\end{array}$ & V & $\begin{array}{c}\text { Não } \\
\text { especificado }\end{array}$ \\
\hline C & Borba et al. ${ }^{9}$ & $\begin{array}{l}\text { Texto Contexto } \\
\text { Enferm } \\
(2008)\end{array}$ & LILACS & $\begin{array}{c}\text { Qualitativa/ } \\
\text { História Oral } \\
\text { Temática }\end{array}$ & $\mathrm{Vl}$ & $\begin{array}{c}\text { IUE } \\
\text { UI } \\
\text { Mista }\end{array}$ \\
\hline $\mathrm{D}$ & $\begin{array}{c}\text { Mata e } \\
\text { Napoleão }\end{array}$ & $\begin{array}{l}\text { Acta Paul de } \\
\text { Enferm } \\
(2010)\end{array}$ & LILACS & $\begin{array}{c}\text { Revisão } \\
\text { Integrativa } \\
\text { Experimental }\end{array}$ & V & $\begin{array}{c}\text { Não } \\
\text { especificado }\end{array}$ \\
\hline$E$ & $\begin{array}{l}\text { Honório e } \\
\text { Santos }{ }^{11}\end{array}$ & $\begin{array}{c}\text { Rev Enferm UERJ } \\
(2010)\end{array}$ & LILACS & $\begin{array}{l}\text { Qualitativa/ } \\
\text { Convergente } \\
\text { Assistencial }\end{array}$ & $\mathrm{VI}$ & $\begin{array}{c}\text { Não } \\
\text { especificado }\end{array}$ \\
\hline $\mathrm{F}$ & $\begin{array}{l}\text { Vianna e } \\
\text { Napoleão }^{12}\end{array}$ & $\begin{array}{l}\text { Cienc Cuid Saúde } \\
\text { (2009) }\end{array}$ & BDENF & $\begin{array}{c}\text { Revisão } \\
\text { Bibliográfica }\end{array}$ & V & $\begin{array}{c}\text { Não } \\
\text { especificado }\end{array}$ \\
\hline G & Jardim et al. ${ }^{13}$ & $\begin{array}{l}\text { Cuid Arte Enferm. } \\
\text { (2011) }\end{array}$ & BDENF & $\begin{array}{l}\text { Revisão } \\
\text { Integrativa }\end{array}$ & V & $\begin{array}{c}\text { Bexiga } \\
\text { hiperativa }\end{array}$ \\
\hline$H$ & $\begin{array}{c}\text { Silva e } \\
\text { D'elboux }{ }^{14}\end{array}$ & $\begin{array}{c}\text { Rev Esc USP } \\
(2012)\end{array}$ & LILACS & $\begin{array}{l}\text { Revisão } \\
\text { Integrativa }\end{array}$ & V & $\begin{array}{l}\text { Bexiga } \\
\text { hiperativa } \\
\text { IUE/Mista }\end{array}$ \\
\hline
\end{tabular}

Id: Identificação do artigo; NE: Nível de Evidência científico. 
Quadro 2. Cuidados de enfermagem conforme as categorias estabelecidas. Recife, 2013.

\begin{tabular}{|c|c|c|}
\hline Categoria & Cuidados de enfermagem & $\begin{array}{c}\text { Artigos } \\
\text { referidos (Id) }\end{array}$ \\
\hline \multirow{3}{*}{$\begin{array}{l}\text { Educação } \\
\text { em } \\
\text { saúde }\end{array}$} & $\begin{array}{l}\text {-Auxiliar o paciente na percepção e adaptação do ser incontinente } \\
\text {-Refletir sobre associações da incontinência urinária e envelhecimento } \\
\text {-Prevenir quedas associadas ao aumento da frequência de micção por } \\
\text { uso de diuréticos por pacientes hipertensos }\end{array}$ & $\begin{array}{c}3 \text { artigos } \\
(A, E, G)\end{array}$ \\
\hline & \multicolumn{2}{|l|}{ Conclusões } \\
\hline & \multicolumn{2}{|c|}{$\begin{array}{l}\text {-Identificação precoce dos fatores de risco da IUE com a incorporação da avaliação no pré-natal } \\
\text {-Educação em saúde auxilia no processo de enfretamento, reabilitação, adaptação e } \\
\text { aceitação ao tratamento } \\
\text {-Autocuidado como melhor forma de enfrentamento da IU } \\
\text {-Garantir o conhecimento teórico prático para lidar com o paciente hipertenso e } \\
\text { incontinente }\end{array}$} \\
\hline $\begin{array}{l}\text { Suporte } \\
\text { psicoemocional }\end{array}$ & $\begin{array}{l}\text {-Estímulo a participação de grupos de apoio e troca de experiência. } \\
\text {-Favorecer confiança e empatia na relação enfermeiro-paciente inctontinente } \\
\text {-Identificar as estratégias de abordagem do paciente com perdas urinárias } \\
\text {-Ampliar a compreensão da totalidade do paciente incontinente } \\
\text {-Estimular retorno às atividades diárias e manutenção da função sexual }\end{array}$ & $\begin{array}{l}4 \text { artigos } \\
(C, D, E, F)\end{array}$ \\
\hline
\end{tabular}

Conclusões

A IU tem influencia negativa nos ambitos emocional, sexual, social e psíquico na vida das parceiras de indivíduos incontinentes

- Modificar do estilo de vida

-Cuidados de higiene e prevenção de infecção

-Estimular exercício físico e redução de peso corporal

-Otimizar ingesta hídrica e empregar alimentação não constipante e

não irritante vesical

-Fortalecer a musculatura do assoalho pélvico

4 artigos

-Estimular uso de cateterismo Intermitente e manter cuidados com

$(\mathrm{D}, \mathrm{G}, \mathrm{F}, \mathrm{H})$

cateter vesical de longa permanência

- Usar eletroestimulação, biofeedback e cones vaginais

Tratamento

Conclusões

comportamental

- IU é uma afecção de etiologia multifatorial

-Modificação de comportamento e estilo de vida quanto a ingesta hídrica, exercícios

físicos e alimentação, reduz fatores de risco para IU

-Excesso de peso leva ao aumento crônico da pressão intra-abdominal, podendo

comprometer a função vesico-urinária

-Fortalecimento da musculatura do assoalho pélvico com exercícios Kegel, melhora

suporte aos órgãos pélvicos e auxiliam fechamento uretral

-Cateterismo intermitente é recomendado em casos de hipocontratilidade detrusora e

dificuldade de esvaziamento vesical

-Eletroestimulação, biofeedback e cones vaginais auxiliam na identificação da

musculatura do assoalho pélvico e inibe hiperatividade detrusora

-Consulta de Enfermagem para precoce investigação de sintomas urinários

-Planejamento dos cuidados a serem executados por cuidador

- Decidir as questões acerca do tratamento

Sistematização

da assistência

- Compreender a rede de apoio familiar e relações sociais

- Identificar modificações na qualidade de vida

$(A, B, E, G)$

de enfermagem

\section{Conclusões}

-Elaboração de protocolos e/ou planos de cuidados individualizados e específicos,

favorecendo a atuação dos enfermeiros na prática clínica

Direcionamento de ações relativas à incontinência urinária

UE: incontinência urinária de esforço; IU: incontinência urinária. 
de ações de enfermagem voltadas para os processos de reconhecimentos de fatores de risco envolvidos e de adaptação e reabilitação do incontinente, favorecendo uma atuação holística desse profissional ${ }^{17}$.

A categoria Tratamento comportamental agregou cuidados da terapia conservadora da IU com foco na modificação de estilo de vida para favorecimento da adaptação do indivíduo incontinente, com aquisição de hábitos alimentares adequados, fortalecimento do assoalho pélvico, prevenção de complicações como a infecção e uso do caterismo vesical, eletroestimulação, biofeedback, e cones vaginais.

Dados similares foram encontrados em estudo qualitativo sobre o impacto da IU na qualidade de vida de idosos em Santa Catarina. Percebeu-se a importância da abordagem de hábitos alimentares e intestinais considerando a influência na piora das perdas urinárias, sendo referido o café como principal alimento irritante vesical ingerido entre os entrevistados. Identificou-se também a associação feita por pacientes incontinentes entre a ingestão hídrica e a frequência miccional, levando-os a estabelecer hábitos de baixa ingesta de água a fim de reduzir o número de idas ao banheiro baseado em suas próprias percepções. Entre os entrevistados não houve associação entre presença de impactação fecal e aumento da frequência urinária, necessitando de estudos com método de maior nível de evidência para confirmação dessa relação ${ }^{18}$.

Em revisão bibliográfica de publicações no período de 1983 a 2003, identificou-se a constipação e consumo de cafeína como algum dos principais fatores de risco para incontinência urinária em mulheres ${ }^{19}$.

No referente a pacientes que fazem uso de cateterismo vesical de demora, sobretudo os pós cirúrgicos, acret-se que uma ingesta hídrica adequada previna a formação de coágulos sanguíneos, diminuindo a probabilidade de obstrução do cateter. Já no que se refere a pacientes com uso da técnica intermitente de cateterismo urinário, infere-se que os cuidados de enfermagem devem estar direcionados para a prevenção potenciais infecções secundária à manipulação ${ }^{6}$.

O manual de condutas médicas promovido pelo Institute of development studies (IDS) em parceria como
Ministério da Saúde e Universidade de São Paulo (USP) define entre as opções iniciais de tratamento da incontinência urinária a reabilitação pélvica, restrição hídrica e treinamento vesical como proposta de técnica comportamental de cuidado ${ }^{20}$.

Estudo de revisão com categorização dos cuidados de enfermagem ao paciente prostatectomizado apontou na categoria "incontinência urinária" dois dos cuidados encontrados no presente estudo: os exercícios de fortalecimento da musculatura do assoalho pélvico e uso de tratamento adjuvante, como a eletroestimulação, corroborando para a verossimilhança entre os dados encontrados ${ }^{6}$.

A última categoria apresentada abordou a Sistematização da assistência de enfermagem com abrangência ao planejamento de cuidados individualizados e direcionado às necessidades do paciente incontinente enfatizando a importância do estabelecimento da rede de apoio ao enfrentamento dessa condição, em particular a presença da família. Foram mencionadas ações de enfermagem para identificação de sintomas urinários e tomada de decisão terapêutica compartilhada com o paciente. A necessidade de uma assistência com base em processos de enfermagem é ressaltada, uma vez que favorecem o cuidado individualizado, consideram o ser em sua totalidade e refletem a excelência por parte da enfermagem com seus pacientes ${ }^{19,21}$.

\section{CONCLUSÃO}

Entende-se que a compreensão e implementaçãode estratégias educativas, o suporte psicoemocional, modificações comportamentais e as ações de planejamento da assistência de enfermagem apresentadas possam auxiliar na aquisição de conhecimentos por parte do paciente incontinente $\mathrm{e}$ cuidador para a tomada de decisão quanto aos comportamentos e atitudes de saúde que auxiliem no processo de adaptação e reabilitação. Destaca-se a necessidade de realizar pesquisas clínicas com metodologias de maior nível de evidência sobre o manejo da incontinência urinária por enfermeiros, fortalecendo o conhecimento quanto a esta temática baseada em evidências científicas que conduzam práticas mais especializadas. 


\section{REFERÊNCIAS}

1. Abrams P, Cardozo L, Fall M, Griffiths D, Rosier P, Ulmsten $U$, et al. The Standardisation of Terminology of Lower Urina ry Tract Function. Report from the Standardisation SubCommittee of the ICS. Urology. 2003;61:37-49.

2. Araújo LB, Santos RCR. Comparação da qualidade de vida de mulheres que realizaram tratamento de eletroestimulação para incontinência urinária de esforço [Monografia]. Belém: Universidade da Amazônia, Centro Ciências Biológicas e da Saúde da UNAMA; 2009.

3. Higa R, Lopes MHBM. Fatores associados com a incontinência urinária na mulher. Rev Bras Enfermagem. 2005;58(4):422-8.

4. Castro RA, Arruda RM, Oliveira E, Zanetti MRD, Bortolini MA, Sartori MGF, Girão MJBC. Fisioterapia e incontinência urinária de esforço: revisão e análise critica. Revista Femina. 2008;36(12):737-42.

5. Honório MO. Educação para o autocuidado: uma alternativa de assistência de enfermagem ao adulto e idoso com incontinência urinária [Dissertação]. Universidade Federal de Santa Catarina, Centro de Ciências da Saúde Programa de Pós-Graduação em Enfermagem; 2006.

6. Santos DRF, Silva F, Saldanha E, Lira A, Vitor A. Cuidados de enfermagem ao paciente em pós-operatório de prostatectomia: revisão integrativa. Revista Eletrônica de Enfermagem, 2012:14(3):690-701. Disponível em: <http:// revistas.ufg.br/index.php/fen/article/view/14980/13442>. Acesso em: 15 maio. 2014. doi:10.5216/ree.v14i3.14980.

7. Lima JLDA, Carvalho GM, Martins AA. Contribuição da Assistência de Enfermagem Obstétrica Pré-Natal: Educação para prevenção e correção da Incontinência Urinária de Esforço (IUE). O mundo da saúde. 2007;31(3):411-8.

8. Bicalho MB, Lopes MHBM. Impacto da incontinência urinária na vida de esposas de homens com incontinência: revisão integrativa. Rev Esc Enferm USP. 2012;46(4):1009-14.

9. Borba AMC, Lelis MAS, Brêtas ACP. Significado de ter incontinência urinária e ser incontinente na visão das mulheres. Texto Contexto Enferm. 2008;17(3): 527-35.

10. Mata LRF, Napoleão AA. Intervenções de enfermagem para alta de paciente prostatectomizado: revisão integrativa. Acta Paul Enferm. 2010;23(4):574-9.

11. Honório MO, Santos SMA. Rede de apoio ao paciente incontinente: a busca por suporte e tratamentos. Rev Enferm UERJ. 2010;18(3):383-8.
12. Vianna MC, Napoleão AA. Reflexões sobre cuidados de enfermagem para a alta de pacientes prostatectomizados. Cienc Cuid Saude. 2009;8(2):269-73.

13. Jardim ADI, Mazzo A, Girão FB, Sonobe HM, Souza MC. Hipertensão arterial e incontinência urinária no idoso:revisão integrativa da literatura. Cuid Arte Enferm. 2011;(1):38-43.

14. Silva VA, D'elboux MJ. Atuação do enfermeiro no manejo da incontinência urinária no idoso: uma revisão integrativa. Rev Esc Enferm USP. 2012;46(5):1221-6.

15. Furlan MFFM, Ferriani MGC, Gomes R. O cuidar de crianças portadoras de bexiga neurogênica: representações sociais das necessidades dessas crianças e suas mães. Revista LatinoAmericana de Enfermagem, 2003;11(6):736-70. Disponível em: <http://www.revistas.usp.br/rlae/article/view/1829/1880>. Acesso em: 15 maio. 2014. doi:http://dx.doi.org/10.1590/ S0104-11692003000600010.

16. Santos CRSS, Santos VLCGS. Epidemiologia das incontinências urinária e anal combinadas. Acta Paul Enferm. 2009;22(3):328-30.

17. Cipriano MAB, Queiroz MVO. Cuidado com a criança portadora de mielomeningocele: vivência da família. Rev Rene. 2008;9(4):72-81.

18. Higa R, Lopes MHBM, Reis MJ. Fatores de risco para incontinência urinária na mulher. Rev Esc Enferm USP. 2008;42(1):187-92.

19. Trigo-Rocha F, Gomes CM, Pompeo ACL, Lucon AM, Arap S. Prospective study evaluating efficacy and safety of Adjustable Continence Therapy (ProACT) for post radical prostatectomy urinary incontinence. Urology. 2006;67(5):965-9.

20. Lazari ICF, Lojudice DC, Marota AG. Avaliação da qualidade de vida de idosas com incontinência urinária: idosas institucionalizadas em uma instituição de longa permanência. Rev Bras Geriatr Gerontol. 2009;12(1):103-12.

21. Mendes KDS, Silveira RCCP, Galvão CM. Revisão integrativa: método de pesquisa para a incorporação de evidências na saúde e na enfermagem. Texto Contexto Enferm. 2008;17(4):758-64.

22. Biblioteca Virtual em Saúde. Documento básico da BVS. Disponível em: <http://www.bireme.br/php/level. php?lang=pt\&component=112>. Acessado em: 07 jun. 2013. 


\title{
Qualidade de Vida: Percepção de Crianças e Adolescentes Estomizados e seus Pais e/ou Responsáveis*
}

\author{
Quality of Life: Perception of Ostomized Children \\ and Adolescents and their Parents and/or Guardians
}

\author{
Calidad de Vida: la Percepción de los Niños y Adolescentes \\ con Estomía y sus Padres y/o Tutores
}

Sandra de Nazaré Costa Monteiro', Ivone Kamada², Ana Lúcia da Silva

*Dissertação de Mestrado apresentada ao Programa de Pós-graduação em Enfermagem da Faculdade de Ciências da Saúde da Universidade de Brasília (UnB), em 29/11/2013.

A estomia é uma situação que atinge pessoas de todas as faixas etárias. Crianças e adolescentes podem adquirir estomas urinários ou gastrintestinais por diversas causas, entre as mais frequentes estão as anomalias congênitas e os traumas ocorridos durante o desenvolvimento. A qualidade de vida é um conceito complexo, de caráter subjetivo e multidimensional, que engloba vários aspectos da vida e que vem ganhando o interesse dos estudiosos. De forma geral, a qualidade de vida de crianças e adolescentes tem sido avaliada a partir dos relatos de adultos, com uma escassez de instrumentos destinados a essa mensuração, o que dificulta a análise por tais sujeitos. Na área de saúde, existe um debate acerca de qual seria o respondente adequado para se avaliar a qualidade de vida da criança e do adolescente, considerando-se importante analisar a correlação entre as respostas da criança, do adolescente e de seus respectivos pais e/ou responsáveis. O objetivo de tal estudo foi conhecer a qualidade de vida de crianças e adolescentes estomizados e seus respectivos pais e/ou responsáveis, a partir de suas próprias percepções. Para tanto, realizou-se uma pesquisa com abordagem quantitativa, transversal exploratória e descritiva com a aplicação de um instrumento de qualidade de vida, que inclui três grandes domínios: mental, social e físico. Os dados foram obtidos por meio de prontuários e entrevista com autorrelato, e posteriormente transformados em análises com o software SPSS 20.0. Foram estudados 20 crianças e adolescentes estomizados entre 8 e 18 anos, e 20 pais e/ou responsáveis. Para a coleta de dados, utilizou-se um questionário sociodemográfico e, para a avaliação da qualidade de vida, aplicou-se a versão brasileira denominada "Módulo Genérico DISABKIDS ${ }^{\circledR}$ para crianças e adolescentes brasileiros com condições crônicas (MGDC-37)". Houve uma boa consistência nas respostas dos grupos. Foram encontradas diferenças estatisticamente significativas em todas as dimensões e domínios. Os estomizados perceberam-se independentes, emocionalmente afetados pela condição de saúde, excluídos do convívio social e com difícil aceitação do tratamento pelo uso do equipamento coletor. Já seus pais e/ou responsáveis notaram a dependência dos filhos e não perceberam a exclusão social que promoveram a partir da superproteção. Houve uma importante correlação entre grupos na dimensão exclusão social, pois os estomizados perceberam-se extremamente excluídos dos espaços de convívio social. O DISABKIDS ${ }^{\circledR}$ MGDC-37 apresenta boa sensibilidade para avaliar a qualidade de vida de crianças e adolescentes a partir de suas próprias percepções, além de demonstrar que esses indivíduos são capazes de fornecerem informações sobre si mesmos e, consequentemente, de sua vida. Esses dados são fundamentais para subsidiar a prática clínica profissional e contribuir com a elaboração de planos assistenciais e protocolos de atendimento específicos para essa população.

DESCRITORES: Estomaterapia. Estomia. Criança. Adolescente. Qualidade de Vida. Pais.

\footnotetext{
'Enfermeira; Especialista em Estomaterapia; Mestre em Enfermagem pela Universidade de Brasília (UnB): Docente da Escola Superior de Ciências da Saúde de Enfermagem - Brasília (DF), Brasil. Endereço para correspondência: SQS 206 - bloco I - apartamento 204 - CEP: $70252-090$ - Brasília (DF), Brasil - E-mail: sncmonteiro@yahoo.com.br

2Enfermeira; Docente; Doutora em Enfermagem pelo Departamento de Enfermagem da UnB - Brasília (DF), Brasil.

${ }^{3}$ Enfermeira Estomaterapeuta; Docente; Doutora em Enfermagem pelo Departamento de Enfermagem da UnB - Brasília (DF), Brasil.

Artigo recebido em: 05/04/2015 - Aceito para publicação em: 14/10/2015
} 


\title{
Prevalência de Úlcera por Pressão em Pacientes em Risco e o Cuidado no Domicílio após Alta Hospitalar*
}

\author{
Prevalence of Pressure Ulcer in Patients at Risk and Home Care after Hospital Discharge \\ Prevalencia de Úlcera por Presión en Pacientes en Riesgo y Cuidado en Domicilio luego \\ del Alta Hospitalaria
}

\author{
Jaísa Valéria Moro', Maria Helena Larcher Caliri²
}

\begin{abstract}
*Dissertação apresentada ao Programa de Pós-graduação em Enfermagem Fundamental da Escola de Enfermagem de Ribeirão Preto, Universidade de São Paulo para obtenção do título de Mestre em Ciências, em setembro de 2015.
\end{abstract}

Pacientes hospitalizados que têm risco para úlcera por pressão (UP) ou apresentam o problema, após a saída do hospital, necessitam de cuidados domiciliares para o manejo da situação. A atenção domiciliar, no âmbito do Sistema Único de Saúde, é uma modalidade de atenção à saúde, em que um conjunto de ações para promoção à saúde, prevenção e tratamento de doenças e reabilitação pode permitir a continuidade dos cuidados. O presente estudo é transversal, com abordagem quantitativa, e foi aprovado pelo Comitê de Ética em Pesquisa da Escola de Enfermagem de Ribeirão Preto. Os objetivos foram: descrever o perfil sociodemográfico e de saúde de pacientes que tinham risco para UP e que receberam alta de um hospital de urgência; identificar o nível de risco para UP após a saída da instituição e encontrar a prevalência de UP, as características da lesão e o contexto do cuidado domiciliar. A coleta de dados foi realizada no domicílio no segundo mês após a alta. Participaram da pesquisa 23 pacientes, com idade média de 50,07 anos, cor branca, maior frequência do sexo feminino, procedentes de Ribeirão Preto. A maioria das participantes era pensionista, casada, com renda familiar mensal de um a dois salários-mínimos e morava com esposo e filhos. O problema de saúde mais frequente foi trauma de crânio, seguido por acidente vascular cerebral. Dentre os que necessitavam de algum cuidado no domicílio, os cuidadores principais eram esposos (45\%). A média dos escores da Escala de Braden para 13 pacientes em risco para UP foi 15,46, enquanto para 10 sem risco, 22. Dentre as participantes em risco, houve predomínio dos idosos (61,5\%). A prevalência de UP foi 21,7\% e, das 8 UP, 50\% localizavam-se na região sacral. Em relação ao contexto do cuidado no domicílio, dos 21 pacientes que receberam encaminhamentos após a alta, 18 (78,3\%) eram acompanhados nos serviços deaúde. Dezesseis sujeitos (69,5\%) referiram ter recebido orientações sobre a prevenção da UP durante a internação. No domicílio, nove pacientes recebiam atenção domiciliar com visita domiciliar, e desses, seis tinham risco para UP e quatro já apresentavam a lesão. Uma pessoa com UP e residente em outro município não recebia atenção domiciliar. Em 44,4\% dos casos, as visitas domiciliares foram realizadas por enfermeiros, auxiliares de enfermagem e médicos. Quanto às medidas de prevenção, em todos os pacientes em risco, era realizada a mudança de decúbito, oito (61,5\%) sentiam alívio da pressão quando sentados, quatro (30,8\%) usavam uma almofada para sentarem-se, sete $(53,8 \%)$ faziam alívio da pressão dos calcâneos e três $(23,1 \%)$ usavam lençol móvel para movimentação no leito. Dos oito pacientes em risco que não tiveram UP durante a internação, nenhum desenvolveu úlcera após a alta. Concluiu-se que os escores da Escala de Braden permitem a detecção da vulnerabilidade dos pacientes para UP e apontam a necessidade de atenção domiciliar para favorecer a continuidade do cuidado após a alta. Por outro lado, deve-se melhorar as orientações para o cuidado preventivo no ambiente hospitalar, além da criação dos mecanismos de comunicação entre os serviços para facilitar a continuidade do cuidado e a segurança do paciente.

DESCRITORES: Estomaterapia. Úlcera por pressão. Prevalência. Assistência domiciliar.

\footnotetext{
${ }^{1}$ Enfermeira na Prefeitura Municipal de Itatiba; Mestre em Ciências pela Escola de Enfermagem de Ribeirão Preto da Universidade de São Paulo USP_ Ribeirão Preto (SP), Brasil. Endereço para correspondência: Rua Alexandre França, 116 - Parque João de Vasconcellos - CEP: $13172-580$ - Sumaré (SP), Brasil-E-mail: ja_valeria@hotmail.com

²Docente da Escola de Enfermagem de Ribeirão Preto da USP - Ribeirão Preto (SP), Brasil.

Artigo recebido em: 04/10/2015 - Aceito para publicação em: 14/10/2015
} 
A Revista Estima (RE), de periodicidade trimestral, é o veículo oficial de publicação da Associação Brasileira de Estomaterapia: estomias, feridas e incontinências - SOBEST. Destina-se à publicação de artigos elaborados por enfermeiros, especialistas ou não, outros profissionais e acadêmicos da área da saúde. Com ênfase na prática clínica, gerenciamento, ensino e pesquisa, são aceitos artigos que possam contribuir para a ampliação do conhecimento e para o desenvolvimento da Estomaterapia como especialidade em todas as áreas de abrangência (estomias, feridas e incontinências, fístulas, cateteres e drenos).

\section{ASPECTOS ÉTICOS}

- Nas pesquisas que envolvem seres humanos, os autores deverão enviar cópia de aprovação emitida pelo Comitê de Ética, reconhe pela Comissão Nacional de Ética em Pesquisa (CONEP), segundo as normas da Resolução do Conselho Nacional de Saúde - CNS 466/2012 ou órgão equivalente, no país de origem da pesquisa, ainda que se trate de estudo/relato ou série de casos. Nas pesquisas desenvolvidas no Brasil, o número do processo/projeto deverá constar na Seção de Material e Método do artigo.

- Todos os artigos publicados são de inteira responsabilidade dos autores, não refletindo obrigatoriamente a opinião dos Editores e dos membros do Conselho Editorial.

- Quando houver a utilização de produtos farmacêuticos, estes deverão ser citados genericamente no corpo do texto. Havendo necessidade de citar a marca, esta deverá ser efetuada no final do texto, como observação.

A Revista Estima apoia as políticas para registro de ensaios clínicos da Organização Mundial da Saúde (OMS) e do International Committee of Medical Journal Editors (ICMJE), reconhecendo a importância dessas iniciativas para o registro e divulgação internacional de informação sobre estudos clínicos, em acesso aberto. Sendo assim, somente serão aceitos para publicação os artigos de pesquisas clínicas que tenham recebido um número de identificação em um dos Registros de Ensaios Clínicos validados pelos critérios estabelecidos pela OMS e ICMJE, cujos endereços estão disponíveis no site do ICMJE (www.icmje.org). O número de identificação deverá ser registrado no final do resumo.

\section{SELEÇÃO E REVISÃO DOS MANUSCRITOS}

- Os manuscritos poderão ser enviados em forma de artigo original, reflexão teórico-filosófica, revisão de literatura, artigo de atualização - incluindo temas de interesse para a estomaterapia - estudo clínico (caso) e resumos de dissertação ou tese.

- Cada manuscrito submetido à RE é inicialmente analisado pelos editores quanto ao cumprimento das normas. Em caso de não atendimento às mesmas, pode ser recusado ou devolvido para revisão.

- Quando aprovado pelos editores, o manuscrito é encaminhado à apreciação de, pelo menos, dois membros do Conselho Editorial, eleitos pelos editores, os quais dispõem de plena autoridade para decidir sobre a sua aceitação, recusa ou sugestão de alterações necessárias. Todas as comunicações e notificações serão feitas ao autor, exclusivamente pelo sistema, por e-mail.

- $\quad$ O manuscrito e a declaração de responsabilidade, cessão de direitos autorais e esclarecimento das relações que podem estabelecer conflitos de interesse deverão ser enviados para a Revista Estima exclusivamente no site www.revistaestima.com.br, com link pelo site www.sobest.org.br

- Quando há mais de um autor, todos deverão ser identificados para a troca de correspondência, fornecendo o nome da instituição e o endereço completo (incluindo endereço eletrônico).

- Para a publicação do estudo ao menos um dos autores deverá ser assinante da Revista Estima

\section{APRESENTAÇÃO DOS MANUSCRITOS}

- Os manuscritos deverão ser inéditos. Não serão aceitos manuscritos encaminhados simultaneamente a outros periódicos ou previamente publicados. Exceções são feitas àqueles publicados/apresentados em anais de reuniões científicas (congressos, simpósios etc.) ou àqueles que os editores da RE julgarem ser de grande relevância para a estomaterapia. Nessa segunda exceção, o manuscrito somente será republicado mediante autorização escrita dos editores do periódico onde foi originalmente publicado.

\section{FORMA DE APRESENTAÇÃO}

- Página de rosto: deve conter título do manuscrito em português, inglês e espanhol; autores com respectivas titulações, instituição de trabalho e endereço para correspondência.

- Título: deve estar em português, inglês e espanhol, sem abreviações, em tamanho 18. O título deve ser conciso e explicativo e representar o conteúdo do trabalho. Deve conter, no máximo, 18 palavras. Espaçamento simples.

Deve haver de 3 a 6 descritores, separados por ponto devendo, também, ser apresentados em português, inglês e espanhol. Caso o manuscrito seja escrito originalmente em espanhol, deve conter ainda título, resumo e descritores em português e inglês. Caso o manuscrito seja escrito originalmente em inglês, deve conter ainda título, resumo e descritores em português e espanhol. Os descritores devem estar de acordo com os Descritores em Ciências da Saúde (DECs) ou MeSH (Medical Subject Headings) e devem ser consultados, respectivamente, nos sites http://decs.bvs.br/ e http://www.nlm.nih. gov/mesh/. Os editores solicitam a utilização da palavra-chave "Estomaterapia" em todos os artigos submetidos, com o objetivo de criar força de evidência para que o mesmo possa ser registrado futuramente como descritor.

O texto do manuscrito deve ser estruturado na seguinte sequência: introdução (que deve conter justificativa), hipóteses (quando cabível), objetivos, material e método, resultados, discussão (contendo limitações e recomendações), conclusão e referências. Anexos somente serão aceitos quando necessários/indispensáveis para o estudo. Ao ser baseado em monografia, dissertação ou tese, o manuscrito deve indicar o título, ano e instituição onde foi apresentada e defendida em nota de rodapé. $\mathrm{O}$ manuscrito deve estar paginado.

- Figuras e tabelas: devem vir ao final do texto, estarem devidamente numeradas e terem as posições indicadas no texto. Quando houver fotografias, estas devem estar em resolução acima de 300dpi. Não serão aceitas fotos ou figuras originárias de outros estudos sem a autorização dos autores originais. As citações e referências devem ser elaboradas de acordo com as normas Vancouver (www.icmje.org).

- Referências bibliográficas: deve ser utilizado o sistema Vancouver para as mesmas, e os editores solicitam que, ao menos uma delas, seja de artigo publicado na Revista Estima.

1) Artigo original: os manuscritos de pesquisa sobre estomias, feridas e incontinências e outros temas relacionados à estomaterapia devem ter, no máximo, 15 páginas, incluindo figuras, tabelas, referências e anexos.

2) Reflexão teórico-filosófica: artigos descritivos e interpretativos, com base em literatura recente, acerca da situação geral e de reflexão sobre temas de enfoque da revista. Devem ter, no máximo, 7 páginas.

3) Revisão de literatura (Sistemática ou Integrativa): estudo abrangente e crítico da literatura sobre um assunto de interesse para o desenvolvimento da Estomaterapia, que utiliza método de pesquisa que apresenta a síntese de múltiplos estudos publicados e possibilita conclusões gerais a respeito de uma particular área de estudo, realizado de maneira sistemática e ordenada, favorecendo o aprofundamento do conhecimento do tema investigado e respeitando a estrutura estabelecida anteriormente para o texto. Limitado a 10 páginas.

4) Atualização: estudos que relatam informações atuais sobre tema de interesse para a estomaterapia, por exemplo, uma nova técnica, e que tem características distintas de um artigo de revisão. Limita-se a 5 páginas.

5) Relato de caso: Estudo/relato de caso deve estar limitado a casos excepcionais, que não constituam amostra significativa e que sejam de grande interesse cientifico, com discussões fundamentadas em pesquisas científicas. Sua extensão limita-se a 4 páginas.

6) Resumo de dissertação ou tese: os resumos devem conter introdução, objetivos, métodos, resultados e conclusões. Limita-se a 500 palavras.

Normas revisadas em novembro de 2015. 


\title{
Participe
}

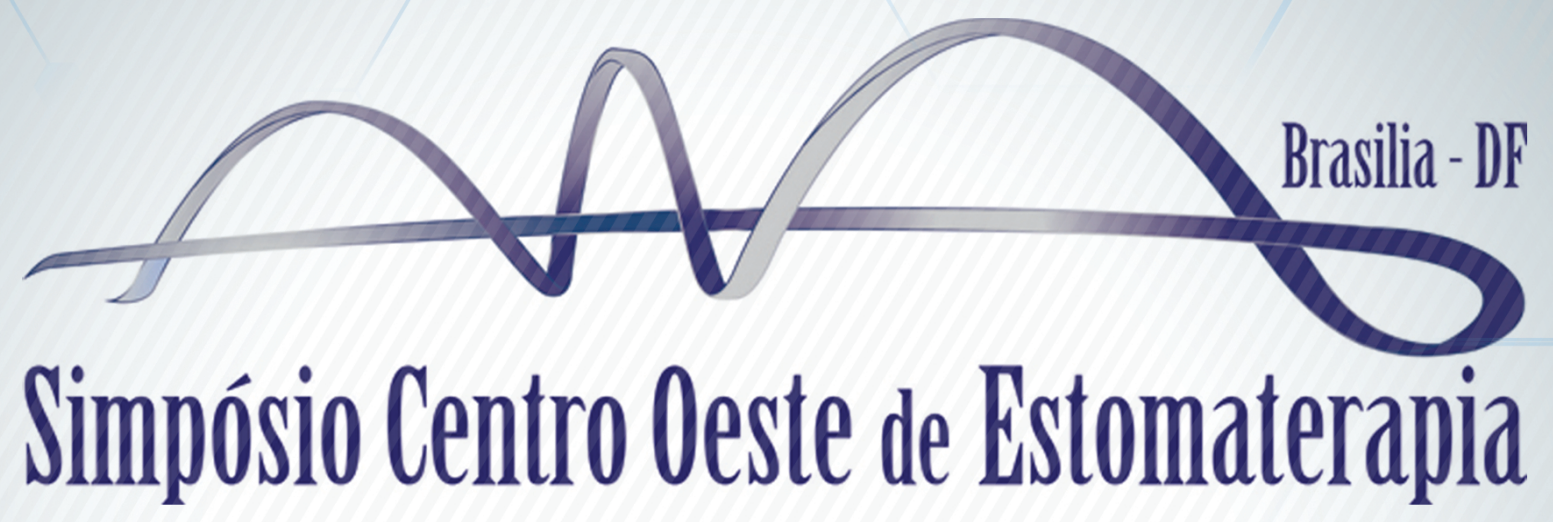

A EXPANSÃO DA ESPECIALIDADE NO PAÍS

Acesse o site do evento e faça a sua inscrição:

sobest.com.br/evento/simposio-centro-oeste-de-estomaterapia

\section{Submissão de Trabalhos: \\ Envie seu resumo até $\mathbf{3 1}$ de maio}

\author{
De 15 a 18 de No Centro de \\ setembro de 2016 Eventos Brasil 21 \\ SHS Quadra 06, Lote 01, \\ Conjunto A - SHS, Brasília \\ DF, 70316-000
}


PRODUÇÃO EDITORIAL

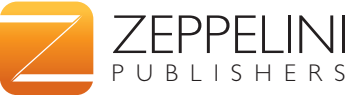

\section{FILANTROPIA}

Rua Bela Cintra, 178, Cerqueira César - São Paulo/SP - CEP 01415-000 Zeppelini - Tel: 5511 2978-6686 - www.zeppelini.com.br Filantropia - Tel: 5511 2626-4019 - www.institutofilantropia.org.br 


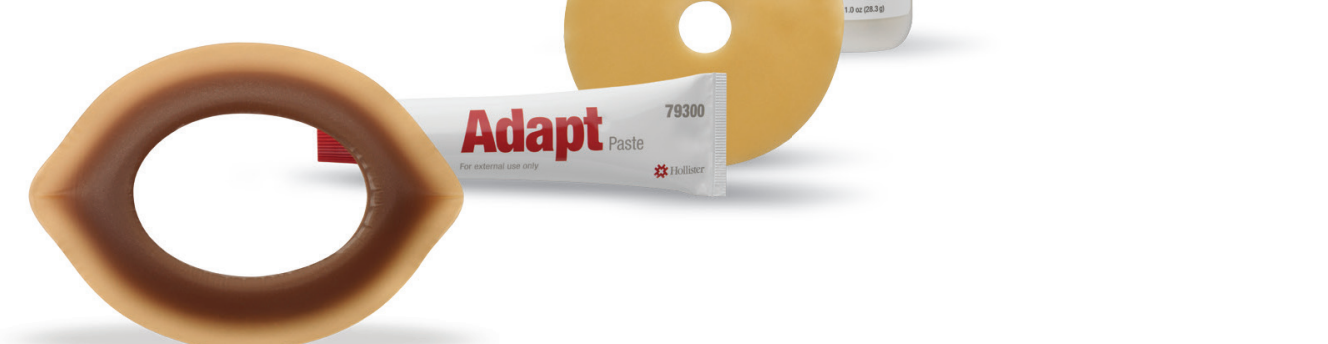

As opções que você quer.

A solução que você precisa.

\section{Linha de Adjuvantes Adapt para estomia.}

Os estomizados confiam em você para trazer soluções que ajudem seu dia a dia.

Com décadas de experiência em estomia, a Hollister desenvolveu a ampla linha de Adjuvantes Adapt.

Assim, você pode escolher o produto correto ou a combinação de produtos que melhor atendam às necessidades dos pacientes.

Ligação Gratuita

Segunda a sexta, das $8 \mathrm{~h}$ às $17 \mathrm{~h}$ qualidade@hollister.com.br 
